$$
\begin{aligned}
& 638(720) \\
& y=83
\end{aligned}
$$

\title{
MEMOIRES
}

PRÉSENTÉS A

\section{LINSTITUT ÉGYPTIEN}

ET PUBLIÉS

SOUS LES AUSPICES

$\mathrm{DE}$

\section{S. A. ABBAS PACHA}

KHÉDIVE D'ÉGYPTE

TOME III - FASCICULE VIII

RÉVISION DES ÉCHINIDES FOSSILES DE L'T́GYP'TE

RENÉ FOURTAU

MEMBRE DE LINSTITUT ĖGYPTIEN, DE LA SOCIÉTÉ GÉOLOGIQUE DE FRAXCE ETC. ETO.

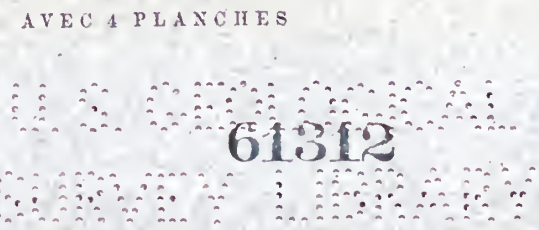

LE CAIRE 1899. 
USGEOLOGLALSURVYY
JUN 221906
LIBRARY

VIENNE - TYP. ADOLPHE HOLZHAUSEN,

IMPRIMEUR DE LA COUR I. \& R. ET DE L'TNIVERSITÉ

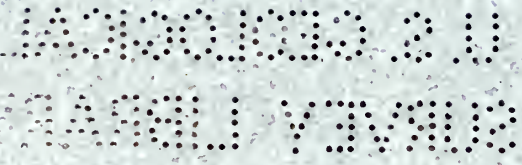




\section{2}

\section{REVTSTON \\ DES \\ ECHINIDES FOSSILES \\ DE L'ÉGY P'TE. \\ PAR \\ RENÉ FOURTAU,

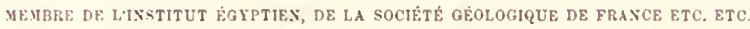

\section{Introduction.}

Ce n'est point un ouvrage absolument nouvean que celui que j'entreprends en publiant ce Catalog'ue; le seul mobile qui m'ait fait agir est, en dehors du manque presque absolu des indications de nivean, la dispersion des espèces citées dans beaucoup d'ouviages différents.

L'importance du catalogue général des Échinides fossiles d'un pays est très grande : je ne crois pas, en effet, qu'il y ait en paléontologie beaucoup) de fossiles qui dépassent les tehinides en importanee géologique. Ils se distinğuent généralement par leur état remarquable de conservation et leur intégrité de tous les fossiles qui les accompagnent; et cela surtout en Égryte, où à part les Ostreidae, la généralité des fossiles se présente à l'état de moules le plus souvent indéterminables, même quant au genre. Les Échinides all contraire sont ici assez abondants, bien conservés et relativement faciles à distinguer. 


\section{$-606-$}

D'un autre côté, eomme en général les Échinides ont une eourte durée phylétique, il arrive que des espèces on même des genres déterminés se rencontrent exclusivement dans certains dépôts et peuvent les caractériser nettement; e'est le cas pour certains Échinides d'Égypte. Mais il reste à fixer d'une manière définitive la position de ces divers niveaux et à établir leur synchronisme avec les étages géologiques. Ceci n'est pas chose facile en Égypte où une bome carte géologique est encore à faire. Les travaux actuels de géologie ne reposant que sur des notes et des matériaux qui, reeneillis, soit par l'auteur lui-même au cours d'une rapide exploration, soit, chose plus fréquente et source encore plus grande d'erreur, par des voyageurs phus tomistes que savants, sont souvent, par la nature même de ces renscignements, sujets à s'écarter de l'exactitude que comportent des ouvrages de eette nature.

C'est surtout dans le 'Tertiaire que la difficulté est sérieuse, car le Crétacé se prolonge avec une grande régularité sur toute la côte septentrionale de l'Afrique, du Maroc au Sinaï et à la Syrie; et l'on pent grâce aux Échinides identifier les conches sur toute cette longue étendue. Mais il n'en est pas de même de tous les lambeaux de Tertiaire qui recouvrent par place le Crétacé et dont le plus développé est celui qui d'Assouan au Caire eneadre la vallée du Nil des chaînes libyques et arabiques.

J'ai donc eherché daus les travaux des différents auteurs, tels que d'Archiac et Delanoue, Bellardi, K. Zittel, J. Walther, MayerEymar, Fuchs, Fraas, etc. etc., d'établir un synchronisme des terrains d'Égypte avec ceux d'Europe, tout en comparant les données de ees anteurs avec les notes et les matériaux recueillis par moi-même au cours de mes nombreux royages pendant un séjour en Égypte de dix années consécutives.

J'en suis arrivé au tableau suivant : 
Calcaires gréseux it Spirigera concentrica Beyrich, de l'Onady Arabah et grès à Crinoüdes du Rod el-Hamâl et de l'Onarly Chellal (Sinaii).

Carboniférien D

ou Démétien

Marnes à Hemiaster cubicus Desor, dı Sinaï et de la Chaîne arabique.

Calcaires et grès à Ostrea Mermeti Coq., O. africana Lamk., Hemiaster Heberti Péron et Gauthier, Plicatula Reynesi Coq., Sphoerulites Schweinfurthi Zittel, Crassatella Pothii Fraas, In Sinaï et de la ehaîne arabique (Ouady Arabah, Onady Keneh, ete. ete.).

Calcaires it Hippurites cornu-xaccinum Brom et Echinoconus aegyptiacus d'Orb. du Gebel Attaka et du Gebel Abou Daragué.

Calcaires it Ostrea accanthonota Coq., Cyphosoma Abbatei Gauthier, Acteonella et Nerinea sp. du massif d'Abou Roach.

Caleaires à Ammonites Fournelii Coq., Plicatula Ferryi Coq., et Rhabdocidaris Crameri de Loriol, du massif d'Abou Roach.

Caleaires à Ostrea acutirostris Mayer-Eymar, Nautilus Danicus Sehloth et Nautilus desertorum Zittel, des environs d'Assonan et des oasis libyques.

Caleaires à Echinocorys ovatus Zittel, Ostrea larva Lam., Janira sexangularis d'Orb., Ostrea Overwegi Coq., Cardita libyca Zittel, de la ehaîne arabique (eourent $S^{t}$ Antoine) et des oasis libyques.

Cénominien infẻrieur

Cénomanien supérieur

T'nronien

Sénonien inférieur

Sénonien supérieur

Danien

Garumnien 
Caleaires à Cardita soudenica Mayer-Hymar, Bothriolampas abundans Gauthier, Cytherea laevigata Mayer-Eymar, Graphularia desertorum 'Zittel, des environs d'Assonan.

Calcaires à Ostrea capriciosa Mayer-Eymar, Operculina libyca Schwager, Lucina Thebaüca Zittel, Conoclypeus Delanouei de Loriol, Linthia cavernosa de Loriol, Aturia Ziczag Sow., des environs de Louxor et de l'oasis de Farafral.

Calcaires a Callianassa nilotica Fraas, Nummulites planulata d'Orb., Sismondia Loghoteti Fraas, des environs d'Assiout et de Minieh.

Calcaires à Nummulites curvispira d'Arehiac, Lobocarcinus Paulino Wurtembergicus Fras, émend. v. Mayer. Nautilus imperialis Sow., Echinolampas africanus de Loriol, Pycnodus Mokattamensis Priem., de la base du Mokattam.

Calcaires à Plicatula polymorpha Bellardi, Carolia placunoïdes Cantr., Ostrea Reilii Fras, O. Clot-beyi Bellardi, dn Mokattan et dn Platean des Pyramides.

Calcaires à Nummulites Fichteli de la Harpe, $N$. intermedia de la Ilarpe, $N$. Rutimeyeri de la Harpe, Orbitoüdes papyracea de la Harpe, des collines de Pacho près Syouah.

Caleaires à Dosinia orbicularis Agr., Lucina multilamellosa Desh., Pholas ammonis Fuehs, du Gebel Ndefer à Syouah.

Calcaires à Ostrea Virleti Desh., Pecten Malvinae Dnbois, Cellepora palmata Michel, Scutella Zitteli Beyrieh, des environs de Syouah, Tarbriz et des Gebel Geneffé, donebet et Damasq.

Sables a Clypeaster aegyptiacus Wright et Strombus c.f. coronatus Defr., du Gebel Chelloul et du pied onest de l'Attaka.

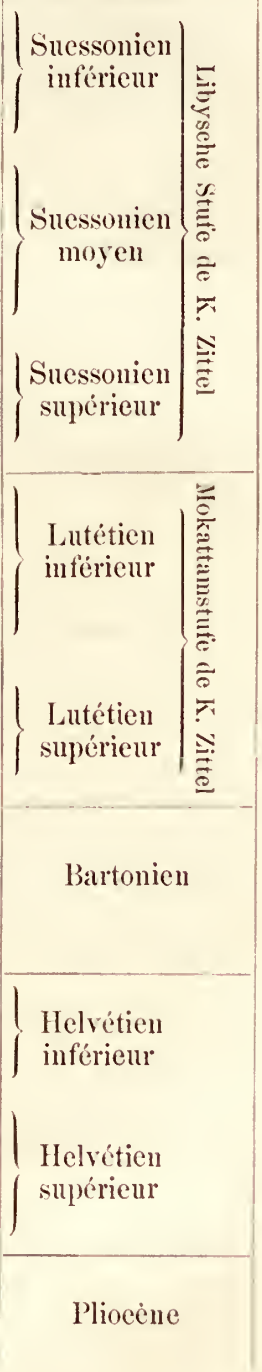


Dans ce tableau j'ai omis intentionncllement le Ligurien et le 'Tongrien des environs du Caire et du Fayoum, ces conches n'ayaut jusqu'à jrésent fourni ancun Échinide. Je n'entrerai pas non plus dans l'exposé des raisons qui m'out conduit à établir ce synchronisme, ne pouvant d'autre part donner trop d'envergure ì cette simple introduction. Je ne me sépare d'ailleurs que fort peu des géologues qui ont le mieux étudié la statigraphie de l'Égýpte. Dans l'indieation des localités j'ai compris la côte Onest du Sinaï, car on ne peut séparer de l'Égypte proprement dite des territoires qui n'en ont été détachés qu'à une époque fort peu éloignée, de même que j'ai repoussé de ce catalogue les Éehinides subfossiles dont on reneontre les débris (lans les sables Salıariens qui courrent les plages soulevées du Pleistocène et de l'époque actuelle; il m'eut fallu citer toutes les espèces vivant actuellement sur les côtes de la Méditerranée et de la Mer Rouge. ${ }^{1}$

Les Échinides d'Égypte ont été souvent les premiers à frapper l'œil du voyageur et du gréologue.

En 1743, le docteur Shaw décrivait deux Échinides trourés par lui aux environs des Pyramides de Ghizeh, ainsi que plusieurs radioles de Cidaridae. - En 1810, Rozières figurait dans l'Atlas de la Description de l'Égypte divers Ĺchinides recueillis soit aux environs du Caire, soit dans la péninsule dı Sinaï. - Èn 1854, Bellardi, dans son Catalogue raisonné des fossiles du nummulitique d'Égypte, en eitait sept; en 1856, Desor en déerivait une douzaine la plupart rapportés par Lefébvre et déposés au Muséum d'histoire naturelle de Paris; en 1863, M. de Loriol publiait deux espèces nouvelles; en 1865, Fraas recueillait un bon nombre d'espèces erétacées, éocènes et miocènes, qu'il décrivait dans son intéressant

1. La même raison m'a fait englober dans ce eatalogue les especes des Oasis du désert libyque, ainsi done la elassifieation * Egypte» comprend non senlement la vallée du Nil, mais aussi la côte Ouest du Sinaï et les Oasis. 
ouvrage "Aus dem Orient»; en 1867, un échinologiste anglais, II. Martin Duncan, décrivait les spécimens rapportés par Holland de son voyage au Sinaï; en 1868, d'Archiac et Delanoue, dans leur description géologique des environs de Thèbes, décrivaient plusieurs espèces nouvelles. - Plus tard, en 1878, Fuchs déerivait les Échinides miocènes recueillis par lui dans un coin du Geneffé auxquels il ajoutait en 1882 ceux récoltés aux environs de Syouah par la mission Rohlfs; enfin en 1880, M. de Loriol publiait sa magnifique monographie des Échinides des terrains nummulitiques d'Égypte, en 1881 il décrivait les espèces éocènes du désert libyque rapportées par Rohlfs et Zittel et il a poursuivi ses études sur les Échinides d'Égypte dans ses notes pour servir à l'histoire des Échinodermes dans lesquelles il a décrit de nouvelles espèces égyptiennes récoltées par MM. Cramer et Mayer-Eymar.

Depuis, les recherches et les travaux de MM. Schweinfurth, Johannes Walther, Mayer-Eymar, Beyrich, Sickenberger, ete. etc., ont enrichi de nouvelles espèces la faune décrite par les auteurs précités et moi-même ai eu la bonne fortune d'en découvrir plusieurs encore inédites.

Il était done presque indispensable de procéder à une révision complète de tous ses documents et de réunir en un seul volume les indications éparses dans tant de notes et d'ouvrages. C'est le seul but que je me suis proposé et que je crois avoir atteint grâce à l'Institut Égyptien. Qu'il me soit permis de remereier tout particulièrement son président, S. E. Yacoub Artin pacha qui a bien voulu accorder à cette modeste étude une place dans le volume des mémoires de l'Institut.

Je me fais aussi un véritable devoir de signaler le précieux concours que m'ont prêté MM. Victor Gauthier, Mayer-Eymar, F. Sacco, H. G. Lyons et A. Pasquali pour mener cette ouvre à bien. 
M. Victor Gauthier a bien voulu m'aider des conseils de sa longue expérience et de son autorité incontestée. Il s'est chargé de l'examen et de la révision des nombreux spécimens recueillis par moi et a décrit les espèces nouvelles : c'est sous sa direction qu'ont été dessinées les planches de cet ouvrage dont je n'ai eu que la partie statigraphique à étudier. Je suis heureux de pouvoir lui témoigner ici toute ma gratitude.

M. Mayer-Eymar nous a communiqué la riche collection d'Échinides tertiaires du musée fédéral de Zürich : Mr. le professeur F. Saceo a bien voulu nous confier les exemplaires du « Regio Museo geologico» de Turin étudiés par Bellardi. M. le capitaine H. G. Lyons, directeur du Service géologique nouvellement créé en Égypte, a consenti à nous prêter les spécimens de la eollection de l'École de Médecine de Kasr-el-Aïny au Caire, ainsi que ceux déjà recueillis par ses collaborateurs et lui; enfin M. Alfred Pasquali a eu la gracieuseté de mettre à notre disposition les curieux documents qu'il avait réunis dans ses courses aux environs du Caire.

Je les en remercie sincèrement.

Le Caire, le $1^{\text {er }}$ Mai 1898.

R. Fourtau. 


\section{RÉVISION DES ÉCHINIDES FOSSILES DE LEÉGYPTE.}

\section{Époque carboniférienne.}

Archaeocidaris? ou Eocidaris? sp.

Syn. ${ }^{1}$ : Archaeocidaris ou Eocidaris sp. - Schweinfurth : Sur une exploration géologique dans l'Ouady Arabah. Bull. Institut Égyptien, 1888.

Il est difficile de juger sur de simples plaquettes si l'on a affaire à l'un ou à l'autre de ces deux genres. Sehweinfurth a reeueilli diverses plaquettes déposées an Musée de Berlin que Beyrieh a attribuées à l'un de ees deux genres, sans préciser exaetement.

Nous ne eitons done cette espèee que sur la foi de l'auteur.

Nivean : Carboniférien D, couches à Orthis resupinata.

Localité : entrée du Rod-el-Hamâl dans l'Ouady Arabah.

\section{Époque crétacée.}

Cidaris glandaria Lang. (sub Cidarites glandarius). 1708.

Syn. : Cidarites glandarius Fraas, Geologisches ans den Libanon, p. 27, pl. nI, fig. $1-10$ (exclus. 11), 187 o.

1. Pour la symonymie des especes et genres que nous citons, nous nous sommes restreints aux auteurs qui ont désigné ces espéces comme provenant d'Égypte ou des pays roisins comme VAlgérie, la Tunisie et la Syrie. 
Nous ne reproduirons pas ici tout ce qui a été dit sur ces radioles, un des plus aneiens fossiles qui aient attiré l'attention: il en est fait mention dans l'antiquité égyptienne sous la xxvi ${ }^{\text {me }} d y-$ nastie; les auteurs grees et latins en ont parlé; les pèlerins en rapportent encore anjourd'hui de la Palestine. L.es paléontologistes ont confondu longtemps eette espèce avec les radioles du $C$. glandifera Goldfuss, du Corallien, et il faut recomnaîre que les deux types se ressemblent beancoup. C'est Fraas qui, en 1878, an retour d'un voyage au Liban, a fait connaitre le premier que cet oursin appartient à la faune crétacée, et, dans son opinion, au Cénomanien. Il n'a cependant pas convainen tous les paléontologistes, car M. Diener place le Cidaris glandaria dans le crétacé inférieur, et M. Blankenhorn dans l'Oxfordien supérieur : on n'est pas encore bien sorti de l'ancienne confusion, M. de Loriol estime que c'est plutôt Fraas qui a raison.

Ces radioles se reneontrent prineipalement dans les débris d'érosion antour du Gebel Almar et dans l'Ouady el-Tih anx environs dı Caire.

Ils doivent done provenir des massifs crétacés de l'Attaka et de l'Abou-Daragué où les Ouadys, qui ont apporté ces détritus, premnent leur souree, et qui sont généralement rapportés au Cénomanien supérieur et placés anssi dans le Thuronien sans que ees différentes opinions soient définitivement établies.

Collections : Pasquali, Fourtau.

Pseudocidarts Pasqualit Gauthier, 1898, pl. i, fig. 1.

Avec les radioles du C. glandaria, Fraas a figuré (op. cit., fig. 11) un exemplaire entièrement lisse qu'il considère comme amené à cet état par le frottement et l'usure, et qu'il réunit spéeifiquement aux autres. Il dome de longs détails pour faire comprendre comment ee radiole a pu perdre ainsi tous ses ornements: 
il remarque cependant que la collerette est plus courte, on plutôt qu'elle n'existe presque pas; de plus, il déelare que l'articulation est crénelée. Ce dernier caraetère seul suffirait pour établir que le radiole appartient à un autre type, ear les tubereules du C.glandaria ont l'articulation lisse, et le test que Fraas a recueilli et qu'il dessine (fig. 1) ne laisse aucun doute à ce sujet.

Un des exemplaires que nous a communiqué M. Pasquali présente justement les mêmes caractères : radiole pyriforme, arrondi à l'extrémité, se rétrécissant jusqu'à la collerette si eourte qu'on peut la eonsidérer comme n'existant pas; bouton médiocrement développé, surface articulaire crénelée; e'est un type caractérisé des radioles du genre Pseudocidaris de Loriol. Ce genre, qui appartient ordinairement au jurassique supérieur et à la eraie inférieure, a eependant déjà un représentant dans le Cénomanien, I's. Dieneri de Loriol, dont les radioles sont inconnus, mais qui provient du Liban. Le test de notre radiole et de eelui de Fraas, qui nous paraît être le même, étant encore ineonnu, l'avenir seul pourra nous apprendre s'il y a quelque rapport entre les deux espèces. La surface est eouverte de très petits granules serrés. épars, sans ordre et ne formant pas de série longitudinale; toutefois, aux deux tiers environ de la longueur à partir du point d'attache, les granules deviennent plus gros, plus spiniformes; ils s'alignent un peu mieux surtout sur un des eôtés. Cette disposition des granules, ainsi que la forme générale, rapproche beaueoup) notre exemplaire de eelui que Quenstedt, eité par Fraas, a figuré dans ses Échinides, pl. 68, fig. 46-48, sous le nom de Radiolus glandarius clavophoenix. Le texte nous apprend que les séries linéaires sont un peu embrouillées à la base, caractère qui se reproduit sur notre exemplaire, comme nous l'avous dit; mais sur le reste du radiole, la figure 46 de l'auteur allemand les donne beaueoup plus régulièrement disposés qu'ils ne le sont sur le nôtre; 
ils augmentent de volume beaucoup plus hant senlement et ne paraissent pas prendre un aspect épineux. La figure 47 , qui représente un radiole moins volumineux, montre les crénelures de la base; la figure 48 a une collerette plus nettement dessinée, et s'éloigne d'autant plus du radiole égyptien. Ce radiole que Quenstedt appelle «datte» est-il bien le même que celui que nous déerivons? Cela nous paraît très difficile à décider; l'analogie entre eux est grande; les différences, quoique sensibles, ne suffisent pas pour les séparer catégoriquement; cependant il nous reste quelques doutes. Quenstedt déelare qu'il ignore la provenance de ses exemplaires; et, dans cette condition, il nous semble plus sage de séparer notre type de ces radioles qui peuvent appartenir à un horizon bien différent.

Yous avous dédié cette espèce à notre excellent confrère II. A. Pasquali, secritaire du contrôleur britannique de la Daïra sanieh de S. A. Le Khédive, qui a recueilli hi-même le type que nous venons de dícrire.

Localité : I)étritus d'érosion près dı Gebel Ahmar aux environs du Caire : provenance probable, Gebel Attaka ou Abou Daragué.

Niveau : Cénomanien supérieur.

Collection : Pasquali.

Rhabdocidaris Crameri de Loriol, 1887. Syn. : Rhabdocidaris Crameri de Loriol, Notes pour servir à l'étude des Échinodermes, fasc. II, p. 60, pl. 26, fig. 6-21. Recueil zoologiune, Snisse, tome Iv, $11^{\circ} 3,1887$.

II. de Loriol a décrit sous ce nom quelques plaques ambulacraires et interambulacraires d'un test qu'il rapporte au genre Rhabdocidaris; il attribue à ce test des radioles trouvés daus la même couche, trìs roisins de ceux du Cidaris .Jouanneti Des Moulins, auquel Cotteau a rémi comme synonyme le C.cyathifera Ag. II. de Loriol affirme que les exemplaires égyptiens forment bien une espèce à part, et que les radioles, malgré une analogie très 
frappante, présentent des caractères particuliers qui ont motivé l'établissement d'une nouvelle espèce.

Niveau : Sénonien.

Localité : Massif d'Abou Roach, à huit kilomètres à l'Ouest des pyramides de Ghizeh.

Collection : P. de Loriol.

C'est probablement à ce type qu'il faut lapporter le Cidaris, ef. Cyathifera de MI. J. Walther, recueilli dans la même localité. C'est encore rraisemblablement à quelques radioles de ce genre que le même autenr a donné le nom de $C$. subvesicularis. ${ }^{1}$

Salexia batrensis Peron et Gauthier, 1879.

Syn. : Salenia batnensis Cottean, Peron et Gauthier, Échinides fossiles de l'Algérie, fase. v, p. 183, pl. xin, fig. 7-13, 1879 .

» K. A. Zittel, Beitrïge zur Geologie und Paläontologie der litı!schen Wiiste und der angrenzenden Gebięte von Aegypten, premiere partic, p. 79, 1883.

Le Musée de Munich possède divers exemplaires de cette espèce algérienne qui ont été recueillis par Selhweinfurth dans l'Ouady Dakel aux envirous du couvent de St Paul.

Niveau : Cénomanien.

Localité : Ouady Dakel, chan̂ne du Galala el-Kiblyeh. En AIgérie cette espéce est assez commune dans le Cénomanien au sud de Batna.

P'seudodiadema sp. Zittel.

Dans la même collection du Musée de Munich se trouvent deux Échinides étiquetés par Zittel (op. cit., p. 79) sous le titre de Pseudodiadema sp. Ils ont été recueillis par Schweinfurth dans la même localité que le Salenia batnensis. N'ayant pas vu ces spécimens, nous ne pouvons en dire plus long et ne les citons qu'à titre documentaire.

Niveau : Cénomanien.

Localité : Ouady Dakel.

1. Cf. J. Walther, Lapparition de la craie aux environs des Pyramides, Bulletin de l'Institut égyptien, 1888. 
Pseldodiadema Mecrieri Gauthier, 1898, pl. I, fig. 23-27.

Dimensions : Diametre . . . . . . . . . 11 millimètres

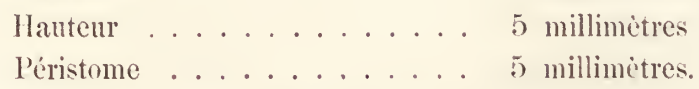

Espèce de petite taille, renflée au pourtour, déprimée à la face supéricure, légèrement pulvinée en-dessous. Appareil apical de grandeur moyenne, subcirculaire, d’après le circuit qui seul subsiste.

Aires ambulacraires droites, médioerement rétrécies au sommet, larges de trois millimètres à l'ambitus. Zones porifères rectilignes, unisériées, formées de paires de pores directement superposées, au nombre de trois par plaque majemre; les paires ne se multiplient pas aux approches du péristome. Espace interzonaire portant deux rangées de tubereules, relativement assez développés, diminuant peu à peu de volume au-dessus de l'ambitus; nous en comptons de dix ì onze dans chaque rangée; des granules marquent les angles des plaques entre les deux rangées.

Aires interambulacraires larges. portant deux rangées de tubercules principaux, un peu plus gros à l'ambitus que cenx des ambulacres, comme eux crénelés et perforés (?) au nombre de dix dans chaque série: ils diminuent médiocrement de volume audessus de l'ambitus. De chaque côté, tout près des zones porifères, se trouve une rangée de tubereules secondaires, beancoup moins gros que les autres, néanmoins assez marqués jusqu'à l'ambitus, au-dessus duquel ils se confondent avec les granules. La zone miliaire entre les deux rangées de tubercules montre des granules en ligne brisée, et ceux des angles des plaques, plus gros que les autres, forment comme le rudiment de rangées secondaires; audessus de lambitus il n'y a plus que des grannles épars et peu nombreux, et le milieu de la zone paraît nu.

Péristome presque à fleur de test, dans une légère dépression, 
avec dix entailles bien marquées. Appareil apical disparu; l'empreinte circulaire qu'il a laissée est un peu moins grande que le péristome.

La petite taille de notre exemplaire le ferait regarder comme un individu jeune encore, si tous les exemplaires connus ne présentaient les mêmes dimensions. Nous n'avons pas entre les mains des matériaux suffisants pour affirmer que les tubercules sont réellement perforés; ils sont crénelés et paraissent offrir des traces de perforation, mais nous n'en avons pas la certitude en ee moment.

Nous avons dérlié cette espèce à M. le professeur Stanislas Mennier du Muséum d'histoire natmrelle de Paris.

Niveau : Cénomanien. Calcaires gréseux à Sphaerulites Schweinfurthi Zitt.

Localité : Ouady Mohr.

Heterodiadema libycum Cotteau, 1864.

Syn. : Hemicidaris lihyca Agassiz et Desor, Catalogue raisonné, p. 34, 1847.

Heterodiadema libycum K. Zittel, Beiträge zur Geologie und Palïontologie der libyschen Wiiste und der angrenzenden Geliete von Aegypten, p. $79,1883$.

Cette espèce, très commune en Algérie, a été rangée successivement par Desor dans le genre Hemicidaris, puis dans le genre Pseudodiadema et par Coquand dans le genre Pygaster; Cotteau, avec beaucoup de raison, en a fait un genre nouveau. Desor cite ce type dans le terrain crétacé d'Égypte; Duncan le comprend parmi les espèces rapportées du Sinaï par M. Holland; ${ }^{1}$ Schweinfurth en a recueilli un assez grand nombre dans les environs du couvent de $\mathrm{S}^{\mathrm{t}}$ Paul, et il les a déposés au Musée de Munich (cf. Zittel, op. cit.). On le rencontre aussi en Provence aux environs de Marseille.

1. Cf. Duncan, Description of the Echinids of the cretaceons rocks of Sinai, Quarterly Journal, tom. xxin, p. 38, 1867. 
Diplopolia VARIOLARIS (Brongniart) Desor, 1856.

Srnn. : Diplopodia variolaris Gauthier, Notes sur les Échinides crétucés recneillis en Tunisie par M. Aubert, p. 15, 1892.

Pseudodiadema variolare Zittel, op. cil., p. 79.

Cette espèce de T'unisie a été recueillie par Schweinfurth dans le crétacé des environs du couvent $\mathrm{S}^{t}$ Paul et déposée par lui au Musée de Munich. Elle est assez rare dans cette localité.

Niveau : Cénomanien.

Localité : Onady Dakel, chaîne du Galala el-Kiblyelı.

Diplopodia sinaica Desor, 1857.

Syn. : Diadena sincicum Desor, Catalogue raisonné, p. 44, 1847.

Diplopodia sinaica Desor; Synopsis, p. 78, 1857.

Desor ne dome de cette espèce qu'une ligne de description: "Espèce du type du Diadema subangularis; point de rangées secondaires de tubercules.»

Terrain crétacé dı Sinaï. Rare.

Le type est an Muséum de Paris.

Pedina sinaica Desor, 1847.

Syn. : Pedina sinaica Desor, Catalogue raisonné, p. 67, 1847.

„ Desor, Synopsis des Échinides, p. 102, 1857.

Desor eite eette espèce dans le erétacé du mont Sinaï, avee un point de doute qui n'est pas superflu, ear le genre Pedina ne s'est rencontré jusqu'à présent que dans les terrains jurassiques. Duncan cite ce Pedina sans y ajouter aucune remarque; nous avons cherclıé en vain si quelqu'auteur y avait fait allusion dans la suite, nous n'avous rien trouvé.

ORTHOPSIS RUPPELLII de Loriol, 1880. Syn. : Diadema Ruppellii $\quad$ Desor, Catalogue raisonné, p. 45, 1847.

Pseudodiadema Ruppellii Desor, Synopsis des Échinides, p. 78, 1856.

Cotteau, Paléontologie française, terrains erétacés, p. $520,1864$. 
I'sendodiadena Ruppellii Duncan, op. cit., $186 \bar{\imath}$.

Lartet, Géologie de la Palestine, Annales des Sciences géologiques, tome ill, p. $833,1872$.

Orthopsis Ruppellii de Loriol, Monographie des Échinides nummulitiques de l'Égypte, p. 11, pl. 1, fig. 16, 1880.

M. de Loriol déclare qu'il n'a pas trouvé de tubercules erénelés sur l'exemplaire cité par les auteurs précédents; que les ambulacres ont une disposition simple qui rappelle les Orthopsis, et il rapporte à ce genre le seul exemplaire conm. Mais bien que Lefébvre qui a recueilli ee fossile l'ait indiqué comme appartenant au terrain crétacé du Sinai, M. de Loriol veut y voir un Échinicle du terrain nummulitique du Mokattam : «Je n'ai pu découvrir, à la vérité, dit-il, ancun nummulite dans les fragments de la gangue encore attachés à l'échantillon, mais elle est tout-à-fait identique à celle d'autres oursins du nummulitique du Mokattam.» Comme le recomnaît ensuite M. de Loriol, on n'a pas encore rencontré jusqu'ici d'Orthopsis tertiaire, ce serait le premier. Nous croyons plus simple de suivre l'indication de Lefébvre et de considérer l'Orthopsis Ruppellii comme erétacé et d'en faire une espèce cénomanienne, eet étage étant très développé dans le Sinaï.

Codiopsis 11. sp. Zittel.

Zittel eite (op. cit., p. 79) de très rares exemplaires d'un Codiopsis n. sp. qui auraient été recneillis par Schweinfurtlı dans le Cénomanien des environs du couvent de $\mathrm{S}^{t}$ Paul et déposés par Ini au Musée de Munieh.

Cyphosoma Abbatei Gauthier, 1898, pl. I, fig. 2-6.

Dimensions : Diamètre . . . . . . . . 16-20 millimètres Hauteur . . . . . . 6-8 millimètres.

Espèce de petite taille, du moins d'après les exemplaires que nous avous sous les yeux, subcirculaire, assez renflée, eonvexe, 
mais déprimée à la partie supérieure. pulvinée en-dessous. Appareil apical inconnu: l'empreinte qu ill a laissée est nettement peutagonale, avec pointe postérieure s'enfonçant dans l’interambulacre impair.

Zones porifères ì peu près droites dans leur tiers supérieur, ourluleuses et formant des petits ares autour des tubercules sur le reste du test; les deux plaques les plus rapprocliées du sommet portent des paires de pores simplement superposées, unisérićes; mais à partir de là jusqu'à l'ambitus, les paires sout fortement higémincées: puis à l'ambitus et an-dessous elles sont de nouveau unisérices, formant des ares de quatre on cinc paires autour du tubereule, les trois ou quatre dernières au hord du péristome sont moins régulièrement alignées. L'espace interzonaire étroit, portant deux rangées de tubereules crénelés, imperforés, assez développés depuis le péristome jusqu'aux deux tiers de la hauteur; li, ils diminuent rapidement de volume jusqu'à l'apex; ils oceupent partout une disposition alterne, phus marquée dans la partie où ils diminuent tout à coup. Nous en eomptons dix dans claque série. La zone miliaire n'existe pas pour ainsi dire : l'espace étroit qui sépare les deux rangées est occupé par une simple rangée de granules qui suivent en ligne brisée la suture des plaques; il y a aussi une rangée liorizontale de graunles entre les tubereules de la même série.

Aires interambulacraires relativement larges, portant deux rangrées de tubereules principaux, au nombre de neuf, diminuant ì peine de rolume ì la partie supérieure, sauf le dernier; ils sont un pen plus développés que ceux de l'ambulacre, comme eux crénelés et imperforés, quelques-uns radiés, et séparés par une rangée de granules. De ehaque côté extérieurement il ý a une rangée de tubercules secondaires beaucoup plus petits, iuégaux, montant jusqu'au septième tubercule primaire. Zone miliaire aussi 
large à l'ambitus que près du sommet, montrant deux rangées de gramules dont cenx des angles phus gros que les autres sont les rudiments de rangées de tubereules secondaires.

Péristome à fleur de test, grand (8 millimètres), portant dix entailles peu profondes, mais assez fortement relevées sur les bords.

L'exemplaire que nous venons de décrire est celui qui mesure 20 millimètres de diamètre; c'est le plus grand que nous commaissions, mais cela ne veut pas dire que l'espéce ne soit pas susceptible d'un plus grand développentent. Nous arons sous les yeux une vingtaine d'autres exemplaires plus petits, qui offrent dans les zones porifères des différences considérables : ceux dont le diamètre atteint seize millimètres ont deux ou trois paires bigéminées seulement, sur les plaques placées à l'endroit où les tubereules ambulacraires diminuent tout à coup de volume; les paires sont unisériées partout ailleurs. Les exemplaires au-ilessous de 16 millimètres n'ont que des paires simples superposées en petits ares. Ces petits individus, que nous avons examinés les premiers, nous avaient d'abord produit l'effet de jemes exemplaires d'une nouvelle espece du genre Gauthieria Lambert: mais l'examen d'individus plus développés nous montra bien vite que nous étions en présence de véritahles Cyphosoma. Nous ne tenons pas compte des deux plaques les plus rapprochées du sommet dont les paires de pores sont unisériées; ce caractère nous paraît sans valeur, d'autant plus que des exemplaires plus développés, s̈il s'en rencontrait, présenteraient peut-être des paires bigéminées jusqu'à lapex.

Tout récemment M. Lambert ${ }^{1}$ a désigné sous le nom d'Heteractis une espèce présentant ce caractère des paires supérieures en simple série, alors que plus bas elles sont bigéminées; il ajoute à 
son type spécifique Heteractis heteroporus le Cyphosoma Lloreae Cotteau, ${ }^{1}$ qui, selọn lui, appartient au même sous-genre. cal cet Heteractis n'est qu'un sous-grenre de l'Asteropsis de Cotteau devenu Actinopsis par suite des exigences de la synonymie. L'un des a-aractères de ce dernier est la disposition spéeiale de ses tubercules extrêmement fins. Nous ne voyous pas très bien eomment le Cyplosoma Lloreae pent appartenir au même genre que l'Asteropsis Lapparenti ${ }^{2}$ M. Lambert leur trouve comme caractères communs : "Etroitesse de l'apex et ambulaeres polypores à zones bigéminées.» Cotteau, dans sa description, dit que l'Asteropsis (Actenopsis) Lapparenti, seule espece du genre, a les paires de pores toutes bigéminées à la face supérieure, mais quan-rlessous de l'ambitus les zones poriferes se rétrécissent ot que les pores sont rangés par triples paires à peine obliques; cela veut dire, eroyousnous, trois paires par plaque majeure. ou disposition oligopore. Quant à l'étroitesse de l'apex, nons ne sarous pas nou plus jusqu’a quelles dimensions l'apex s'appelle étroit; Cottean dit de son exemplaire : "Appareil apieal assez grand, pentagonal, ì eu juger par l'empreinte qu'il a laissée.»

Quoi qu'il en soit, nous ne eroyous pas que notre noureau type puisse rentrer daus le genre Actinopsis eu passant par le sousgenre Heteractis; e'est, pour tous ses caractères, un pur Cyphosoma, sauf que les deux plaques supérieures u’ont pas de pores bigéminés; nous n'attachous pas, comme nous l'avous déjà dit, d’importance à ce létail.

Nous avons dédié cette espéce à S. E. Abbate pacha, vice-président de l'Institut Figyptien et président de la Société Khédiviale de Géographie.

Niveau : Sénonien inférieur. Caractérise un banc de ealcaire

1. Cf. Cotteau, Échinides éocènes de la province d'Alicante, p. 103, pl. xwr.

2. (f. Cotteau, Échinides nonveaux ou peu conms, $2^{\mathrm{e}}$ série, 1. 22, pl.111, fig. 1-i), 1883. 
compact au-dessous de l'horizon à lumachelles d'huitre et audessus des griès bruns.

Localité : Abou Roach à huit kilomètres au Norr-Ouest des Pyramides de Ghizel.

C'est sans doute de cette espèce dont parle J. Walther, ${ }^{1}$ lorsqü il dit que les bancs de calcaires contre lesquels s'appuient les dernières maisons du village d'Abou Roach renferment une énorme quantité de petits Pseudodiadema.

Holectypus kxchus Desor (sub Discö̈dea excisa), 1847. syn. : Holectypus excisus =smb, Discö̈dea excisu Desor, Catalogue raisoné des Échinides fossiles, $18+\pi$.

Holectypus excisus Duncan, Description of the Echinids of the cretaceons rocks of Sinä, Quart. Journ., tome xxmi, p. 38, 1867.

K. A. Zittel, Beitrïge zur Geologie and Palüiontologie der libyschen Wiiste und der angrenzenden Geliete von Aegypten, $1^{\text {ro }}$ partie, 1). $79,1883$.

Nous citons cette espèce d'après les listes de Duncan et de Zittel. La haute eompétence de l'échinologiste anglais qui affirme que l'espice du Sinaï ne peut être disting'uée de l'H. excisus type suffirait pour nous autoriser à l'inscrire dans ce catalogue. Depuis Schweinfuith en a recueilli de nombreux exemplaires en Égypte aux environs du couvent de St Paul. Nous pouvons ajouter que l'II. excisus, assez répandu en France, se trouve aussi en Algérie, en 'T'unisie et dans le Liban.

Niveau : Cénomanien supérieur.

Localités: Ouady Boudrah (Sinaï, recueilli par Holland), Othady Dakel (chaîne du Galala el-Kiblyeh, recueilli par Schweinfurth et déposé par lui au Musée de Munich).

1. Cf. J. Walther, L'apparition de la craie anx environs des Pyranides, Bull. Inst. Ésyptien, $18 \times 8$. 
Holectypus cenomanexsis Guéranger; 1859.

Syn. : Holectypus cenomanensis Guéranger, in Cotteau et 'lriger, Échinides de la Surthe, p. 173 , pl. 30 , fig. $5-10,1859$.

Duncan, Descript. of the Echinodernata from the coust of Arabic etc., Quart. Journ., vol. xxi, p. 354, 1865.

Duncan, Descript. of the Echin. of the cretaceous rocks of Sinai, Quart. Journ., vol. xxur, p. 3S, 1867.

Thomas et Gauthier, Échinides fossiles de Truisie, 1). 57, 1859.

de Loriol, vi, Notes pour servir à lhistoire des Échinodermes, Revne suisse de zoologie, (ieneve, tome $\mathrm{v}$, fasc. 2, p. $155,1897$.

Cette espèee a été reeneillie par M. A. Pasquali dans les détritus d’érosion près du Caire. J'en ai recueilli quelques exemplaires dans l'Ouady Bondrah au Sinaï. On la trouve assez fréquemment en Algérie et M. Lartet l'a rapportée de Syrie. Dans le Liban elle a été reeueillie par M. Zumoften, professeur de physique à l'Lniversité St Joseph de Beyrouth, qui l'a communiquée à M. de Loriol à l'ouvrage duquel nous renvoyons pour la synonymie complite de l'espèce.

Niveau : Cénomanien.

Loealités : Détritus d'érosion du Ouady Kachah près le Caire (Pasquali, provenance probable Gebel Abou Daragué), Ouady Boudralı (Sinaï).

Holectrypus crassus Cottean, 1861.

Syn. : Holectypus crassus Cotteau, Paléontologie française, terrain crétacé, tome vil, p. 55 , pl. 1017, fig. 1-5, 1861.

\Thomas et Gauthier, Description des tichinides fossiles recueillis dans la région des Hauts Plateaux de la T'unisie, p. 59, 1889.

„ K. A. Zittel, op. rit., p. 79, 1883.

Zittel eite en le faisant suivre de la mention très rare l' $H$. crassus comme ayant été recueilli par Schweinfurth daus le eénomanien de l'Ouarly Dakel. 
Discomea relinat'A Desor, 1847.

Syn. : Discoidea pulvinata Desor, Catalogue raisonné des Échinides, p. $89,1547$.

\$ Desor, Synopsis des Échinides fossiles, p. 179, 1858.

$>\quad$ K. A. Zittel, op. cit., p. 79, 1883.

Desor dans le Synopsis caractérise ainsi cette espèce : "Espèce de taille moyeme, circulaire, remarquable par son bord très obtus et renflé. Périprocte occupant moins de la moitié de l'espace entre le péristome et le bord. 'Terrain (rétacé d'Éġypte.» Elle est, paraît-il, abondante dans l'Ouady Dakel et aux environs du courent de $S^{t}$ Paul où Schweinfurth l'a recueillie.

Niveau : Cénomanien.

Localité : Châne du Galala el-Kiblyeh.

Echisocones Aegrptiacus d'(Orbigny, 1856.

Syn. : Echinoconus cegyptiacus dorbigny, Paléontologie française, terrain crétacé, tome vr, p. 544 , pl. 1005 , fig. $7-9,1856$.

Cette especee, rapportée d'abord par Lefebre comme provenant des environs du Caire, a été rencontrée depuis en Égypte par II. A. Pasquali dans les détritus d'érosion des environs du Gebel Akmar et peut être attribuée an Cénomanien supérieur ou plutôt au 'Turonien et proviendrait des couches de l'Attaka on de l'Abou Daragué.

Collections : Pasquali, Fourtau, Muséum de Paris.

Echinobrissus pseudomininus Peron et Gauthier, 1881. Syn. : Echinobrissus psendo-minimus l'eron et Gauthier, Échinides fossiles de l'Algérie, fase. 7 , p. 78 , pl. r, fig. 2- $7,1881$.

J. Walther, L'apparition de la craie anx: environs des Pyramides, Bull. Inst. Figypt., 1888.

Nous n'avons pas vu les exemplaires de Walther qui se trouvent au Musée de Munich; comme il est facile de confondre ce type avec des espèces roisines; nous ne le citons que d'après l'auteur avec d'autant plus de réserve que la même localité d'Abou-Roach 
nous a fourni deux espèces nouvelles d'Echinobrissus que nous décrirons ultérieurement.

Niveau : Sénonien.

Localité : Gebel Abou Roach.

Nuchliolites Luynesi Cotteall, 1867.

Syn. : Nucleolites Luynesi Cottean, Voyaye du duc de Luynes, p. 153, pl. xur, fig. 15-19, 1867.

„Schweinfurth, Sur la déconverte d’une faune paléozö̈que dans le grè̀ nußien, Bull. Inst. Figypt., 1886.

Les exemplaires recueillis par Schweinfurth sont au Musée de Berlin, où ils ont été détcrminés par Beyrich; nous eitons l'espéce sur la foi de l'auteur.

Niveau : Sénonien. Les exemplaires, dit Schweinfurtl, sont tellement nombreux qu'ils forment une espèce de brèche.

Localité : Ouady Haouachieh, châne arabique versant de la Mer Ronge près du Gebel Gareb.

Claviaster Cornutus d'Orbigny, 1855.

Syn. : Archiaciu cornuta Agassiz, Catalogue raisonné des Echinides fossiles, 1). 101. 1847. Claviaster cornutus iOrbigny, Paléontologie française, terrain crétacé, tome vi, p. 282 , pl. 909 , fig. $1-5,1855$.

* Cottean, Échimides nouveaux ou pen connus, tome 1, p. 226, pl. xxxu, fig. :-4, 1880.

Ce genre bizarre, encore completement incomm, a eu pour type un exemplaire provenant du Sinaï; d'Orbigny le croit Turonien. D'autres espèces ont été recueillies depuis : $\mathrm{Cl}$. libycus 'Thomas et. Gauthier, dans le Cénomanien supérieur de 'T'unisie; Cl. Beltremieuxi Cotteau, du Cénomanien de la Charente. En 1880, Cotteau figure un exemplaire recueilli par M. Boreau dans la Charente inférieure à Beaumont dans les poudingues du Crétacé supérieur (Dordonien). Il l'attribue sans hésiter au $\mathrm{Cl}$. cornutus, tout en faisant observer que chez cet exemplaire les pores ambulacraires sont semblables dans les cinq aires, tandis que d'après la descrip- 


\section{$-628-$}

tion et les figures données jar d'Orbigny, l'aire ambulacraire inpaire est composée de pores beancoup plus petits. En 1883, dans les "Échinides du Sud-Onest de la France», Cotteau cite de nonveau cet exemplaire comme parfaitement caractérisé et identique au $C l$. cornutus, et le place cette fois dans le Sénonien infériemr. Nous n'avous pas vu cet oursin, mais nous ne sommes pas convaincus de son identité avec l'espèce dı Sinaï qui appartient très probablement à l'étage Cénomanien.

\section{Hemiaster cumices Desor, 1847.} Syn. : Heniaster culicus Desor, Catal. rais. des Fich. foss., p. 174, 1847.

» d'Orhigny, Paléontologie française, p. 23т, pl. 879, 1\$5う..

ॠ. A. Zittel, op. cit., p. 79, 1883.

Les exemplaires que nous avons pu étudier ont été recueillis par M. Fourtan an Sinaï (Ouady Boudrah) en compagnie d'autres fossiles qui montrent qu'ils appartiennent à l'étage Cénomanien. M. Schweinfurth en a également rapporté me belle série de l'Ouady Dakel aux environs du monastère de $\mathrm{S}^{t}$ Paul, dans la chaîne arabique. La forme anguleuse de eette espèce, telle qu'elle est représentée dans la Paléontologie française ne se trouve exacte que pour les exemplaires de grande taille, à un âge moins avancé, même à une taille de 40 millimètres en longueur, l'H. cubicus est plutôt cordiforme, épais, à aires ambulacraires longues et médiocrement élargies. Cette différence de forme, selon l'âge, a occasionné plus d'une erreur. An Sinaï, on trouve avec les grands exemplaires parfaitement typiques des jeunes dont on n'a pas toujour's reconnu la nature véritable.

L'appareil apical est ethmolysien, c'est-à-dire que le corps madréporiforme sépare non seulement les génitales postérieures, mais excède même les ocellaires. Cette disposition est facile à constater même sur des individus n' ayant pas encore atteint tout leur développement et conservant encore la forme épaisse et subcordi- 
forme des jennes. Nous n'arons pas entre les mains de petits exemplaires assez bien conservés pour en vérifier l'appareil; il est probable, comme nous l'a montré l'étude des grands Hemiaster. algériens, que le corps madréporiforme y est moins étendu que chez les grands individus.

Niveall : Cénomanien. Caractérise les marnes à la base de cet étage.

Localités : Ouady Boudrah et Gebel Hammam Moussa (Sinaï, exemplaires nombreux, mais de conservation médiocre), Ouady Dakel et chaine du Gebel Galala el-Kiblych (Schweinfurth in. Zittel. op. cit.), Ouady Keneh.

Henitaster Bat'Nensis Coquand, 1862.

Syn. : Hemiaster hatnensis Coquand, Mémoires de la Société d'émulation de Provence, tome ir, p. 248, pl. xxvir, fig. 6-8, 1862 .

»Cottenr, Peron et Gauthier, Échimides fossiles de l'Alyérie, fase. 1 , p. 118, 1878 .

» Thomas et Gauthier, op. cit., 1). 12, 1889 (voir cet onvrage pour ha synonymie plus complete).

" Gauthier, Notes sur les Échinides recueillis en T'misie por M. Aubert, p. 12, 1892.

K. A. Zittel, op. cit., p. 79, 1883.

De rares exemplaires recueillis par Schweinfurth ont été déposés par lui au Musée de Munich et figurent dans la liste que donne K. A. Zittel (op. cit.).

Niveau : Cénomanien.

Localité : Ouady Dakel.

Hemaster Heberti (Coquand), Peron et Gauthier, 1878.

Syu. : Epiaster Heberti Coquand, Mémoires de la Société d'émulation de Provence, tome Ir, p. 242, pl. xxv, fig. $7-9,1862$.

Hemiaster Heberti Peron et Gauthicr, Echinides fossiles de IAlgérie, fasc. Iv, p. 129 , pl. vir, fig. $1-3,1878$.

Nous avous entre les mains plusieurs exemplaires de cette espèce, de tailles diverses, recueillis au Sinaï par M. Fourtau. MímoIREs, T, III. 
L'un de ces exenplaires qui présente les mêmes dimensions que l'un des individus typiques de Tenoukla (Algérie) lui ressemble tellement qu'il serait très difficile de les distingner l'un de l'autre s’ils étaient privés de leur étiquette. Cet Hemiaster est trìs commun en Algérie et en T'unisie, dans l'étage Cénomanien. Il a été anssi recueilli par M. Pasquali dans le détritus d'érosion des environs dn Caire et proviendrait comme tous ceux de ce gisement des couches de l'Attaka ou de l'Abou Daragué.

Niveau : Cénomanien.

Localité : Ouady Boudrah et Ouady 'Tayebah (Sinaï) : détritus d'érosion des environs du Caire (Pasquali).

Hrimaster proclivis Peron et Gauthier, 1878. syn. : Heminster proclivis Cottean, Peron et Gauthier, Lichinides fossiles de l'Algriere, fase. iv, p. 121 , pl. v, fig. $1-4,1878$.

K. A. Tittel, op. cit., p. $79,1883$.

Même observation pour cette espèce que pour H. batnensis.

Hemiaster gracilis? Cottean.

Syn. : Hemiaster gracilis? Dunsm, Descript. of the Echin. of the cretaceous rocks of Sincei, Quart. Jomrn., tome xxm, p. 39, 1867.

Duncan a cité cette espèce de la Sarthe parmi les Échinides reeneillis an Sinaï par M. Holland. Il est probable qu'il y a confusion. L'auteur anglais remarque d'ailleurs que certaines espèces à vaste extension géographique (widewandering) ont une tendance à différer du type; l'assimilation n'est done pas certaine.

Niveau : Cénomanien.

Localité : Sinaï (Ouady Boudrah et Ouady Mokatteb).

Duncan nons avertit que les Échinides qu'il décrit ont été recneillis par Holland an Sinaï dans l'Onady Boudral et dans l'Onady Mokatteb. I'our ce qui est de la premiere localité elle est exacte, car j’y ai récolté moi-même plnsienrs Échinides, mais, pour la seconde, elle est inalmissible, car l'Onady llokatteb est nne vallée monoclinale entre les grès sinaïtiques sans fossiles et les roches archèennes; il y a 
done eu erreur de Holland qui a dî confondre l'Uuady Seh el-Sidr. formé par la jonction de l'Ouady. Qineh et de l'Ouady Mokatteb aree ce dernicr.

Hemiaster Folineli Deshayes, 1848.

Syn. : Hemiuster Fourneli Deshayes in Agassiz et Desor, Catal. rais. des Eichin. foss., p. 123,1848 .

Cotteau, Perou et Gauthier, Échinides fossiles de l'Algérie, fasc. vir, p. 58, pl. 11 , fig. $1-8,1881$.

Thomas et Gauthier, Fichinides des Mants Plateanx de la Tunisie, 1). 15, 1889 (roir cot ourage pour la synonymie plus complete).

D. Walther, Liapparition de la craie aux envirms des Pyramides, Bull. Inst. Ëgypt., 1885.

II. J. Walther dit aroir recueilli à Abou Roach aree d'autres Échinides plusieurs Hemiaster qu'il attribue ì H. Foumeli. Je n'ai pas vu les échantillons de Walther, mais jai récolté moimême à Abou Roach au niveau dont parle le géologue allemand trois Hemiaster en assez mauvais état, dont cependant ancun des caractères visibles n'est en contradiction arec l'H. Foumeli. Je ne puis done citer cette espèce qu'en faisant quelques réserves.

Niveau : 'Turonien supérieur: Conches ì Cyphosoma Abbatei.

Localité : Abou Roach.

Epiaster distinctus d'Orbigny.

Espèce citée au Sinaï par Duncan, qui nous prévient que c'est une légère variété du type. - Cénomanien.

Periaster elatus (Des Moulins) d'Orbigny.

Cité par Duncan avec la même observation que pour l'espèce précédente. Sinaï, - Cénomanien.

LinthHA OBLONGa (d'Orbigny, 1854).

Syn. : Periaster oblongns d'Orbigny, Paléontologie française, terrain crétacé, tome vi, p. 275, pl. 900, 1854.

Linthia oblonga Peron et Gauthier, Échinides fossiles de TAlgérie, fasc. vi, p. $79,1880$. 


\section{$-632-$}

D'Orbigny a sigualé cette espèce comme recueillie par M. Lefébvre avec des Radiolites, an Gebel Garèbe près de Suez à un niveau qu'il rapporte à son ítage Turonien. On la rencontre en Algérie, dans l'étage T'uronien, aux collines du Moulin à Vent près de Batıla; en France, elle est assez commune aux environs d'Angoulême, à la base de l'étage Angoumien, dans le Turouicu supérieur.

Niveall : Thronien.

Localité : Je ne commais point de Gebel Garèbe près de Suez, seule une petite éminence au pied de l'Abou Daragué porte le nom de Krouéba, éest peut-être là que Lefébvre l'a récoltée à moins que ce ne soit dans les couches qui bordent le massif central grranitique du Gebel Garib à 220 kilomìtres au Sud de Suez sur les côtes de la Mer Rouge, entre cette montagne et Gebel Zeit.

\section{Micraster sp. Zittel, 1883.}

Zittel (op. cit., p. 65) dit avoir recueilli daus la couche qui courome le Gebel Lift dans l'Oasis de Dakel de petits exemplaires de .Yicraster qưil ne désigne pas spécifiquement.

Niveau : Aturien : Couches ì Spondylus Dutempleanus et Gryphaea vesicularis.

Localité : Gebel Lift.

Echinocorys (ANanchytess) ovatus Zittel, 1883.

Zittel (op. cit.) cite fréquemment dans les couches du Garumnien ou de l'Aturien des Oasis l'Ananchytes ovata dout il fait presque la caractéristique de ces couches. Je ne comais d'Afrique que deux individus recueillis dans le crétacé supérieur d'Algérie et encore sont-ils en mauvais état. Il est assez curieux de voir cette espèce si répandue en France, se retrouver dans les Oasis libyques, si l'on en croit Zittel. 
Nivean : Garumnien? Aturien?

Localités : Gebel Lift (Oasis Dakel), Gebel Ter (Uasis Khargeh), Gebel Oum el-Reneiem (Oasis Khargeh).

\section{Époque éocène.}

\section{Échinides endocycliques.}

RHABDOCIDARIS ITALA Laube, 1867.

Syn. ${ }^{1}$ : Rhabdocidaris itala Lanbe, Echinod. d. Vicent. tert. Geh., Sitzungsberiehte der Akad. der Wissensel., Wien, $186 \pi$, p. 240 et 1868 , p. 9, pl, I, fig. 3.

„ de I.oriol, Eociine Echinoideen aus Aegypten und der libyschen Wiiste, 1). 7, pl. 1, fig. 2-9, 1881.

„k. A. Zittel, op. rit., 1883, p. cxix.

II. de Loriol a figuré le test et une série de rarlioles; nous avons entre les mains un assez grand nombre de ces derniers; la plupart ressemblent plus étroitement au type figuré par Laube qu'aux variétés dessinées par M. de Loriol.

Niveau : Lutétien I.

Localités" : Mokattam, Minieh, Oasis de Moëleh, Ararlj (désert libyque), plateau des Pyramides de Ghizeh.

1. Ponr toutes les especes déerites par M. de Loriol, nous ne citons à la Synonymie que l'antenr de l'espéce et ceux qui l'ont indiquée en Égypte ou dans les pays roisins. Pour tous les antres anteurs nous renvoyous aux listes synonymiques, si exietes et completes de II. de loriol.

2. Pour les localités j'ai suivi le plus possible les noms arabes usités dans le pays, jai done dû suppriner les nombreuses localités yue II. Mayer-Eymar a dédiẻes sons le nom générique de Garet (?) à ses amis et connaissances, sauf celles dont j’ai pu rétablir l'ilentité. M. Mayer-Eymar sait saus doute aussi bien que moi que le Congrès intermational de Géographie de Venise a adopté une résolution disant que l'on devait avant tout se servir des noms nsités par les habitants des pays que l'on d'erivait. Comme M. Mayer-Eymar n'en a teun aucun compte, je me vois dans la nécessité de supprimer de ce catalogue les trois quarts de ses localités qui ne peuvent ètre illentifiées que par lui et de les remplacer par l'étiquette très vague : áummu- 
Collections : Zittel, de Loriol, Mayer-Lymar (Musée de Zurich), Fourtau, Gauthier.

Rhabuocindis Minikhensis Mayer-Eymar, 1897, pl. I, fig. $7-8$.

Syn. : Lihabdocidaris Miniehensis Mayer-Kymar, in collect.

Dimensions : Diamètre . . . . . . . . . 38 millimètres.

Hauteur . . . . . . . 22 22 millimetres.

Nous ne commaissons qu'un exemplaire du test de cette espèce, sensiblement déformé par compression, assez net cependant pour que nous puissions en donner une deseription suffisante.

Exemplaire de taille moyenne, subrotulaire, assez renflé à l'ambitus, déprimé en-dessus et en-dessous. Aires ambulacraires larges de 5 millimètres au pourtour, droites on très légèrement onduleuses. Zones porifëres formées de paires de pores ronds, un peu obliques, eonjugués par un sillon bien marqué; les paires sont séparées par des cloisons. Granules interzonaires formant quatre rangées, assez gros et réguliers dans les rangées externes, plus petits, moins alignés, souvent doubles et même triples dans les interues.

Aires interambulacraires larges de 17 millimètres, dépassant plus de trois fois la largeur des aires ambulaeraires, portant deux rangées de gros tubereules perforés, non erénelés, un peu moins développés près du péristome, puis augmentant régulièrement de volume et diminuant peu aux approches de l'appareil apieal; il y en a sept par rangées; scrobicules médioeres entourés d'un cerele de granules serrés, pen accentués; ees cereles scrobiculaires sont toujours entiers, presque ronds, un pen ovales; à la partie supérieure, ils sont séparés l'un de l'autre par deux rangées de gra-

litique d'ígypte», pour le cas oì il n'y a pas d'autres localités. An surplus j’ai déjà explrimé mon opinion lá-dessus, opinion qui a été partagée par l'Institut Égyptien (cf. R. Fourtul, Note sur les Sismondia d'Égypte, linll. Inst. Égyptien, $1^{\circ}$ 3, 1897). 
nules. Zone miliaire large de 4 millimètres à l'ambitus, partout garnie de granules serrés, disposés en séries horizontales de huit ou dix à l'endroit le plus large; des rangées de même nature, mais plus courtes se remarquent près des zones porifères formant un triangle entre l'aire ambulacraire et les cercles des scrobicules.

l'empreinte laissce par l'appareil apical est subcirculaire et plus grande que le péristome qui est dans une légère dépression et ne mesure guère que 7 à 8 millimitres de diamètre. Un fragment de radiole engagé dans la gangue à la partie supérieure est trop incomplet pour que nous puissions en avoir une idée exacte; il est subcylindrique et convert de stries longitudinales tris fines.

L'espèce la plus voisine parmi les Cidaris égyptiens est le $R h$. Zitteli de Loriol, qui a à pen près la même taille; ce dernier se distingue facilement par ses aires interambulacraires plus crensées entre les rangées de tubercules, par son péristome plus grand, par sa granulation moins serrée, par ses tubercules moins développés et surtont par les granules de l'espace interzonaire dans les ambulacres qui sont disposés tout autrement et bien plus régulièrement. Parmi les espèces étrangères à l'Égypte le Rh. Poucchi Cottean se rapproche de notre espèce par la largeur de ses zones miliaires, mais il en diffère beancoup par ses tubercules interambulacraires plus nombreux et crénelés, par la disposition de ses granules ambulacraires plus régnliers, par sa forme plus large et moins élevée.

Nivean : Lutétien I ${ }^{\mathrm{b}}$.

Localité : Recueilli à Minieh par M. Mayer-Eymar.

Collection : Musée de Zurich.

Rhabiocidaris Zíteli de Loriol, 1881.

Syn. : Rhabdocidaris Zilleli de Loriol, Eocine Echinoideen aus Aegypten und der libyscken Wiiste, p. 8, pl. 1, fig. 1 is 11. 
Rhabdoridaris Zitteli K. A. Zittel, Beiträge zur Creologie und Palüontologie der libyschen Wiiste und der angrenzenden Gelicte von Aegypten, 1883 , p. cri.

Espèce peu élevée, arrondie; pourtour un peu décagonal par suite du renflement des aires interambulacraires. Zones porifëres droites, larges, superficielles: pores petits, conjugués par un sillon: les paires sont séparées par des cloisons aiguées et d'apparences lisses: l'espace interzonaire montre six rangées de granules petits dans les rangées externes, microscopiques dans les internes, d'ailleurs régulièrement disposés, arec quelques petites verrues intermédiaires.

Interambulacres renflés, portant deux rangées de tubercules saillants, au nombre de huit par séries, crénelés, perforés, entourés de scrobicules à peine crensés et couronnés de granules peu serrés. Péristome dans une légère dépression, dépassant en largeur le tiers du diametre total.

Niveau : Suessonien supérieur (Londinien II, de M. MayerEymar).

Localités : El-Gouch Abou Saïd à l'Onest de l'Oasis de Farafrah, Gebel Drounka ${ }^{1}$ (près el-Syout), Bir Mourr (Oasis Farafralı, côté Est).

Collection : Zittel (Musée de Munich).

Rhabdocidaris Lorioli Mayer-Eymar (in collect.), pl. I, fig. $17-21$.

M. Mayer-Eymar a recueilli me série de radioles assez variés dans leur forme qu'il a rapportés au genre Rhabdocidaris. La facette articulaire est lisse, le bas de la tige assez régulièrement

1. Le Gebel Drounka est la montagne désignée par tous les anteurs allemands sous le nom de e'Todtenberg", montagne des morts, à cause de la grande nécropole égyptieme de Lycopolis qui est creusée dans ses flancs. Nous lni avons restitné son nom arabe. 


\section{$-637-$}

cylindrique; le bouton assez saillant et surmonté d'une collerette lisse mesurant 6 a 10 millimètres en hauteur; an-dessus de la collerette la tige reste presque eylindrique pour quelques radioles, ou bien elle devient ovale, subtriangulaire et même complètement plate sans être trop mince; le plus grand fragment plat que nous ayons mesure 7 millimètres de largeur. Sur tous la tige porte des séries longitudinales de gros tubereules épineux, médiocrement rapprochés, et, entre ces séries, d'autres plus nombreuses de granules moins accentués, reliés entre eux ou isolés, tous d'apparence spiniforme. Ils sont bien plus abondants d'un côté du radiole que de l'autre; le plus grand de ces fragments atteint 39 millimètres.

M. Mayer réunit ì ces radioles quelques fragments de test, peu considérables, sauf un qui est malheureusement corrodé à tel point qu'on ne peut guère en préciser les caraetères; d'ailleurs il n'est pas certain que les plaques et les radioles appartiennent au même type. Ces radioles nous paraissent différer de tous ceux que nous commaissons dans les terrains éocènes; ceux qui sont plats ne rappellent que de loin les radioles du Porocidaris Schmidelii dont la collerette est moins haute et granuleuse, et qui en outre ont la facette articulaire crénelée, ce qui suffit pour distinguer les deux types.

Niveau : Suessonien moyen (Londinien I de M. Mayer).

Localités : Dounkoun, Kourkour.

Collection : Musée de Zurich.

Rhabdocidaris solitatia Mayer-Eymar, 1898.

M. Mayer-Eymar a désigné sous ce nom un radiole arrondi, diminuant régulièrement de diamètre de la base à l'extrémité, mesurant 35 millimètres de longueur et 5 de diamètre à l'endroit le plus épais, et qui devait être un peu plus long, ear l'extrémité fait défaut. La facette articulaire paraît avoir été crénelée; le bouton 
peu développé est surmonté d'une collerette à bord supérieur, oblique, autant que nous pouvons le distinguer; le reste de la tige est couvert de granules épineux, inégaux, mal rangés en série; il y avait probablement de fins granules intermédiaires, mais la surfaee est corrodée et ne nous permet pas de les distinguer nettement.

Il sera nécessaire, pour avoir une eomnaissance précise de ee type, de reeueillir de nouveaux matériaux; ainsi isolé eet exemplaire ne peut pas fournir les caraetères complets d'une espèce. Les radioles dont il se rapproehe le plus sont eeux du Cidaris Taramelli, tels du moins qu'ils sont figurés dans la Paléontologie française, ${ }^{1}$ mais il ne samait y avoir identité si notre radiole a réellement la surfaee artieulaire erénelée.

Nivean : Lutétien I.

Localité : Mokattam.

Colleetion : Mrusée de Zurieh.

Porocidaris Schmideili Desor (Miinster), 1856.

Syn. : Cidarites Schmidelii Miinster in Goldtuss, Petrefacta Germaniae, I, 1).120, pl. 40, fig. 4, 1830.

Porocidaris Schmidelii Desor, Synopsis, p. 47, pl. vin, fig. 22, 1856.

» $\quad$ P. de Loriol, Monographie des Ĺchinides nummulitiques de l'Égypte, p. 5, pl. 1, fig. 1-15, 1880.

\ P. de Loriol, Eocïne Echinoideen aus Aegypten und der libyschen Wiiste, p. 9, pl. 1, fig. 10, 11, 1881.

Nous renvoyons pour la deseription de eette espèce aux deux ouvrages cités de M. de Loriol; nous ne saurions rien ajouter à l'étude remarquable qui a été faite par notre savant confrère; nous nous eontenterons de préeiser les différentes localités où l'on a reneontré le $P$. Schmidelii en Égypte, ainsi que l'horizon qu'il oceupe.

1. 'Terrain éocène, tome Ir, pl. 302, fig. 1. 
Niveaux et localités : Suessonien. - Bognoron (?) entre les oasis de Doukoun et de Kourkour (Mayer-Lymar), Gebel Drounka près d'El-Syout. - Lutétien I. Mokattam. Plateau des P'yramides de Ghizeh, Minieh, Gebel el-Feschn, Abattoir du Caire, ${ }^{1}$ Ouadi Hof près Hélouan, oasis de Moeleh; Gebel Arabah et Ouady Feiran (Sinaï - R. Fourtau). - Lutétien II. Mokattam, Ouady el-Tih, Ouady Bellardi (? !). ${ }^{2}$

Dictyopletrus Hamei Duncan et Sladen, 1882. Syn. : Dictyopleurus Haimei Dunean et Sladen, The fossil Echinoidae of Hestern Sind, p. 39 , pl. 1x, fig. $4-5,1882$.

" P. de Loriol, Notes pour servir à l'étude des Échinodermes, I, p. 29, pl. xxxiv, fig. 7,1884 .

M. de Loriol a cité cette espèce indienne comme se trouvant au Mokattam en s'appuyant sur un exemplaire suffisamment conservé que nous lui avions envoyé; il nous avait été remis par un collègue en géologie depuis longtemps décédé, qui nous avait affirmé qu'on le lui avait apporté de cette localité. Aucun autre exemplaire de Dictyopleurus n'ayant été recueilli depuis ce temps, nous craignons qu'il n'y ait eu quelque confusion, bien que la présence du D. Haimei en Égrpte ne soit pas impossible.

Micropsis fraasi P. de Loriol, 1880.

Syn. : Psendodiadema Ruppellii Fraas, Geologisches aus dem Orient, Würtemb. Naturw. Jahresschrift, p. 27i, 1867 .

Micropsis Fraasi P. de Loriol, Monographie des Échinides des couches nummulitiques de lígypte, p. 13, pl. I, fig. 17, 1880.

1. MI. Mayer-Eymar indiqne comme loealité pour plusienrs especes "Alattoir $d$ n Caire». Je ne comnais an Caire que denx abattoirs : l'un, lancien, en plein fanbourg de F'aqallah est l'aneienne mosquée du Zaher construite en gros bloes du Gionehy, l'autre, le nouveau, au sud du quartier de Sayeda Zeïnab près des buttes de décombres du Vieux Caire. Ni l'un ni l'antre ne sont hattis sur du roeher. La véritable localité est un roeher a 400 mètres an Sud-kst de l'Abattoir de Sayedah\%einab.

2. Loealité baptisée par M. Mayer-lymar, doit probablement être me petite ererasse ravince au pied Sud-Ouest du Mokattam du côté de l'Oualy el-Tih. 
Exemplaire unique recueilli par Fraas, remarquable par ses nombreux tubercules et la rareté des granules qui les aeeompagnent soit dans les aires ambulacraires, soit dans les aires interambulaeraires.

Niveau : Lutétien II.

Localité : Mokattam.

Collection : Musée de Stuttgart.

Micropsis Mokattanexsis Cotteal, 1880.

Syn. : Micropsis Mokattamensis Cotteau : Echinides nouveanx ou peu comns, I, p. 22:2, pl. 31, fig. 1-4, 1880.

$3 \quad$ I. de Loriol, op. cit., p. 14, pl. Iv, fig. 1, 1880.

Cette espèce diffère un peu des autres Micropsis par ses zones porifères parfaitement rectilignes. Elle ressemble beaucoup au Cyphosoma superbum Dames, du Vieentin, qui en diffère par ses langées de tubereules seeondaires tout à fait régulières, ses granules peu nombreux et laissant le milieu des aires interambulacraires presque dénudés au lieu d'être très serrés et partont uniformément répandıs.

Niveau : Lutétien II, en-dessous des couches à Cardium Schueinfurthi.

Localité : Mokattam.

Collections : Cotteau, Musée de Zurieh, Pasquali.

Echinopsis Libycus de Loriol, 1881.

Syn. : Echinopsis libycus de Loriol, Eocïne Echinoideen aus Aegypten und der libyschen Wiiste, p. 10, pl. I, fig. 12, 1881.

> K. A. Zittel, op. cit., p. cvi, 1883.

Loealités et niveaux : Suessonien moyen. - El-Gouch Abou Saïd (Zittel) et Gebel Drounka près el-Syout. - Lutétien II ${ }^{\mathrm{b}}$. Environ de Diméh (Fayoum) - (d'après M. Mayer-Eymar). 
Mistechinus Mayeri de Loriol, 1897.

Syn. : Mistechinus Mayeri P. de Loriol, Notes pour servir ¿̀ létude des Échinodermes, V, p. s, pl. I, fig. 2, 3, 1897.

Espèce unique d'un genre créé par M. de Loriol pour des échinides récoltés par M. Mayer-Eymar. Se distingue des Micropsis et des genres voisins par la singulière disposition des paires de pores dans les zones porifères, d'abord directement superposées, elles se groupent ensuite en petits ares transverses de trois paires, parfaitement semblables à ceux des zones porifëres du genre Echinus. Dans l'unique espèce connue jusqu'ici, les tubereules des aires ambulacraires disparaissent à la face inférieure, ce qui lui donne un aspect très particulier, mais il se pent, comme le fait remarquer M. P. de Loriol, que ce ne soit là qu'un caractère spécifique.

Niveau : Lutétien I.

Localité : Oasis de Moeleh à 50 kilomètres au Sud du Fayoum. Collection : Musée de Zurich.

\section{Echinides exocychiques.}

Fibliaria Lorioli 'Thomas et Gauthier, 1889.

Syn. : Fibularia Lorioli Thomas et Gauthier, Description des Échinides recneillis en Tnnisie par M. Thomas, p. 102, pl. vi, fig. 17-21, 1889.

Cotteau, Paléontologie française, terrain tert. éocène, tome $\mathrm{II}$, p. 391, pl. 295, fig. 7-14, 1892 .

- P. de Loriol, Notes pour servir à l'hist. des Échin., V, p. 6, 1897.

Espèce de petite taille, renflée, de forme elliptique, aussi large en avant qu'en arrière. Face supérieure convexe, face inférieure bombée. Apex central. Aires ambulacraires superficielles, ambulacres non fermés, aigués au sommet, courts; l'antérieur plus large que les autres. Zones porifëres bien développées, droites, composées d'environ dix paires de pores ronds, non conjugués. Péristome 
central rond et petit; périprocte petit, légèrement ovale, place à la face inférieure à $1 \mathrm{mill}{ }^{1} / 2$ du péristome.

Niveau : Lutétien II.

Localités : Mokattam (Pasquali et Mayer-Eymar). - Carrière an sud du cimetière de Kafrah près les Pyramides de Ghizeh (li. Fourtau),

'Thagastea Luciani de Loriol (Sub. Echinocyamus), 1880. Syn. : Echinocyamus Luciani P. de Loriol, Monog. des Échin. nummul. de l'Égypte, p. 18, pl. 11, fig. 8-15, 1880.

Thagastea Luciani R. Fourtun, Note sur les bancs ì Callianassa d'Égypte, Bull. Inst. Egypt., fasc. 3, 1897 .

Quand M. Pomel eut publié son genre Thagastea, nous arons poli à la meule plusieurs exemplaires de l'Echinocyamus Luciani pour nous assurer de la présenee des eloisons internes; nous n'en avons trouvé ancune : eet échinide ne peut donc pas rester parmi les Echinocyamus; il appartient an genre Thagastea, qui ne diffère des Fibularia que par sa forme plus ou moins allongée et irrégulière.

Niveau : Lutétien II, couches à Callianassa.

Loealités : Ouady el-Tih près dı Caire, Mokattam.

Sismoxdia Logotheti Fraas, 1867.

Syn. : Sismondia Logotheti Fraas, Ans dem Orient, Wïrt. naturf. (iesellsch., tome xxin, p. 280 , pl. vi, fig. 9, 1867.

\. Pe Joriol, op. cit., p. 16, pl. 11, fig. 1-5, 1880.

K. A. Zittel, op. cit., p. cr, 1883.

R. Fourtau, Note sur les Sirmondia d'Égypte, Bull. Inst. Egypt., fasc. 3, 1897.

Cette jolie espèce est caractérisée par sa face supérieure eonique, sa face inférieure uniformément concave, son bord mince, ses ambulaeres non eostulés et ses tubercules tries écartés à ]a face supérieure. 
Niveau : Caractérise le Suessonien supérieur (Londinien II, de M. Mayer) de la Haute-Égypte.

Localités : Gebel Drounka près El-Syout. - Environs de Louxor.

Collections : Mrusée de Stuttgart. Zurich, Muséum de Paris. R. Fourtau.

Sisuovdia Soemandi de Loriol, 1880. Syn. : Sismondia Soemamni de Loriol, op. cit., p. 17, pl. 11, fig. 6, 7, 1880.

R. Fourtau, Note sur les Sismondia d'Égypte, Bull. Inst. Egypt., fise. 3, 1897.

Petite espèce de forme ovale, rétrécie en avant et en arrière, mais plus fortement en avant; face supérieure plate, face inférieure légèrement pulvinée, déprimée an centre; bord épais. $A_{p}$ pareil apical central; péristome au milieu de la légère dépression de la face inférieure; périprocte petit, place près du bord.

Niveau : Lutétien I et II, selon M. Mayer-Eymar.

Localité: Onady el-Tih. Mokattam (Mayer-Eymar), Gebel Abiad près la nécropole de Kayed Bey (R. Fourtau).

\section{Sismoxdi Plaxulata d'Archiac (sub. Echinocyamus).}

Fraas a cité le Sismondia planulata dans les couches du Mokattam, où il oceuperait la même position que le S. Soemanni. Les deux espèces sont très voisines; elles diffèrent cependant par quelques caractères : par les pétales ambulacraires plus renflés et plus larges chez le $S$. Soemanni, par son bord plus épais, par sa partie postérieure plus rétrécie; de plus la taille du S. plamulata est beaucoup plus grande. Peut-être y a-t-il eu confusion entre les deux espèces; peut-être existent-elles simultanément au Mokattam; il faudrait, pour résoudre définitivement la question, pouvoir examiner les exemplaires recueillis par Fraas. 
Sisuronina Zitteli Mayer-Eymar 1898.

Syu. : Sismondaea ${ }^{1}$ (sic) Zitteli Mayer-Lỵmar, Nene Échiniden aus den NummulitenGebieten Aegyptens, Vierteljaliresschrift der Nat. (iesell. Ziirich, p. 3, pl. III, fig. 5. 1898.

M. Mayer-Eymar a recueilli ì Minieh un assez grand nombre de Sismondia de petite taille, de forme presque circulaire, à bord relativement assez épais, qui diffèrent certainement des deux espèces égyptiennes que nous venons de signaler. Le test est moins allongé, moins pentagonal que celui du S. Soemanni; le périprocte est plus rapproché du bord. On ne samait non plus confondre ce type avec le S. Logotheti; il n'est ni subconique endessus, ni creusé en-dessons, et il a le bord plus arrondi et plus épais. L'espèce la plus roisine serait le S. Desori Coquand, de l'éocène d'Algérie : ce dernier est plus pentagonal, plus mince au pourtour et il a le périprocte encore plus rapproché du bord.

Niveau : Suessonien supérieur.

Localité : Minieh.

Sismonda Macrophyla Mayer-Lymar, 1898. Syu. : Sismondaea macrophylla Hayer-1ymar, op. cit., p. 2, pl. m, fig. 1, 1898.

Un seul exemplaire de très petite taille subconique en-dessus et déprimé en-dessous comme les jeunes du S. Logotheti; un peu moins allongé que cette dernière espèce et à pétales ambulacraires plus larges.

1. M. Mayer-Lymar écrit Sismondaea au lieu de Sismondia et en donne la raisou snivante : d'après les règles de la terminologie les noms terminés en a doirent prendre en latin lorsqu'on en fait un nom de genre la termiuaison ea ct lorsque c'est un nom d'espéce la terminaison ai. Le genre créé par Desor étant dédié au géologne italien Sismouda doit done être écrit Sismondaea et non Sismondia qui, dapres les dites règles, devrait en ce cas rappeler un Sismondi, de même on a décrit Rhabdocidaris Sismondai du Miocène de Madiere et non Rh. Sismondii. En l'espèce M. Mayerlyunar me paraît aroir raison, mais comme c'est Desor qui a commis la faute, je ne puis sans crainte dajouter eucore un nouveau chapitre à la synonymie déja si chargée des Échinides adopter le nom correct qui est seul a employer alors que tous le's paléontolognes ont admis celui de Simondia. 
Niveau : Lutétien II, d'après M. Mayer-Eymar.

Localité : Ouady el-Tih près du Caire.

Il nous parait bien aventureux d'établir une nouvelle espèce de Sismondia sur un seul exemplaire de petite taille.

Clypeaster Breunigit Laube, 1867.

Syn. : Clypeaster Breunigii Laube, Vicent. Echinod., Sitzungsber. der Wiener Akad., Bil. Lvi, I, p. 243, 1867.

- P. de Loriol, Eocïne Echinoideen aus Aegypten und der libyschen Wiiste, p. 12, pl. I, fig. 18-19, 1881.

\ K. A. Zittel, op. cit., p. cxxiv, 1883.

Les exemplaires de cette espèce, étudiés par M. de Loriol, ne sont que des fragments; mais quelques-uns représentent le test presque entier, et l'assimilation avec le type du Vicentin n'est pas douteuse.

Selon M. de Loriol quelques fragments peurent appartenir ì des espèces différentes, mais la plus grande partie appartient au Cl. Breunigii.

Niveau : Bartonien : couches à Nummulites Fichteli.

Localité : Environs de Syouah, à l'Est, entre Aradj et Rhartehn.

Conoclypeus conordeus (Leske) Agassiz, 1839.

Voir pour la synonymie de Loriol, Monographie, loc. cit., p. 24. Ajouter : K. A. Zittel, Traité de Paléontologie, p. 518 et 522, fig. 375 et 382, vol. 1, 1883.

II. de Loriol n'a eu entre les mains qu'un exemplaire égyptien un peu déformé de cette belle espèce. J'ai pu en avoir plusieurs de la collection de l'École de Médecine de Kasr el-Ä̈ny (Caire). Ils se rapportent bien au type décrit par notre savant confrère (Échinides tertiaires de la Suisse, 1875). C'est grâce aux spécimens rapportés par lui du Désert de Libye que MI. K. Zittel a pu séparer le genre Conoclypeus de la famille des Cassidulidées et de la tribu des Atélostomes pour en faire une famille à part dans la tribu des Gnathostomes, famille qui trouve admirablement sa place entre les Echinoconidées et les Clypeastridées. 
Nivean : Suessonien moyen.

Localité : Gebeleïn près Edfou. Esneh? Désert de Libye entre Syouah et l'Oasis de Beharieh (K. Zittel).

Collections : Muséum de Paris; École de Médecine de Kasr elAïny (Caire), Musée de Munich (K. Zittel).

Conoctrpeus Delanouei de Loriol, 1880.

Syn. : Conoclypeus Delanouei de Joriol, Monogr. (op. cit.), p. 26, pl. 11, fig. 17, 1880.

» K. A. Zittel, op. cit., p. crr, 1883.

* Cotteau, Paléontologie française, terrain éocène, p. 11, pl. 219, 1891.

Espèce voisine du C. conoideus, mais qui en diffère par plusieurs caractères indiqués avec soin par M. de Loriol : ambulacres beaucoup plus étroits, zones interporifères portant moins de tubercules, cloisons à une seule rangée de granules au lieu de deux, base constamment très elliptique.

Niveau : Suessonien moyen.

Localités : Gebel Chevaoussa près Esneh, Gebel Drounka près el-Syout, Gebel Deir el-Bahari près Louxor, Gebel 'Ter près Esneh (Zittel), Gebel Oum el-Renneiem (Oasis de Khargeh) (Schweinfurth), Gebel Essaouieh prìs Sohag (Tissier).

Aublypygus dilatatus Agassiz, 1840, pl. I, fig. 13-16.

Syn. : Voir la synonymie dans l'ouvrage de M. de Loriol : MLonogr, des Échin. nummul. de l'Égypte, p. 28 , pl. mr, fig. 2.

Y ajonter :

Amblypygus dilatatus K. A. Zittel, op. cit., p. crr, 1883.

Clypeus (semi-Clypeus) pretiosus Mayer-Eymar, op. cit., p. 3, pl. nn, fig. 6, 1898.

L'exemplaire du musée de Stuttgart décrit et figuré par M. de Loriol avait été récolté par Fraas au Mokattam et rapporté par cet auteur à Echinolampas Studeri.

Un deuxième exemplaire est cité par M. de Loriol comme appartenant à sa collection et provenant des environs de Louxor recueilli par M. Ed. Naville, mais notre savant confrère déclare 
conserver quelques doutes sur son attribution à Ambl. dilatatus. Cependant Zittel dit en avoir récolté au même niveau à Gebel 'T'er' près Esnelı.

M. Mayer-Eymar a reeueilli au Mokattam un individu de grande taille qui mesure 80 millimètres en longueur et en largeur, et 32 en hauteur, il ne nous paraît pas pouvoir se séparer spécifiquement de l'individu figuré par M. de Loriol; mais il mérite une mention partieulière. La forme en est subeonique; la partie supérieure incomplètement conservée, mais bien nette et bien fraîche, présente les deux aires ambulacraires postérieures intactes, et l'antéricure de droite presque eomplète; le bord est pulviné; la partie inférieure fort détériorée montre néanmoins la dépression eentrale et le périprocte. Le développement des aires ambulacraires est très remarquable, car les pétales atteignent 14 millimìtres en largeur, dont $3 \frac{1}{2}$ pour ehaque zone porifère, et 7 pour l'espace interzonaire; tandis que dans un autre exemplaire de 60 millimètres de longueur les pétales n'exeèdent pas 8 millimètres en largeur, dont 2 pour ehaque zone porifere et 4 pour l'espace interzonaire.

La différence en surface est très sensible, comme on le voit; mais la proportion reste la même : l'espace interzonaire égale en largeur les deux zones porifères réunies. La granulation est plus fine et plus serrée sur le grand exemplaire égyptien; le périprocte mesure 27 millimètres en longueur et 12 en largeur, avee les deux extrémités arrondies. Nous faisons figurer ce remarquable individu.

M. Mayer-Eymar a eu la fâcheuse idée de rapporter cet oursin éoec̀ne au gemre jurassique Clypeus, un Clypeus sans sillon. Dans la fig'ure qu'il a donnée, l'exemplaire a été placé de travers, et présente comme ambulacre impair l'ambulacre postérieur de droite. L'auteur a pris pour le périproete une légère eassure qui se trouve sur l'ambulacre impair détérioré, tandis qu'il n'y avait qu'à re- 
garder à la face inférieure pour voir le magnifique périprocte d'Amblypygus, long de 27 millimetres, que nous arons fait reproduire fig. 16.

Localités et niveaux : Suessonien II (?), Louxor (Naville), Gebel Ter (Zittel). - Lutétien I, Mokattam (Fraas et Mayer-Eymar).

Collections : Musées de Stuttgart, Munich et Zurich, P. de Loriol.

Genre GisopyGts Gauthier, 1898.

M. de Loriol a rapporté au genre Rhynchopygus d'Orbigny quatre espèces qui n'y entrent que difficilement, car elles ont les pores ambulacraires allongés dans les séries externes et conjug'uées par un sillon dans chaque paire, tandts que les vrais Rhynchopygus n'ont que des pores ronds, très petits, non conjugués. Notre savant confrère voyait dans ces échinides un type intermédiaire entre le genre dans lequel il les a compris et les Cassidulus, et l'observation est très juste; seulement ce type intermédiaire ne s'adapte bien ni à l'un, ni à l'autre genre. Si la nature des pores ambulacraires les sépare du premier, leur périprocte transverse les éloigne du second. Ce dernier caractère avait frappé notre regretté confrère et ami commun Cottean qui pensait que ces oursins devaient rentrer dans le genre Pygorhynchus; mais, ontre que leur périprocte, bien que transverse, n'est pas disposé comme celui de ce dernier genre, leur face inférieure arec son péristome orné de grosses protubérances et de phyllodes bien développés ne convient pas au genre Pygorhynchus, mais les rapprocherait plutôt des Cassidulus. Il en résulte qu'il faut nécessairement faire quelque violence aux trois gemres cités pour y faire entrer ces types égyptiens, et que leur place y sera toujours contestable. Nous croyons done plus simple de les grouper sous un nom générique particulier, Gisopygus qui se distingue des Rhynchopygus par ses ambu- 
lacres à pores allongés et conjugués, des Cassidulus par son périprocte transverse, des Pygorhynchus par son périprocte reposant sur un petit rebord et par son péristome à bourrelets et phyllodes plus accentués.

Ce genre comprend les quatre espèees décrites par M. de Loriol.

Gisopyges NavilLei de Loriol (sub Rhynchopygus). Syn. : Rhynchopygus Navillei de Loriol, Monographie, p. 29, pl. Iv, fig. 2. 1880.

" de Loriol, Eocäne Echinoideen aus Aegypten und der libyschen Wiiste, p. 17, pl. II, fig. 6-8, 1881 .

Espèce de forme ovale, allongée, arrondie en avant, tronquée earrément et rétrécie en arrière au bord postérieur. Face supérieure assez élevée, uniformément eonvexe; face inférieure presque plate. Sommet ambulacraire exeentrique en avant; périprocte ovale, transverse, s'ouvrant un peu au-dessus de la troncature postérieure sur un petit replat du test qui rappelle la disposition de cet organe ehez les vrais Rhynchopygus, mais qui est loin d'égaler celui du Rh. Marmini d'Orb. - Ambulaeres assez larges, superficiels, courts et inégaux; les zones porifères sont composées de pores ovales allongés, les externes plus long's conjugués par un sillon.

II. Iconomopoulos, ingénieur aux chemins de fer égyptiens, nous a communiqué un monle siliceux de cette espèee, bien conservé pour son état, de taille plus grande que tous les exemplaires que nous avons vus, car il mesure 38 millimetres en longueur, la face inférieure complitement plate est très remarquable par suite du développement des protubéranees et du floseelle qui entoure le péristome : on croirait être en présence d'un véritable Cassidulus; la bande lisse se distingue entre le péristome et le bord postérieur même sur ee silex; nous sommes bien loin ici du genre Pygorhynchus.

Niveau : Lutétien I et II.

Localités : Mokattam, Plateau des Pyramides de Ghizeh (Ieo- 
nomopoulos), Beni-Hassan (où il serait du Suessonien supérieur d'après MI. Mayer-Eymar).

Gisopygus Thebensis de Loriol (sub Rhynchopygus).

Syn. : Rhynchopygus Thebensis P. de I.oriol, Monographie, p. 30, pl. iv, fig. 3-4, 1880. $>\quad$ K. A. Zittel, op. cit., p. cvir, $18 s 3$.

Cette espèce se distingue facilement du $P$. Navillei par son bord postérieur dilaté et échancré, par sa face supérieure en forme de toit et par sa face inférieure déprimée au milieu dans le sens de la longueur. Les pores ambulacraires comme ceux de l'espèce précédente sont inégaux, allongés et conjugués dans chaque paire par un sillon.

Niveau : Suessonien moyen.

Localité : Gebel Deir-el-Bahari près Louxor.

Gisopygus ZitTELI de Loriol (sub Rhynchopygus). Syn. : Rhynchopygus Zitteli de Loriol, Eocäne Echinoideen aus Aegypten und der libyschen Wüste, p. 18, pl. n, fig. 11, 1881.

, K. A. Zittel, op. cit., p. crv et cv, 1883.

'T'est ovale régulièrement, sans rostre tronqué en arrière. Aires ambulacraires étroites, courtes, dont les zones porifères sont très rapprochées, effilées à l'extrémité et presque fermées; les pores, moins développés, sont néanmoins conjugués, d'après la figure grossie $9 c$; les pétales postérieurs sont un peu plus longs que les antérieurs; l'aire interambulacraire postérieure est renflée entre les ambulacres et son extrémité couvre légèrement le périprocte. Celui-ci est assez bas et s'ouvre peu au-dessus de la base.

Niveau : Suessonien supérieur, couches à Fabularia Zitteli.

Localités : Minieh, Gebel Drounka près el-Syout (Zittel). Ouady Gamous en face Rodah (R. Fourtau).

Gisopygus SiUtexsis de Loriol (sub Rhynchopygus). Syn. : Rhynchopygus Siutensis de Loriol, Eocäne Echinoideen aus Aegypten und der libyschen Wiiste, p. 19, pl. II, fig. 12, 1882.

» K. A. Zittel, op. cit., p. cv, $18 s 3$. 
Espèce de taille plus petite que les autres, mais plus élevée, avec face supérieure presque en forme de toit. Elle est représentée par un seul individu incomplet lui-même; les ambulacres sont larges et les pores allongés; les postérieurs plus longs que les autres sont peu divergents. Le péristome est peu distinct; le périprocte est inconnu; de sorte que cet exemplaire ne fait partic que provisoirement du genre Gisogypus.

Niveau : Suessonien supérieur, couches à Fabularia Zitteli.

Localité : Gebel Drounka prìs el-Syout.

\section{Pygorhychus graxdiflorus Mayer-Eymar, 1898.}

Syn. : Pygorhynchus grandiforns Mayer-Eymar, Neue Echiniden ans den NummulitenGebilden Aegyptens, Vierteljahresschrift der Naturf. Gesellsch. in Zïrich, p. 3, pl. mI, fig. 5, 1898.

Espèce établie sur un seul exemplaire : la forme est presque circulaire, largement ovale, peu élevée à la partie supérieure, ì bord rond et épais. Pétales ambulacraires saillants; périprocte transverse en haut de la face postérieure. On ne roit ni le péristome, ni les pores ambulacraires.

Niveau : Suessonien supérieur (Londinien II de M. Mayer).

Localité : Miniels.

\section{Echisanthes Zitteli de Loriol, 1881.}

Syn. : Echinanthus Zitteli P. de Loriol, Eocüne Echinoideen aus Acgypten und der libyschen Wïste, p. 19, pl. In, fig. 1-2, 1881.

\. A. Zittel, op. cit., p. $\operatorname{cxxr}, 1883$.

Grande espèce, du type de l'E. scutella Lam., mais s'en distinguant par sa forme plus allongée, ses pétales ambulacraires plus inégaux et plus longs, son péristome plus petit.

Niveau : Bartonien, couches ì Numm. Fichteli et Clypeaster Breunigii.

Localité : A l'Est de Syouah, Aradj. 


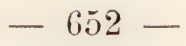

Echinanthes libycus de Loriol, 1881.

Syn. : Echynanthus libycus P'. de Loriol, Eocïne Echinoideen aus Aegypten und der libyschen Wiiste, p. 21, pl. In, fig. 3, 1881.

$\Rightarrow \quad$ K. A. Zittel, op. cit., p. cxix, 1883.

Espèce encore plus grande que la précédente, ovale, allongée, à face supérieure renflée avec un péristome et un périprocte très petit.

Niveau : Lutétien II.

Localité : Désert libyque entre Aradj et le Birket Sittreh.

Pygures nunueliticus Mayer-Eymar, 1898. Syn. : Pygumus nummuliticus Nayer-Eymar, op. cit., p. 5, pl. m1, fig. 3, 1898.

Encore un échinide nummulitique rapporté à un genre jurassique. Le fragment dont il s'agit et que M. Mayer-Eymar a bien voulu nous communiquer présente trois pétales ambulacraires en fer de lance, dont les deux postérieurs. Le reste du test n'existe pas. La partie conservée a été lavée à l'acide ce qui a détruit l'ornementation. Cependant en y regardant avec une bonne loupe, on reconnaît çà et là dans les interambulacres des traces de gros tubercules, et M. Mayer lui-même a marqué à la plume, entre les deux ambulacres postérieurs, les traces d'un fasciole péripétale que reproduit la figure dlessinée. Il n'existe pas de fasciole chez les Cassidulidées, M. Mayer le sait sans donte aussi bien que moi. C'est un fragment d'Euspatangus qu'il a désigné sous le nom de Pygurus.

Genre Bothriolanpas Gauthier, 1898.

Syn. : Pliolanzpas (pars) Thomas et Gauthier, Échinides recueillis dans la région des hauts plateanx de la Tunisie, p. 97, pl. vi, fig. 7-9, 1889.

Test de taille moyeme ou petite à pourtour ì peu près ovale, renflé assez régulièrement ì la face supérieure et subcaréné en arrière de l'apex, plus ou moins pulviné ou plat à la face inférieure. Apex excentrique en avant.

Appareil apical montrant quatre pores génitaux en trapèze entre 
lesquels se développe le corps madréporiforme; les cinq pores ocellaires très petits oecupent les angles extérieurs.

Pétales ambulacraires plus ou moins développés, à pores linéaires ou subvirgulaires, dans les rangées externes, presque ronds dans les internes; les paires sont ordinairement serrées et parfois nombrenses; tous les pétales sont semblables.

Péristome dans une légère dépression du test, pentagonal, plus large que long, entouré d'un floscelle bien marqué et de bourrelets interambulaeraires.

l'ériproete ovale dans le sens de l'axe antéro-postérieur, placé an bord inférieur, à l'extrémité d'un rostre peu prononcé qui termine la face postérieure plus visible d'en bas que d'en haut. Granulation eommune à la famille des Cassidulidées.

Ce genre pour la forme générale et la position du périprocte ressemble completement aux Pliolampas Pomel; il s'en distingue par sa granulation plus fine, ses paires de pores plus serrés dans les pétales ambulaeraires, et surtout par son péristome qui est pentagonal, plus large que long, tandis que, chez les Pliolampas, il est pentagonal, plus long que large; les différenees, les senles qu'il soit possible de constater, paraissent être de peu de valeur et plutôt spécifiques que génériques; je m'y suis trompé moi-même quand j'ai déerit le Pliolampas tunetana reeneilli par. II. Thomas en 'Tunisie. J'ai bien remarqué alors les différences que je viens de signaler, et ee n'est pas sans de grandes lésitations que j'ai réuni génériquement l'espèce éocène de Tlunisie au type mioeène décrit par M. Pomel; il me semblait à cette époque que les earaetires distinetifs ne suffisaient pas pour établir un autre gemre. 1)epuis, j'ai reeomnu d'une manière ineontestable que les Pliolampas dérivent des Echinanthus (Desor) et sont miocènes; j'en ai en la preuve en reeueillant dans le Mioè̀ne des bords de l'étang de Lavaldue (13. du Rhone) l'Echin. Meslei dont les grands exem- 


\section{- $654-$}

plaires présentent pour la position du périprocte la forme régulière des Echinanthus; les autres, un pen moins élevés, montrent l'ouverture anale descendant un peu, puis contournant le bord, au point que quelques-uns appartenant certainement à la même espèce sont de véritables Pliolampas. ${ }^{1}$ La transition est manifeste, et. d'un autre côté, elle a été observée également par M. Pomel. Les Bothriolampas sont éocènes et dérivent des Bothriopygus d'Orbigny (non Pomel). Déjà, dans les espèces recueillies en Algérie dans les dernières couches de la Craie, le bord postérieur a une tendance à s'amincir, et le périprocte, au lieu de rester au milien de la face postérieure, descend assez souvent plus bas. Il y a plus de quinze ans que, dans ma collection persomelle, j'ai fait deux séries des nombreux exemplaires que je possède du Bothriopygus Coquandi Cotteau, et que je les tiens séparés dans deux boîtes, bien que les attribuant à la même espèce. Les uns ont le périprocte régulièrement placé au milieu du bord postérieur; les autres l'ont plus bas, contournant le bord et presqu'à la face inférieure. Si je compare ces derniers aux exemplaires d'Égypte que je vais décrire, quelques-uns sont de véritables Bothriolampas; la transformation, hésitante à la fin de l'époque crétacée, s'est eftectuce complètement dans le terrain éocène, où l'on ne rencontre plus de Bothriopygus.

Le genre crétacé Pygurostoma Cotteau et Gauthier que jai établi pour un groupe d'échinides recueillis par M. de Morgan dans le Louristan² (Perse) présente d'assez apparents rapports avec mon type éocìne. La forme, beaueonp plus grande, est également ovale et le périprocte occupe à peu près la même position. On ne saurait cependant confondre ces deux genres : à la face

1. Voir C'ottean, l'eron et (ianthier, Échinides fossiles de l'Algérie, fissc. x, p. 137.

2. Cottean et (iauthier, lichinides de Louristan, in de Morgan, Mission scientinique en P'erse, tome in, lart. I1, p. 51, 1895. 


\section{$-65 \div-$}

supérieure les l'ygurostoma présentent de larges pétales ambulacraires, en fer de lance, presque fermés à l'extrémité, avec des pores plus développés et tous linéaires; la partie dorsale est complètement dépourvue de carène, et, par conséquent, il n'y a pas de rostre postérieur; le périprocte, relativement petit, allongé. étroit, s'ouvre en fossette moitié en-dessous et moitié sur le bord postérieur; le péristome avec ses grosses protubérances interambulacraires et son floscelle aussi développé que eelui des vrais P'ygums donne ì la partie inférieure une pliysionomie toute diffërente.

Mon nouveau genre compte pour le moment deux espèces bien distinetes: Bothriolampas tunetana déerit en 1889 sous le nom générique de Pliolampas et $B$. abundans, dont je vais domer la description.

Bothriolanpas abcridas Mayer-Eymar (sub Pygorhynchus), pl. I, fig. $9-12$.

syn. : Pygorhynchus alundans Mayer-Eymar, Revision der Formenreihe der Clypeaster altus, Vierteljahresschrift iler Naturf. Gesellsch. in Ziirich, p. 1, 189 ז.

Dimensions : Longueur . . . . . . . 33-38 millimitres

Largenr . . . . . 27-30 millimètres

Hauteur . . . . . 17-16 millimitres.

Espèce de taille moyeme, presque ovale, très légèrement tronquée en avant, subrostrée en arrière, ayant sa plus grande lauteur tantôt près de l'appareil apical, tantôt en arrière aux $\%$ de la longueur, et sa plus grande largeur dans la seconde moitié des interambulacres pairs postéricurs. Face supérieure bombée, médiocrement relevée en avant, montrant une carène dorsale pen acrusée, mousse au lieu d'être aigue et de ehaque côté une ligne de renflements noduleux; cette double ligne noduleuse existe aussi dans les interambulacres latéraux, et beaucoup moins accentuée dans les antérieurs. Bord pulviné; les nodosités se contimuent 
en-dessous jusqu’à la limite du floscelle péristomal, aussi saillantes et souvent plus qüà la face supérieure, le test est déprimé dans la région buccale. Apex excentrique en avant ${ }^{11} / 33$.

Appareil apical rectangulaire, avec le corps madréporiforme au milieu et les quatre pores génitaux occupant les angles sans palantre portés par des plaques distinctes, ee qui est la disposition la plus commune dans les Cassidulidées; les cinq pores ocellaires sont très petits.

Aires ambulacraires superficielles toutes semblables; pétales étroits, courts, les trois antéricurs de même longueur, les postérieurs un peu plus longs, avee trois ou quatre paires de pores en plus, s'étendant à peine jusqu'aux ${ }^{2} / 3$ de la longueur totale du test. Zones porifères très étroites, portant des paires serrées et assez nombreuses de petits pores inégaux, les internes ronds, les externes obliques et ovalaires; nous comptons environ 24 paires par série dans les pétales du trivium et 28 dans ceux du bivium. L'espace interzonaire, très légèrement saillant, est à peu près aussi large que les deux zones porifëres rémies; la largeur totale des pétales n'excède pas 2 millimètres $1 / 2$.

Péristome excentrique en avant, au tiers antérieur, pentagonal, plus large que long, orné de bourrelets interambulacraires médiocres, et de phyllodes à quatre rangées de pores à l'extrémité des aires ambulacraires. - Périprocte ovale, coupant le bord postérieur, au-dessous d'un petit rostre formé par la carène dorsale, ce qui le rend invisible d'en haut.

T'ubercules ordinaires it la famille des Cassidulidees, très fins et serrés à la face supérieure, un peu plus gros en-dessous.

En comparant le B. abundans an B. tunetana, nous trouvons des diffẻrences très sensibles dans les caractères spécifiques. Liespèce égyptienne est plus allongée relativement à sa largeur; elle a les pétales ambulacraires beancoup moins longs et moins larges 
et les tubercules plus fins; l'espèee tunisienne ne montre pas de rentlement noduleux dans les aires interambulaeraires, son péristome est plus largement ouvert.

Niveau : Snessonien inférieur.

Localité : Gebel Garah près Assonan.

Echinolampas africanus de Loriol, 1880.

Syn. : Lichinolampas africamus P'. de Ioriol, Monographie des Lichinides nummulitiques de l'Égypte, p. 30, pl. In, fir. 1-pl, w, fig. 5-6, 1880.

> P. de Loriol, Eocïne Echinoideen, etc. p. 23, pl. vir, fig. I, 1881.

> Cottean, I'aléontologie française, terre éocine, t. II, p. 743, pl. 380 , fig. $3-5,1894$.

Zittcl, op. cit., 1. crv, cxr, cxix, 1883.

R. Fourtau, Note sur la stratigraphie du Molattam, Bull. Soc. Géol. de France, $3^{\text {e }}$ série, tome $\mathrm{xxy}, 1$. $210,18 \% \overline{7}$.

Grande espèee se rapproehant des Conoclypeus par ses ambulacres larges et longs, mais s'en distinguant par son péristome orné de phyllodes bien développés, et ne pouvant plus se eonfondre avec les Conoclypens depuis que l'on sait que eeux-ei sont pourvis de mâehoires.

J'ai recueilli an Sinaï dans l'Ouady Feiran près de son embouchure quelques spéeimens qui présentent quelques différenees avec le type décrit par M. de Loriol. Ces différenees ne sont toutefois pas assez grandes pour en faire des espèees nonvelles, tout au plus pouvons-nous les indiquer comme de simples variétés.

Niveau : Lutétien I et II.

Localités : Beni-Hassan et Aradj (Zittel) Mokattam, Platean des Pyramides de Ghizeh et Garet Beyrieh! (sic) au Sud-Est du Caire ${ }^{1}$

1. N. Mayer ayant oublic de joindre me carte a la nomenclature des (iarets dont il a parsemé le désert des deux côtés de la vallée du Nil, il m'est difficile d'indiquer clairement la localité; cependant je crois que le Garet Beyrich est le monticule :un Sul-list du Caire connu par les indigènes sous le nom de Ouarchet el-Rifü cn face le village arale de bassatin. 
(Mayer-Eymar), Ouady Hof près Helonan. - Ouady Feiran et Gebel Araba (Sinaï) (R. Fourtau).

Collections: Musées de Stuttgart, Munieh, Zurich, Éeole de Médecine de Kasr el-Aïny au Caire, Muséum de Paris, Cotteau, de Loriol, Fourtau, Pasquali et Gauthier.

(On trouve aussi l'E. africanus en 'Tunisie.

Echinolanpas FraAsi de Loriol, 1880. Syml. : Echinolampas Fraasi P. de Loriol, Monographie, etc., p. 36, pl. v, tig. 1, 1880.

P. P. de Loriol, Eocïne Echinoideen, etc., p. 23, pl. vir, fig. 1, 1881.

>Cottean, I'aléontologie firançaise, tome $\mathrm{n1}, \mathrm{p} .156,1890$.

Cette espèce recueillie par Fraas avait été rapportéc par lui it Conoclypeus conoideus tout en faisant certaines réserves. On peut. l'en disting'uer facilement par le périprocte qui est trausverse au lieu d'être longitudinal et par les bourrelets péristomaux très peu saillauts et inégaux, sans parler de la présenee de plyyllodes bien aceusés.

Niveau : Lutétien I, couches au-dessous du niveau à Lobocarcinus Paulino Wurtembergicus.

Localités ${ }^{1}$ : Mokattam. Beni-Hassan (Zittel). Platean des Pyramides de Ghizel.

Collections : Mnsées de Stuttgart, Munich, Zurich et 'Turiu. Muséum de Paris, École de Médecine de Kass el-Aïny, Cotteau, de Loriol, Fourtau, Pasquali, Gauthier.

Echinolatrpas ()siris (Desor) de Loriol, 1880. Syn. : Conoclypeus Osiris Dusor, Cutalogue raisonné des Échinides, p. 109, 1847. Desor, Synopsis des Échinides, p. 321, 1857.

Echinolampas Osiris l'. de Loriol, Monographie, etc., p. 37, pl. vI, fig. 1, 1880.

1'. de Loriol, Eocïne Echinoideen, etc., p. 21, pl. Iv, fig. 1, $18 \$ 1$.

1. Zittel (op. cit., p. cvir) signale l'E. F'rausi dans le suessonien d'Esueh avec un joint de donte aui a certes sa raison d'être. 
Eckinolampes Osiris Cottean, Paléontologie ficençaise, Eocène, t. 1r, p. 15\%, 1890. R. Fourtul, Note sur les Sismondia, etc, Bull. Instit. E.gypt., fisc, 3,1897 .

Espèce dı même groupe que les précédentes à base largement ovale, à face supérieure élevée et eonvexe, un peu conique au point eulminant; ambulacres longs et larges, inégaux, superticiels. Granulation toute particulière.

Niveau : Lutétien.

Localité : Montradan' (Ég'ypte, d’après Desor). Negloa à l'List de l'oasis de Béharieh.

Collections : Muséum de Paris, Musées de Turin, de Munich et de Zurieh.

Echinolanpas Periemiri de Loriol, 1880. Syn. : Echinolampas Pevieri P. de Lotiol, Monographie, elc., 1). 39, 11. v, fig. 2, 1580 P. de Loriol, Eocäne Echinoideen, etc., 1). 25, pl. vil fig. 2-3, 1881 .

" Thomas et Gauthier, Description des Kichinides recueillis dans la région des hauts plateaux en Tunisie, p. \$5, $188 \%$. Cottean, Paléontologie fronçaise, liocéne, t. 11, p. 126, 1894.

Espèce d'assez grande taille, beaucoup moins haute que les précédentes, pourtour très régulièrement ovale, face smpérieure triss déprimée et uniformément convexe. Ambulacres costulés, apex au ${ }^{45} / 100$ de la longueur. Péristome relativement petit, excentrique en avant, pentagone, très pen enfoneé, entouré d'un floscelle apparent. P’ériprocte inframarginal placé très près du bord.

Niveaux et localités : Suessonien supérieur. Environs de Thèbes (M. Husson). - Lutétien I, Beni-Hassan (Zittel), Onady Huf prìs Hélouan" (M. Cramer), Mokattam. Plateau des Pyranides de

1. A propos de Montradan jai fait observer (op, cit.) yue ce nétait pas un nom arabe, mais comme $E$. Osiris se trouve an Regio Museo geologico de Turin euroyé par Clot bey a Bellardi, il y a tout lieu de croire que Montradan n'est autre que Mokattam mal écrit par celui qui a enroyé le type a besor.

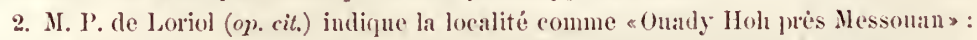
il y a lí deux fautes dimpression que nous arons dû eorriger et la loealité est rétablie comme Oualy. Ilof pres llélouitu. 
Ghizeh (R. Fourtau). - Bartonien (?) à l'Est de l'Oasis de Syouah entre Ä̈n Tagelirt et Rharten, conches à Num. Fichteli (Zittel).

Collections : Musées de Zurich et de'Turin. P. de Loriol, Fourtau.

Echinotampas amygidala Desor 1847.

Syn. : Echinolampas amygdala Desor in Agatssiz et Desor, Catalogue raisonné des Ĺchinides, p. 106, 1847 .

¿ P. de Loriol, Monographie, ete., 1. 40, pl. v1, fig. 2-3, 1880.

Cotte:ul, P'aléontologie française, t. 11, p. 159, 1890.

C'ette espèce se disting'ue facilement par l'ovale parfait de sal forme, sa face supérieure presque parallèle à l'inférieure et la rondeur uniforme de son pourtour.

Niveaux et localités : Suessonien moyen, Gebel Drounka près el-Syout et Claîne arabique ì 15 kilomètres à l'Est d'Esneh (II. Mayer-Eymar). - Lutétien I, Mokattam (M. A. Naville). Le type a été rapporté par' Lefebvre sous l'étiquette. T'errain nummulitique d'Égypte.

Collections : Mnséum de Paris, Mnsée de Zurich, P. de Loriol.

Echivolampas globulus Laube, 1867.

Syn. : Echinolampas globulus Latube, Beitrag zur. Kennhniss der Echinodermen des vincentinischen Tertiürgebietes, Sitzungsb. der Wiener Akad. vol. xvi, $1^{\text {re }}$ partie, p. $239,1867$.

> P. de Loriol, Monographie, etc., p. 42, pl. vil, fig. 1-5, 1880. - (Voir cet ouvrage pour la synonymie complète.)

P. de Loriol, Eociine Echinoideen, etc., p. 26, pl. In, fig. 4, 1881 .

Cette espèce parait être également répandue dans tout l'Éocène d'Égypte. Elle se rapproche assez de l'E. ellipsoidalis d'Archiac, mais ses ambulacres sont notoirement plus larges, le profil de sa face supérieure est moins horizontal et plus déelive, sa face inférieure est moins déprimée autour du péristome et non renflée sur le plastron. 
Niveaux et localités : Suessonien moyen. Environs de Louxor (M. Delanoue), Gebel Drounka près el-Syout (Fraas). — Lutétien I et II, Mokattam (A. Pasquali). Tranchée d'el Orta au Sud du Gebel Ahmar' (II. Cramer), Plateau des Pyramides de Ghizeh (II. E. Lecoffre). - Bartonien - Aradj (Zittel).

Echinolaypas Crameri P. de Loriol, 1880.

Syn. : Echinolampas Crameri P. de Loriol, Monographie, etc., p. 44, pl. v, fig. 4-10, 1850 .

> P. de Loriol, Eocïne Echinoideen, etc., p. 32, pl. mi, fìg. 8, 1881 .

> $\quad$ Cotteau, Paléontologie française, Éocène, t. Ir, p. 158, 1890.

> R. Fourtau, Les bancs ì Callianassa d'Égypte, Bull. Inst. Égypt., fasc. 3, 1897.

Forme assez variable, mais toujours de petite taille. Péristome excentrique en avant, assez grand, transverse, légèrement pentagonal et enfoncé. Périprocte grand, ovale, transverse, tout-à-fait marginal, tronquant même le rostre postérieur.

Niveau : Lutétien II (d'après M. Mayer-Eymar) avec Thagastea Luciani.

Localité : Ouady el-Til, Bir Moussa (M. Mayer) Gebel Ghiouchy, Sikket el-Dabban.

Echinolampas Aschersoni de Loriol, 1881. Syn. : Echirolampas Aschersoni P. de Loriol, Eocïne Echinoideen, etc., p. 28, pl. vin, fig. 2, 1881.

$\gg \quad$ K. A. Zittel, op. cit., p. cxx, 1883.

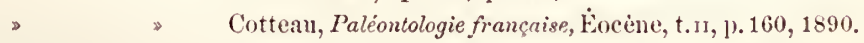

Un seul exemplaire connu recueilli par le professeur Ascher-

1. M. P. de Loriol indique sur la foi de M. Cramer la localité comme alontagne Rouges, en arabe Gebel Ahmar. Le Gebel Almar, étant un piton de quartzite datant de l’époque plëistocéne, ne peut contenir des échinides éocènes. La véritable localité est celle que nous indiquons et qui est la couche de calcaires éocènes sur laquelle repose le Gebel Ahmar (cf. R. Fourtau, Stratigraphie du Mokattam, Bull. Soc. Géol. de France, $3^{e}$ série, tome xxv, p. 228, fig. 1, 1897).

MÉMOIRES, T. III. 
son sur la route des cararanes entre le Fayoum et l'Oasis Beharieh.

Nireau : Lutétien I.

Localité : Hammamat el-Kadi (Zittel).

Echinolampas subciminimicts Desor, 1853.

Voir pour la synonymie de cette espèce qui se tronve anssi dans le Vicentin. 1. de Loriol, Eocïne Echinoideen, etc., 1. 29, pl. r., fig. 2, 4.

Cette espèce qui se troure aussi dans le Vicentin a été recueillie ¿̀ l'Est du désert de Syouah, dans un calcaire blane avee Nummulites Gizehensis.

Echinolames libreus de Loriol, 1881.

Syn. : Echinolampas libycus P. de Loriol, Eociine Echinoideen aus Aegypten und der libyschen Wüiste, p. 31, pl. v, fig. 1, 1881.

》Cottean, Paléontologie française, p. 160, 1890.

Trìs grande espèce, ovale, rétrécie en avant, arec pétales anbulacraires longs, inégaux. Zones porifères étroites, inégales; dessus voûté de hauteur moyenne. - Cinq exemplaires.

Localité: A l'Est de l'Oasis de Syouah avec l'espèce précédente.

Echinolampas amigdalisa Mayer-Eymar; 1898.

Syn. : Echinolampas amygdalina Nayer-Kymar, op. cit., p. 4, pl. mI, fig. 4, 1898.

C'est la variété de l'E. globulus (minor) décrite et figurée par M. de Loriol (Eocäne Echinoideen, etc., p. 27, pl. InI. fig. 4-7).

Niveau : Suessonien moyen.

Localité : Châ̂ne libyque à 15 kil. à l'Ouest d'Esmeh (Mayer).

Echinolanpas Mirienexsis Mayer-Eymar, 1898. Syn. : Echinolampus Miniehensis Nayer-Eymar, op. cit., p. 4, pl. rr, fig. 1, 1898.

Espèce de taille moyenne, ovale, médiocrement renflée à la face supérieure, un peu plus étroite en arant qu'en arrière. Apex excentrique en arant. Pétales ambulacraires larges et longs, légèrement renflés dans l'espace interzonaire. 
Niveau : Suessonien supérieur (Londinien II de Mr. Mrayer).

Localité : Minieh.

Echinolanis pratecedexs Mayer-Eymar, 1898. Syn. : Echinolantus pracedens Mayer-Eymar, op. cit., p. 4, pl. iv, fig. :2, 159 s.

Cette espèce n'est représentée que par un senl exemplaire. Malgré sa taille plus grande et sa forme un peu gibbeuse à lapex. le type nous paraît très voisin de l'E. amygdalina qu'on rencontre dans la même localité et au même nivean.

Niveau : Suessonien moyen (Londinien I de M. Mayer).

Localité : Châne libyque à 15 kilomètres à l'Ouest d'Esneh (Mayer-Eymar).

Cassidulus amygdala Desor, 1853-?.

Syn. : Cassidulus amygdalu Desor, Archives des sciences physiques et naturelles, tome xxiv, p. $14 \%$.

I. Mayer-Eymar a attribué à cette espèce un exemplaire déformé, mal conservé, dont on ne voit nettement que la partie postérieure. Appareil apical peu excentrique en avant; la partie postérieure est plus rapidement déclive que ne l'indiquent les figures données par M. de Loriol dans l'Échinologie Helvétique (p. 49, pl. III, tig. 5-6). —C"est d'ailleurs jusqu’̀ présent le seul Cassidulus recueilli en Égypte.

Niveau : Suessonien moyen (Londinien I de M. Mayer).

Localité : Châne libyque à 15 kilomètres à l'Ouest d'Esneh. - A. Ybert (Suisse) le C. amygdala appartient au Lutétien I.

Caratomes londinianes Mayer-Eymar, 1898. Syn. : Caratomus londinianus Mayer-Eymar, op. cit., p. 5, pl. sv, fig. 3, 1898.

Petite espèce subpentagonale, assez élevée, convexe à la partie supérieure. Appareil apical excentrique en avant; pétales ambulacraires bien distincts; les pores sont arrondis et disposés par paires peu serrées. Périprocte triangulaire, sous le petit rostre postérieur; péristome mal conservé. 
C'est la première fois que nous nous tronvons en présence d'un véritable Caratomus tertiaire, car celui que Cotteau a nommé $C$. Le Honi n'appartient pas à ce genre. Les deux exemplaires de M. Mayer ressemblent beaucoup au C. rostratus Agassiz du Cénomanien et plus étroitement encore au $C$. trigonopygus Desor; ils ont, comme ce dernier, les pétales bien visibles, ce qui est rare dans ce genre, le périprocte bien triangulaire, et ils ne s'en distinguent guère que par leur test un peu plus éleré.

Niveau : Suessonien supérieur (Londinien de M. Mayer).

Localité : Gebel Drounka près el-Syout.

Hemimaster Pellati Cotteau, 1863. Syn. : Hemiaster Pellati Cotteau, Échin. foss. des Pyrénées, p. 117, pl. vi, fig. $7-9$. de Loriol, Monographie, etc., p. 46, pl. vir, fig. 6, 1880.

II. de Loriol a rapporté à cette espèce un exemplaire unique, incomplet, cassé en avant, recueilli au Mokattam par Delanoue. La forme de l'exemplaire égyptien est plus élevée et moins large que celle du type pyrénéen; M. de Loriol déclare ne voir que deux pores génitaux dans l'appareil. Depuis, Cotteau (Paléont. franç., terr. tert., Éocène, I, p. 419) a réuni son exemplaire tỹpe au Ditremaster nux Munier-Chalmas et a mis en synonymie l'exemplaire égyptien qu'il regarde comme identique au sien, et qui, dès lors, doit prendre le nom de Ditremaster nux.

Collection : Muséum de Paris.

Hemiaster Archiaci de Loriol, 1880. Syn. : Itemiaster Archiaci de Loriol, Monographie, etc., p. 48, pl. rir, fig. 7-8.

Trachyaster Archiaci Cotteau, Paléontologie française, terrains tertiaires, tome I, 1). $407,188 \%$.

Petite espèce très élevée, subglobuleuse, confondue par Delanoue et d'Archiac ${ }^{1}$ avec une espèce de l'argile de Londres, dont

1. Delanoue et d'Archiac, Note sur la constit. géol. des environs de Thèbes, Hemiaster Bowerbanki. Comptes-rendus de l'Acad. des Sciences, vol. Lxir, p. 706. 
elle se distingue facilement par sa forme plus relerée en arrière, plus arrondie en avant et par ses ambulacres pairs plus superficiels. Cottean l'a comprise dans le genre Trachyaster, type tertiaire qui se distingue des Hemiaster par sa forme plus renflée et par le développement, dans l'appareil apical, du corps madréporiforme qui sépare les plaques génitales et sort de l'appareil. Ce dernier caractère n'est point constaté par M. de Loriol, et Cotteau n'en parle pas, tout en attribuant lespèce an genre Trachyaster.

Niveau : Suessonien moyen.

Localité : Environs de Louxor.

Collection : Muséum de Paris.

Heniaster Schweinfurthi de Loriol, 1881.

Syn. : Hemiaster Schweinfurthi de Loriol, Eocïne Echinoideen, etc., p. 34, pl. vm. fig. 3, $4,5,1881$.

Ditremaster Schweinfurthi Cotteau, Paléontologie française, Éocẻne, t.r, p. 428, 1887.

Cette espèce ne présentant que deux pores génitaux dans lappareil apical, rentre dans le genre Ditremaster Munier-Chalmas, qui n'était pas encore établi à l'époque où M. de Loriol l'a étudiée et décrite.

Niveau : Suessonien inférieur.

Localité : 'Très abondant dans les couches marneuses d'ElGouch Abou Saïd, à l'ouest de Farafrah.

Collection : Musée de Munich (Zittel).

Palaeostona Zittei de Loriol, 1881.

Syn. : Palneostoma Zitteli de Loriol, Eocïne Echinoideen, etc., p. 33, pl. virr, fig. 1, 1881.

Le genre Palaeostoma Lovén se distingue des Hemiaster par son péristome qui, au lien d'être labié en arrière, affecte une forme pentagonale sans aucune saillie. L'espèce décrite par M. de Loriol est de petite taille; elle est ornée d'un faible fasciole péripétale, et ne se distingue des Hemiaster que par la forme de son pé- 
ristome; l'appareil apical est très excentrique en arrière; on n'en distingue pas les pores.

Niveau : Suessonien inférieur.

Localité : Nekeb, à l'Est de l'Oasis de Farafrah.

Collection : Musée de Munich (Zittel).

Brissopsis angusta Desor, 1847.

Syn. : Brissopsis angusta Desor, Catalogue raisonné des Échinides, p. 121, 1847.

Desor, Synopsis des Échin. foss., p. 379, 1857.

de Loriol, Monographie, etc., p. 49, pl. vin, fig. 9, 1880.

Cottean, Paléontologie française, Eocène, I, p. 202, 1886.

Un seul exemplaire, le type décrit par Desor, existe au Muséum de Paris avec l'étiquette de Lefebvre : "Nummulitique d'Égypte.»

Je ne puis dans ces conditions domner des indications plus précises de niveau et de localité jusqu'à ce qu'on recueille de nouveaux exemplaires.

Collection : Muséum de Paris.

Brissopsis LoRioli Bittner (sub Toxobrissus), 1880, pl. I, fig. 3-4.

Syn. : Toxobrissus Lorioli Bittner, Beitrïge zur Kenntniss altertertiörer Lchinidenfannen der Sïdalpen, p. 102, pl. iv, fig. 7-8, 1880.

Dimensions de notre exemplaire : Longueur . . . . . . 26 millimètres Largeur . . . . . . . 29 millimètres Hauteur . . . . . 17 millimètres.

Individu de forme ovale, un peu plus rétréci en arrière qu'en avant, et tronqué à ces deux extrémités; partie postérieure un peu plus épaisse que la partie antérieure; la plus grande largeur est au milieu. Face inférieure pulvinée, renflée lans la région du plastron. Apex légèrement excentrique en avant.

Appareil apical montrant quatre pores génitaux rapprochés, avec le corps madréporiforme séparant les plaques postérieures et se prolongeant en arrière. 
L'ambulacre impair n'est pas suffisamment visible pour le décrire.

Aires ambulacraires paires antérieures divergentes, logées, pour la partie pétaloïde, dans des sillons larges de trois millimètres et demi, de profondenr moyenne; zones porifères assez larges, formées de pores allongés; il y a de 18 à 20 paires dans chaque zone; mais la série antérieure compte, en partant du sommet, 9 paires atrophiées. Pétales postérieurs moins divergents, légèrement recourbés en-delors vers leurs extrémités, un peu plus long que les antérieurs, comptant 20 paires de pores, dont une dizaine atroplicées dans les séries postérieures.

Péristome ovale, transverse, éloigné du bord de 10 millimètres. Périprocte transverse, s'ouvrant au hant de la face postérieure. Fascioles peu visibles sur notre unique exemplaire très médiocrement conservé.

Ce type égyptien nous a paru se rapporter très nettement à l'espèce que M. Bittner a décrite sons le nom de T. Lorioli: les dimensions du test, la physionomie de l'exemplaire sont exactement les mêmes que chez le type provenant des Alpes du Vicentin; la seule différence qu'il soit possible d'y constater, e'est que le nombre des paires de pores atrophiées dans les pétales antérieurs est plus considérable chez l'individu égyptien, 9 au lieu de 4; tandis que les pétales postérieurs sont exactement semblables. Nons ne croyons pas que la différence que nous signalons puisse empêcher de réunir le type du Mokattam au type des Alpes méridionales, ear ce caractère est assez variable, et tous les autres détails sont parfaitement concordants. La présence du B. Lorioli en Égypte porte à $S$ le nombre des espèces communes à cette contrée et an Vicentin.

II. Bittner nous a vivement critiqué, il $y$ a trois on quatre ans, pour aroir dit que le genre Toxobrissus Desor tombe en synonymie de Brissopsis Agassiz, et doit être supprimé : il alléguait que 
le genre Brissopsis a pour type B. lyrifera Forbes, et que le gemre Toxobrissus a été établi sur le Br. concentrica Wright. Nous ne l'ignorions pas; mais comme il n'y a pas de caractères génériques distinctifs entre ces deux Échinides, le genre T'oxobrissus nous paraissait et nous paraît encore superflu. Desor l'a fondé en s'appuyant sur cette particularité que dans les ambulacres postérieurs il y a des paires de pores atrophices et que les pétales sont très rapprochés; mais il suffit de prendre un Brissopsis lyrifera pour voir tout de suite que ces deux détails y existent. L'extrémité des pétales postérieurs n'est pas arquée, e'est vrai; mais qui done oserait soutenir qu'une courbe presque insignifiante de l'extrémité des pétales postérieurs est un caractère suffisant pour constituer un genre nouveau? D'ailleurs, ce n'est pas à nous que revient le mérite d'avoir fait le premier cette observation; il appartient tont entier à notre honoré confrère et ami Y. P'. de Loriol qui depuis longtemps a montré combien est vaine la différence qu'on a voulu établir entre les deux genres. La plupart des échinologistes ont reconnu la justesse de ses remarques à ce sujet, et même M. Pomel, qui avait maintenu le genre Toxobrissus dans sa Classification méthodique, a dû recomnâtre son erreur; il a rendu aux Brissopsis tout ce qu'il avait attribué au genre de Desor, et il a créé, pour les espèces qu'il avait comprises dans le genre Brissopsis, le genre Brissoma qui ne nous paraît pas indispensable.

Niveau : Le B. Lorioli a été rencontré en Égypte dans le Lutétien supérieur.

Localité : Mokattam (Gebel Emarab près l'Ouady el-'Tih) (R. Fourtau).

Collection : R. Fourtau.

ANisaster gibBerulus Michelin (sub Hemiaster). Syn. : Hemiaster gibberulus Michelin, in collect.

Periaster subglobosus Fraas, Aus dem Orient, Wïrt. Jahreshefte, p. 278, 1867. 
Agassizia gibberula Cotteau, Échin. nouv. et peu comms, $1^{\text {re }}$ série, 1). 193, pl. xxv11, fig. $3-7,1875$.

de Loriol, Monographie, etc., p. 51, pl. vin, fig. 1-7, 1850. de I.oriol, Eocäne Echinoideen, etc., p. 36, 1881.

Anisaster confusus Pomel, Note sur deux Échinides du terrain éocène, Bull. Soc. Géol. de France, $3^{\mathrm{e}}$ série, t. xuv, p. 608, 1886.

Anisaster gibberulus Cottean, Paléontologie française, Ėocène, t. I, P. 379, 1887.

Cet échinide, dont tout le monde aujourd'hui a des spécimens, a été l'objet de bien des discussions; e'est un type très voisin des Agassizia, et pour lequel il n'était pent-être pas absolument indispensable de créer un genre nouveau.

Niveau : Lutétien II.

Localités : Ouady el-'Til, Gebel Ammounah, 'Tranchée d'el Orta derrière le Gebel Ahmar, Mokattan. Gebel Kibli el-Ahram.

On rencontre aussi cette espèce en T'unisie, au Gebel Trozza. Des échantillons en manvais état ont été recueillis par le R. P. Olnwalder aux environs de Souakim et envoyés par lui à notre confrère M. A. Pasquali.

Linthia Delanouei de Loriol, 1880. Syn. : Linthia Delanouei de Loriol, Monographie, etc., p. 53, pl. v11, fig. 12.

» $\quad$ de Loriol, Eocäne Echinoideen, etc., p. 36, pl. vin, fig. 6, 1881.

$\triangleright \quad$ Cotteat, Paléontologie française, Gocène, t. 1, p. 264, 1886.

Cette belle espèce se rapproche du L. Orbignyana Cottean, mais elle en diffère par sa forme moins orbiculaire, moins échancrée en avant, sa face supérieure plus renflée, ses ambulacres antérieurs pairs moins divergents avec des zones porifères composées de paires de pores plus nombreuses, ses ambnlaeres postérieurs plus rapprochés, relativement plus long's et arqués, enfin par son aréa anale triès aceusée.

Niveau : Suessonien moyen.

Localités : Gebel Der près Esneh. - Envirous de Louxor. Gebel Korardan près de Guirguch.

Collections : Muséum de Paris, Musée de Munich. 
Linthia Cavernosa de Loriol, 1880.

Syn. : Linthia cavernosa de Loriol, Monographie, etc., p. 55, pl. vin, fig. 8-10. de Loriol, Eocäne Echinoideen, etc., p. 41, pl. vin, fig. 7, 1851. Cotteau, Puléontologie française, Éocène, t. I, p. 265, 1886.

Se distingue du $L$. latisulcata par ses ambulacres postérieurs bien moins longs, du $L$. Orbignyana par ses ambulacres plus étroits et plus creusés, les postérieurs sont plus divergents. De plus, la faee supérieure est moins renflée et le sillon antérieur plus profond.

Niveau : Suessonien moyen, couches à Opereulines.

Localités : El-Aouli près Edfou. - Gebel Fatira près Louxor, Gebel Oum el-Renneiem (oasis Chargeh).

Collections : Muséum de Paris, Musée de Munich.

Linthia latisulcata Desor (sub Periaster), 1857.

Syn. : Heniaster latisulcatus Desor, Catal. rais., p. 125, 1847.

Periaster latisulcatus Desor, Synopsis des lichin. foss., p. 387, 1857.

Linthia latisulcata do Loriol, Monographie, etc., p. 57, pl. vir, fig. 11, 1880. Cotteau, Paléontologie française, etc., t. I, p. 263, 1886.

La description domée par M. de Loriol se rapporte au moule en plâtre d'un exemplaire rapporté par Lefebvre sous l'étiquette "Nummulitique d'Ĺgypte». L'original a été égaré, en tout cas M. de Loriol ne l'a pas ell entre les mains.

Collection : Muséum de Paris.

Linthia Naviliei de Loriol, 1880.

Syn. : Linthia Navillei de Loriol, Monographie, etc., p. 58, pl. vin, fig. 12, 1880.

» de Loriol, Eocäne Échinoideen, ete., p. 40, pl. Ix, fig. 7, 1881.

» Cotteau, Paléontologie française, Éocène, t. I, p. 266, 1886.

Genre établi par M. de Loriol en 1880 sur un exemplaire un peu usé et sur l'aspeet du faeies général. Depuis, en 1881, d'autres exemplaires rapportés par Zittel ont eonfirmé son diagnostique.

Localités et niveaux : Lutétien I, Mokattam (le type). - Ge- 
bel Drounka près el-Syout, couches à Alvéolines (Suessonien supérieur) (Zittel).

Collections : P. de Loriol, Zittel.

Linthia Arizensis d'Archiac (sub Hemiaster), 1859.

Syn. : Hemiaster Arizensis d'Archiac, Bull. Soc. géol. Fr., 2e série, t. xvr, p. 804, 1859.

Periaster Arizensis Cotteau, Échin. foss. des Pyrénées, p. 126, pl. vr, fig. 11-12, 1863.

Linthic Arizensis de Loriol, Monographie, etc., p. 60, pl. vir, fig. 10-11, 1880.

Espèce voisine du L. Biarritzensis Cotteau, mais son sillon antérieur est moins large, moins profond, échancrant moins le bord et moins renflée par sa face supérieure.

Niveau : Londinien I.

Localité : Environs de Louxor.

Collection : Muséum de Paris.

Linthia Aschersoni de Loriol, 1881.

syn. : Linthia Aschersoni de Loriol, Eocïne Echinoideen, etc., p. 37, pl. rx, fig. 1-4, $18 \mathrm{~s} 1$.

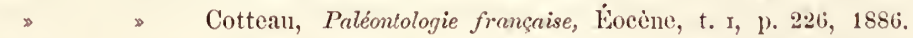

Espèce de taille moyeme, subcirculaire, un peu plus longne que large, médiocrement renflée à la partie supérieure, presque plate en-dessous. Sommet central.

Niveau : Suessonien moyen.

Localité : El-Gouch Abou Saïd, à l'ouest de Farafrah; Gebel Der près d'Esneh.

Collection : Zittel.

Lintuia Esnehexsis de Loriol, 1881.

Syn. : Linthia Esnehensis de Loriol, Eocäne Echinoideen, etc., p. 39, pl. x, fig. 5-6, 1881.

Cotteau, Paléontologie française, Eocène, t. I, 1). 267, 1886.

Espèce de taille moyenne, voisine des Linthia subglobosa et inflata, dont elle se distingue par sa partie antérieure plus déclive, par son appareil apical excentrique en arrière, par sa partie postérieure plus rétrécie.

Nivean : Suessonien moyen. 
Localité : Gebel Der près Esneh.

Collection : Zittel.

Pericosmus Pasquatil Ganthier, 1898, pl. in, fig. 1-2.

Dimensions : Longueur ......... . 76 millimètres

Largeur . . . . . . . . . 77 millimètres

Hauteur . . . . . . . . . . 38 millimètres.

Espèce de grande taille, un peu plus large que longue, assez élevée, renflée, presque uniformément bombée à la face supérieure. Bord arrondi, épais, interrompu en avant par une profonde échanerure du sillon impair; dessous convexe; face postérieure tronquée, subtriangulaire. Apex légèrement exeentrique en avant, 35/76.

Appareil apieal dans une dépression, insuffisamment conservé sur notre unique exemplaire.

Aire ambulaeraire impaire logée dans un sillon peu accentué et peu profond près du sommet, s'élargissant progressivement et atteignant au bord inférieur une largeur de 18 millimètres et une profondeur de 9. Zones porifères formées de paires obliques de petits pores, d'ailleurs peu visibles sur notre exemplaire où elles sont recouvertes de débris de madrépores.

Aires ambulacraires paires un peu plus divergentes en avant qu'en arrière; pétales logés dans des sillons profonds, assez larges et bien fermés à l'extrémité. Zones porifères larges, égales, formées de paires de pores inégaux, les externes linéaires et allongés, les internes subovales ou ronds; ils sont séparés par un on deux granules. L'espace interzonaire est un peu plus étroit qu'une des zones. Le sillon des pétales antéricurs est long de 28 millimètres et large de 5; celui des pétales postérieurs est aussi large, mais n'exeède pas 22 millimètres en longueur. Les plaques porifères sont assez hautes et par conséquent les paires de pores assez écartées : je n'en compte que 27 dans les pétales antérieurs et 23 dans les postérieurs. 
La face inférieure de l'exemplaire est mal conservée et le péristome est invisible. Périprocte occupant une grande partie de la troncature postérieure, transverse.

Fasciole péripétale bien visible, en ligne brisée, remontant assez laut dans les interambulacres; le fasciole marginal est moins bien conservé; on en constate néanmoins des traces certaines en plusieurs endroits.

Des tubercules petits et assez serrés couvrent la face supérieure, plus multipliés dans le voisinage des sillons ambulacraires; cenx de la face inférieure sont un peu plus développés.

En comparant ce type égyptien aux espèces connues du geme Pericosmus, j'ai tout d'abord été frappé de la ressemblance qu'il présente, pour la forme générale, avec certains exemplaires de ma collection appartenant au P. spatangoides de Loriol, du Vicentin; la disposition des sillons ambulacraires, le profil de la partie supérieure, la physionomie générale sont parfaitement semblables dans les deux espèces, et j'ai cru un moment être en présence d'un individu de très grande taille du type de S. Giovami Ilarione. Fn examinant de plus près les caractères spécifiques, j'ai reconnu que les zones porifères des pétales ambulacraires étaient différentes; le type égyptien, malgré sa grande taille, ne porte que 27 et 23 paires de pores, tandis qu'un exemplaire du Vicentin, de taille bien inférieure, en eompte au moins 30 dans les pétales antérieurs et 28 dans les postérieurs. Cette différence ne me permet pas de réunir les deux espèces; on peut ajouter encore que l'apex est un peu moins excentrique en avant chez le Pericosmus Pasqualii.

Niveau : Lutétien II.

Localité : Mokattam, du côté de l'Ouady Kaschab.

Collection : A. Pasquali. 
SCHIZASTER AFRICANU's de Loriol, 1863.

Syn. : Schizaster africanus de Loriol, Descript. de deux Échin. nonv. du Nummulitique d'Égypte, p. 5, pl. 1, fig. 2. - Mém. de la Soc. de Pliys. et d'Hist. natur. de Genève, t. xvı, $1^{\text {er }}$ partic, 1863.

Fraas, Geolog. aus dem Orient, p. 279, 1867.

- Lartet, Géol. de la Palestine, Amı. Sc. géol., t. in, p. 84, 1872.

» de Loriol, Monographie, etc., p. 61, pl. vin, fig. 13 et 14, 1880.

» de Loriol, Eocäne Echinoideen, etc., p. 49, pl, xr, fig. 1, 1881.

* Cottean, P’aléontologie française, Éocène, t. I, p. 367, 1887.

» 'Thomas et Ganthier, Échin. recueillis sur les Hants Plateanx de la Tunisie, p. 93, 1889.

Espèce facilement reconnaissable par son ensemble très renflé et très arrondi, sa face inférieure très convexe, ses ambulacres antérieurs pairs très divergents, très longs, très larges et très flexueux, ses ambulacres postérieurs acuminés.

Niveau : Lutétien.

Localités : Mokattam, Ouady Moathil (chaîne arabique) Suessonien? à el-Gouch Abou Saïd, oasis de Farafrah.

Se rencontre aussi en Tumisie dans la partie supérieure des couches à Nummulites.

Schizastere Gaudry de Loriol, 1880.

Syn. : Schizaster Gaudryi de Loliol, Monographie, etc., p. 64, pl. ix, fig. 1, 1880.

Cottean, Paléontologie française, Éocène, t. r, p. 368, 1887.

Cette belle espèce se fait remarquer par son ensemble relativement déprimé et par sa face supérieure très peu renflée et peu déclive.

Niveau : Suessonien moyen.

Localité : Gebel Fatira près Louxor.

Collection : Muséum de Paris.

Schizaster ZitTeli de Loriol, 1880.

Syn. : Schizaster Zitteli de Loriol, Monographie, etc., p. 66, pl. זx, fig. 2, 1880.

ఎ de Loriol, Eocïne Echinoideen, etc., p. 46, pl. Ix, fig. 10, 1881.

* Cottean, Paléontologie française, Ėocène, t. 1, p. 369, 1887.

Cette espèce intéressante se rapproche sous certains rapports 
du Sch. Bellardii Ag.. mais elle s'en distingue facilement par sa forme moins renflée, son sommet plus central, ses aires interambulacraires ni renflées, ni relevées à leur sommet, ses ambulacres antérieurs pairs un peu plus flexueux.

Localités et niveaux : Suessonien moyen, Gebel Der près Esneh (Zittel), environs de Louxor (Delanoue). - Lutétien II, Mokattam (Zittel, R. Fourtau).

Collections : Muséum de Paris, Zittel, Fourtau.

Schizaster foveatus Agassiz, 1840.

Syn. : Schizaster foveatus Agassiz, Cat. ectyp. mus. neoc., p. 3, 1840.

Voir la snite de la Symonymie dans de Loriol, Monographie, etc., p. 63.

Ajouter : de Loriol, Eocïne Echinoidcen, etc., p. 44, pl. xx, fig. 8-9, 1881. Cotteau, Paléontologie française, Eocène, t. I, p. 350, 1887.

Cette espèce est assez voisine d'apparence de l'Hemiaster Scillae Wright et de l'Hem. globosus Desor, mais elle s'en distingue d'emblée par son sillon antérieur bien plus profond et échancrant davantage le bord.

Niveau : Lutétien I.

Localité : Mokattam.

Collection : Muséum de Paris.

Schizaster Mokattamensis de Loriol, 1881.

Syn. : Schizaster Mokattanensis de Loriol, Eocïne Echinoideen, etc., 1).41, pl. x, fig. 1 et 2,1881 .

Cotteau, Paléontologie française, Éocène, t. I, p. 371, 1887.

Espèce de taille moyenne, presque circulaire, laute, renflée: sommet ambulacraire, presque central, alors que le point culminant est tout à fait en arrière; il n'y a que deux pores génitaux.

Niveaux et localités : Suessonien Gebel Der près Eisneh (Zittel). Lutétien Mokattam (Zittel, Mayer-Eymar, Fourtau).

Schizaster Rohlfsi de Loriol, 1881. Syn. : Schizaster Rohlfsi de Loriol, Eocäne Echinoideen, etc., p. 43, pl. x, fig. 3 et 6, 1881.

» $\quad$ Cotteau, Paléontologie française, Eocène, t. r, p. 3i1, 1887. 
Espèce de taille moyenne, un peu allongée, subglobuleuse, haute, arrondie en avant. Aire ambulacraire impaire logée dans un sillon large et profond, qui s'atténue près du bord et l'échancre à peine. L'appareil apical ne montre que deux pores génitaux. Niveau : Lutétien II.

Localité : Mokattam près du Caire. Plateau des Pyramides de Ghizeh (R. Fourtau).

Schizaster Jordani de Loriol, 1881. Syn. : Schizaster Jordani de Loriol, Eocïne Echinoideen, etc., p. 47, pl. x, fig. 7-10, 1881. \ $\quad$ Cotteau, Paléontologie française, Éocène, t. 1, p. 372, 1887.

M. de Loriol en connaît trois exemplaires; ils sont d'assez forte taille, mais tous médioerement eonservés; le pourtour est ineomplet. L'espèce est peu renflée; les sillons ambulaeraires sont longss et profonds, assez étroits; le péristome est éloigné du bord; l'ajpareil apieal montre quatre pores génitaux. Fascioles peu visibles.

Niveau : Bartonien (?).

Localité : A l'est de l'oasis de Syouah, près d'Aradj, dans un ealcaire rempli de petites nummulites.

Opissaster 'THebensis de Loriol (sub Schizaster), 1880. Syn. : Schizaster Thebensis de Loriol, Monographie, etc., p. 69, pl. Ix, fig. 5-6, 1880. » de Loriol, Eociine Echinoideen, etc., p. 49, pl. x, fig. 4 et 5. » $\quad$ Cottenu, P'aléontologie française, Éocène, t. I, 1). 370, 1887. Opissaster Thebensis Gauthier, in Cotteau, Paléontologie française, Éocène, t. II, p. 704, pl, 373, fig. 1-7, 1894.

Cette espèce a été aussi reneontrée en 'T'unisie, sur la rive gauche de l'Aïn Cheriehira. Les exemplaires de eette localité n'ont pas de fasciole latéro-sous-anal, et M. de Loriol n'en a pas vu non plus sur les exemplaires égyptiens. Il nous a semblé par eonséquent que eette espèce devait être placée dans le geure Opissaster Pomel, et Cotteau l'a déerite sous ce nom générique daus la Paléontologie. 
Niveau : Suessonien supérieur.

Localités : Environs de Thèbes, Gebel Drounka près de ElSyout, couches ì Sismondia Loghoteti.

Observations sur le groupe des Macropneustes.

Le groupe des Macropneustes auquel nous arrivons demande quelques observations que nous croyons tout d'abord devoir consigner ici. Il a toujours régné une assez grande confusion dans le genre Macropneustes lui-même et bien des espèces lui ont été attribuées, même par L. Agassiz, l'auteur de ce genre, qui ne lui appartiennent pas. En 1883, M. Pomel, étudiant ce geure, ${ }^{1}$ en sépara les espèces qui n'ont pas les aires ambulacraires paires déprimées ou sont privées d'un fasciole sous-anal; il établit ainsi le geure Hypsospatangus pour les spécimens ayant les aires ambulacraires paires complètement superficielles et dépourvus de fasciole sous-anal; puis, en fixaut nettement les limites du genre Macropneustes, il indiquait la possibilité de l'absence du fasciole sous-anal dans certaines espèces à ambulaeres déprimés, comme Macropneustes crassus Agassiz, et il ajoutait que, si ces espèces sont réellement dépourvues de fasciole sous-anal, il y aurait lieu de les distinguer par un nom spécial. Or, nous avons acquis la certitude qu'un de nos exemplaires ne possède pas de fasciole sous-anal, et nous nous trouvons ainsi amené à créer un nom geénérique nouveau Megapneustes dont il sera le type. En outre, M. Pomel, faisant la remarque que M. de Loriol dans sa Monographie des Échinides nummulitiques de l'Égypte avait admis parmi les Euspatangus un type à ambulacres pairs creusés, Eusp. Cotteani, a établi pour cet oursin le genre Plesiospatangus: ce qui fait qu'aujourd'hui le groupe des Macropneustes et des Euspatangus doit se subdiviser en cinq genres, dont voici la diagnose abrégée :

1. Classification méthodique et genera, p. 30 et suiv. 


\section{$-678-$}

1. Aires ambulacraires paires déprimées;

Fasciole péripétale ne limitant pas nettement les gros tubercules de la face supérieure;

Fasciole sous-anal entourant le talon;

Macropmeustes Agassi\%.

'Type Macropneustes Deshayesi Ag.

2. Aires ambulacraires paires déprimées;

Fasciole péripétale ne limitant pas nettement les gros tubercules re la face supérieure;

Point de fasciole sous-anal;

Megupneustes Gauthier.

'Type Megapneustes grandis Gauthier.

3. Aires ambulacraires complètement superficielles;

Fasciole péripétale ne limitant pas nettement les gros tubercules de la face supérieure;

Point de fasciole sous-anal;

\section{Hypsospatangus Pomel. \\ 'Type Hypsospatangus Meneghini (Desor) Pomel.}

4. Aires ambulacraires paires superficielles;

Fasciole péripétale limitant nettement les gros tubercules de la face supérieure;

Fasciole sous-anal entourant l'écusson;

Euspatangus Agassiz.

Type Euspatangus ornatus Agassiz.

5. Aires ambulacraires paires déprimées;

Fasciole péripétale limitant nettement les gros tubercules de la face supériemre:

Fasciole sous-anal entourant l'écusson;

Plesiospatangus Pomel. Type Plesiospatangus Cotteaui (de Loriol) Pomel. 
Cette multiplication des genres pour des types si voisins est nécessitée par la méthode admise dans les classifications récentes. Le caractère le moins important de eeux qui sont ici en jeu est peut-être la dépression, parfois très faible, des aires ambulacraires paires; on ne saurait cependant ne pas en tenir compte sans jeter un grand trouble dans les classifications actuelles. Il y a moins de vingt ans, on se contentait faeilement de deux genres : Macropneustes, Euspatangus; eneore Duncan regarde-t-il le second comme un sous-genre du premier. Aujourd'hui il y a cinq genres; il pourra y en avoir un plus grand nombre plus tard pour ce même groupe, car on pourrait découvir de nouveaux types où la disposition des aires ambulacraires, des faseioles et des gros tubercules occasionneraient d'autres combinaisons. Pour le moment, revenons aux Échinides de l'Égypte.

\section{Hypsospatangus Amon Desor (sub Macropneustes).}

Syn. : Macropneustes Ammon Desor, Catal. rais. des Échin., p. 115, 1847.

„ Desor, Synopsis des Échin. foss., 1). $+11,1858$.

„ Lartet, Gréol. de la Palestine, Ann. des Sciences géol., t. iII, p. $84,18 \pi 2$.

„ de Loriol, Monographie, etc., p. 71, pl. x, tig. 2, 1880.

Hypsospatangus Ammon Pomel, Classif. méthod. et genera, 1). 31, 1883.

Cottean, Paléontologie française, Éocène, t. I, p. 96, 1886.

Espèce de grande taille, à base ovale; face supérieure hémisphérique, à peu près uniformément convexe; point culminant excentrique en arrière. Appareil apical excentrique en avant, peu développé: ambulacre impair différent des autres, logé dans un sillon nul près du sommet, s'accentuant peu à peu en approchant du bord qu'il échancre profondément. Pétales des ambulaeres pairs à fleur de test, larges et longs, les postérieurs plus allongés que les antérieurs et moins divergents. Périprocte placé très bas à la face postérieure. Tubercules primaires de la face supérieure assez distants, émergeant an milien de fins granules; ils ne sont 


\section{- $680-$}

pas limités par le fasciole péripétale. Point de fasciole sousanal.

Niveaul : Suessonien?

Localité : Gebel Medinet (Delanoue).

Hypsospatangus Lefebvrei de Loriol (sub Macropneustes). Syn. : Macropnenstes Lefelvvei de Loriol, Monographie, etc., p. 75, pl. זx, fig. 7-9, 1880. » de Loriol, Eocïne Echinoideen, etc., p. 50, pl. xr, fig. 23, 1881.

IYypsospatangus Lefebvrei Cottean, Paléontologie française, t. I, p. 97, 1886.

Espèce beaueoup moins volumineuse et surtout beaucoup moins liaute que la précédente, de forme ovale, déclive d'arrière en avant. A mbulacre impair dans un sillon évasé éehanerant à peine le bord. Pétales des ambulacres pairs superfieiels, longs, assez larges, inégaux, les postérieurs plus allongés que les antérieurs. Périproete placé en haut de la face supérieure; fasciole péripétale touchant l'extrémité des pétales, effacé en avant, ne limitant pas eomplètement les gros tubereules dans la partic antérieure.

II. de Loriol, qui a déerit deux fois eette espèce avee des exemplaires différents, n'a pas déeouvert de traee de fasciole sous-anal; sur quelques exemplaires bien conservés les granules semblent se rassembler étroitement, mais l'auteur déelare que, malgré des recherehes très soigneuses, il n'a pas trouvé de faseiole. Cependant la figure grossie $2^{\text {d }}$ de la planche XI, domée en 1881, dessine un fasciole en éeusson, imaginé sans doute par le dessinateur; nous aimons mieux eroire à ce qu'affirme nettement la description qu'il n'y a pas de fasciole sous-anal. Si le dessinateur avait raison, cette espèce ne trouverait place dans aucun des einq genres que nous avons exposés plus haut, et il faudrait en eréer un sixième pour elle.

1. On eomprendra notre hésitation : le type est de Lefebrre qui l'a étiqueté "Nummulitiqne d'Egypte». - M. de Loriol ajonte : "Lnn autre éehantillon très usé de Gebel Medinet (rapporté par M. Delanone).» 
Niveau : Suessonien moyen et supérieur.

Localités : Environs de Louxor (Delanoue), El-Gouch Abou Saïd (oasis de Farafrah). - Gebel Drounka près el-Syout. Environs de Minieh, couches à Alvéolines.

Hypsospataygus Ficheri de Loriol (sub Macropneustes), 1880. Syn. : Macropneustes Ficheri de Loriol, Monographie, etc., p. 74, pl. xx, fig. 10, 1880.

Liopatagus Ficheri Pomel, Classif. méthod. et genera, p. 30, 1883.

Leiopmenstes Ficheri Cotteau, Paléontologie française, Éocẻne, t. I, p. 127, 1885.

Nous n'entrerons pas ici dans la discussion des genres Leiopatagus Pomel olim ou Liopatagus Pomel 1883 et Leiopneustes Cotteau 1886. Ces genres nous paraissent assez inutiles pour le type qui nous occupe, bien qu'on ait voulu l'y faire entrer. En effet, ils comprennent des Spatangoïdes très mal comuns, dont le principal caractère serait de n'avoir pas de fasciole; or, M. de Loriol dans la description de son Macropneustes Ficheri dit textuellement: "Çà et là on distingue des fragments du fasciole qui était très marginal.» Cet échinide ne peut donc pas être compris dans les genres sans fasciole, et celui qu'il porte est probablement un fasciole péripétale, qui paraît très marginal, parce que les pétales ambulacraires s'étendent presque jusqu'au bord. Nous le plaçons, jusqu'à plus ample informé, dans le même genre que l'H. Lefebvrei; l'exemplaire est unique et la face inférieure est inconnue: toute classification ne peut être que prorisoire.

Niveal : Suessonien moyen.

Localité : Environs de Louxor.

Megapneustes grandis Gauthier. 1898, pl. II, fig. 5-6.

Notre intention était de prendre pour type du genre Megamenestes le Macropneustes crassus Agassiz. Mais le seul exemplaire connu étant en assez mauvais état, il nous a semblé plus prudent de recourir à une espèce nouvelle. M. de Loriol dans sa description du M. crassus ne parle pas de fasciole sous-anal, et, 
en effet, il ne doit pas en exister sur cette espèce, puisqu'il l'attribue au genre Macropneustes; on croyait à cette époque que ce genre ne portait pas de fasciole sous-anal. Le mauvais état de l'exemplaire du Muséum pouvant laisser quelque doute à cet égard, nous aimons mieux prendre pour type une espèce qui en est bien certainement dépourvue.

Dimensions : Longueur . . . . . . . . 115 millimètres

Largeur . . . . . . . . . 96 millimètres
Hauteur . . . . . . . 60 millimètres.

Espèce de très grande taille, assezz régulièrement ovale, allongée, un peu plus étroite en arrière qu'en avant, échancrée sensiblement au bord antérieur par le sillon impair et légèrement tronquée en arrière. Face supérieure élevée, convexe, plus renflée en arrière qu'en avant où elle se déprime un peu à partir de l'apex. Le point culminant se trouve ainsi placé en arrière de l'appareil apical, à 70 millimètres du bord antérieur. Côtés renflés, pourtour arrondi, épais; face inférieure à peu près plate. Apex excentrique en avant $50 / 115$.

Appareil apieal dans une légère dépression, très pen étendu, montrant quatre pores génitaux dont les deux postérieurs sont plus écartés que les autres; le corps madréporiforme déborde assez largement en arrière; les cinq pores ocellaires sont portés par de très petites plaques interealées daus les angles extérieurs.

Ambulacre impair logé dans un sillon à peu près nul au sommet, s'élargissant progressivement et se creusant peu à peu jusqu'au bord qu'il échancre fortement; il se continue à la face inférieure jusqu'au péristome. Zones porifères très rapprochées près de l'apex, très étroites, formées de petites paires de pores virgulaires, très ténus, séparés dans chaque paire par une cloison granuliforme. On ne distingue bien, de ehaque côté, que les 16 ou 17 premières paires qui se distaneent de plus en plus; les suivantes s'effacent 


\section{$-683-$}

bientôt et sont d'ailleurs de plus en plus éloignées, les plaques atteignant jusqu'à einq millimètres de hauteur. L'espace interzonaire est couvert d'une fine granulation entremêlée de quelques tuber'ules secondaires.

Aires ambulacraires paires situées dans une dépression du test large, évasée, peu profonde; elles sont longues et inégales, les antérieures plus courtes que les postérieures, s'étendant toutes presque jusqu'au bord; leur largeur est médioere relativement ì la taille de l'oursin. Zones porifères égales, assez étroites, formées de paires de pores linéaires, horizontaux, acuminés à la partie interne; les paires sont séparées par des cloisons granuleuses; elles sont an nombre de 44 dans chaque série des pétales antérieurs et de 57 dans les pétales postérieurs. L'espace interzonaire, plus étroit qu'une des zones, porte de petits tubereules. Les pétales antérieurs ont leur extrémité un peu infléchie en avant.

Aires interambulacraires larges, convexes à la partie supérieure, portant sur le milieu des plaques de chaque moitié une ligne de faibles nodules, assez accentués cependant pour produire au milieu de l'aire une sorte de dépression sensible jusqu'au bord.

Le péristome, par suite d'une cassure du test, n'est pas visible sur notre exemplaire; il était exeentrique en avant, loin du bord, au tiers environ de la longueur totale. Périprocte grand, ovale, s'ouvrant au milieu de la troncature postérieure, dans une aire entourée de faibles nodosités, avee une légère dépression au-dessous, qui est peut-être due à une eassure.

Tubercules primaires nombreux à la face supérieure, formant sur chaque plaque interambulacraire une série linéaire qui suit la courbe de la suture; ils sont plus multipliés, mais moins gros ì la partie antérieure, le long du sillon impair. La face inférieure est couverte sur toutes les aires interambulacraires de tubercules $i$ peu près semblables, assez serrés, uniformes, même sur le plastron. 


\section{- $684-$}

Fasciole péripétale étroit, bien visible sur notre exemplaire; il passe à l'extrémité des pétales ambulacraires sans remonter dans les interambulacres, sauf, légèrement, au-dessus du périprocte; ̀̀ la partie antérieure il est interrompu au milieu des aires interambulacraires, et disparaît complètement entre les deux lignes de nodules qui mettent en relief, comme nous l'avons dit, le milieu des plaques, de sorte qu'on ne le voit nulle part traverser le sillon impair, bien que sur ce point le test de notre exemplaire soit d'une netteté parfaite. Partout où il existe, le fasciole limite mal les gros tubercules; quelques-uns le franchissent et apparaissent au-dehors dans les interambulacres latéraux et postérieurs. Dans les interambulacres antérieurs, où le fasciole fait défaut en partie, les tubercules descendent jusqu'au bord sans interruption, diminuant un peu de volume vers le bas. Il n'y a aucune trace de fasciole sous-anal.

Le $M$. grandis n'est pas sans rapports avec le $M$. crassus; les ambulacres présentent la même disposition; mais notre exemplaire est plus allongé, moins élevé, plus déprimé en avant de l'appareil apical. La disposition des gros tubercules est aussi très différente; ils semblent être clairsemés et de dimensions médiocres sur l'exemplaire d'Agassiz, tandis qu'ils sont d'assez fortes dimensions, nombreux, serrés et formant des séries horizontales dans les aires interambulacraires de notre espèce.

Niveau : Suessonien supérieur.

Localité : Gebel Drounka près El-Syout.

Megapneustes crassus (Agassiz) Gauthier. Syn. : Macropneustes crassus Agassiz, Cutal. raisonné des Échinides, p. 115, 1847.

Desor, Synopsis des Échin. foss., p. 411, 1858.

$\gg \quad$ Lartet, Géol. de la Palestine, loc. cit., t. III, p. 84, 1872.
$\Rightarrow \quad$ de Loriol, Monographie, etc., p. 128, pl. x, fig. 1, 1a, pl. xi, fig. 1, 1880.

Cotteau, Paléntologie française, Ėocène, t. x, p. 179, 1886. 
Grande espèce, à base presque ovale, échancrée en avant, légèrement tronquée en arrière; face supérieure renflée, assez uniformément convexe; le point culminant parait à peu près central. Face inférieure presque plane; pourtour arrondi. Ambulacre impair dans un large sillon assez profond près du bord. Ambulacres pairs antérieur's divergents, un peu arqués en avant, logés dans des dépressions peu profondes, largement évasées; ambulacres postérieurs à peine plus longs, également déprimés. Péristome rapproché du bord antérieur; périprocte grand, ovale, à moitié de la hauteur de la troncature postérieure. Fasciole péripétale; point de fasciole sous-anal.

Niveau : Lutétien I.

Localité : Oasis de Moeleh.

Euspatangus formosus de Loriol, 1863.

Syn. : Euspatangus formosus de Loriol, Description de deux Échin. nummulit. de l'Égypte, Mém. soc. Phys. et d'Hist. nat. de Genève, t. xvir, rre partie, p. 4, pl. I, fig. 1, 1863.

Fraas, Geol. aus dem Orient, loc. cit., p. 270, 1867.

Lartet, Géol. de la Palestine, loc. cit., p. 84, 1872.

de Loriol, Monographie, etc., p. so, pl. xr, fig. 2-4, 1880.

> de Loriol, Eocäne Echinoideen, etc., p. 53, pl. xı, fig. 5-6, 1881.

> Cotteau, Puléontologie française, Éocène, t. r, p. 80, 1886 .

Espèce de grande taille, plus ou moins déprimée, quelquefois assez renflée, médiocrement échancrée en avant, formant à la face supérieure une courbe peu prononcée au milieu de laquelle se trouve le point culminant, sensiblement et régulièrement déclive à l'approche de la face postérieure. Appareil apical peu développé. Sillon impair à peine marqué à la face supérieure, large, mais peu profond au bord. Pétales ambulacraires longs, s'étendant jusqu'au pourtour, les postérieurs plus développés. Gros tubercules très abondants dans les interambulacres pairs, très rares MÉMOMRE, T. MI. 
dans l'impair. Fasciole péripétale limitant les tubercules; fasciole sous-anal entourant l'écusson.

La hauteur de cette espèce est variable: M. de Loriol indique de 0.33 à 0.39 par rapport à la longueur; nous avous sous les yeux un exemplaire qui domne la proportion de 0.455 .

Un autre de nos exemplaires a une forme carrée très remarquable; nous ne croyous pas cependaut pouvoir le séparer du type spécifique, auquel nous le joignons comme variété quadratus.

Niveau : Lutétien I.

Localités : Gebel Sidment (Fayoum), Mokattam.

Collections: P. de Loriol, Gauthier, Fourtau.

Euspatangus Cairexsis de Loriol, 1897.

Synn. : Euspatangus Cairensis de Loriol, Notes pour servir ì l'étude des Échinodermes, v, p. 4, pl. 1, fig. 1, 1897.

Espèce de taille plus petite que la précédente, mais lui ressemblant étroitement. M. de Loriol ne les a séparées que récemment, après avoir étudié des matériaux plus abondants rapportés d'Égypte par M. Mayer-Eymar. La première espèce étant sujette à de sensibles variations, nous ne trouvons guère dans celle-ci d'autres earactires constamment différents que son sillon impair un peu plus prononcé à l'approche dı sommet, et sa carène dorsale qui reste droite jusqu'à l'extrémité sans se courber vers la face postérieure comme chez l' Eus. formosus.

Niveau : Lutétien II.

Localité : Oualy el-Tih. Environs de Dimeh (Fayoum, rive occidentale du Birket-Karoun) (Garet Kä̈ser!! de M. MayerEymar).

Euspatangus tuberosus Fraas, 1867.

Syn. : Euspatangus tuberosus Fraas, Geol. aus dem Orient, loc. cit., p. 279, pl. vi, fig. 8, $186 \pi$.

de Loriol, Monographie, etc., p. 85, pl. xi, fig. 5, 1880. Cotteau, Paléontologie française, Éocène, t. I, p. 82, 1886. 
Grand fragment orné de gros tubereules, très usé, rapporté sans preuves certaines an genre Euspatangus. Cottean le rapporterait plus volontiers au genre Sarsella, et M. de Loriol lui trouve assez de ressemblanee avec le Breynia Vicentina Dames.

Niveau : ?

Localité : Rencontré dans les débris d'érosion de l'Ouady el'Til.

Euspatangus libycus de Loriol, 1881. Syn. : Euspatangus libycus de Loriol, Eocïne Echinoideen, etc., p. 52, pl. xr, fig. 4, 1881. \ Cottean, Paléntologie française, Eocène, p. 87, 1886.

Espèce de petite taille, assez rétrécie et subtrouquée ì la partie postérieure, plus large et légèrement éehancrée en avant. Appareil apical excentrique en avant; sillon impair insensible près du sommet, se déprimant peu à peu; pétales ambulacraires pairs étroits, les antérieurs transverses et logés dans une faible dépression, recourbés en arrière à l'extrémité; les postérieurs droits, moins divergents et complètement superficiels. Gros tubereules nombreux près du fasciole. Péristome assez éloigné du bord antérieur; périprocte piriforme, s'ouvrant au sommet de la face postérieure. Fasciole péripétale touchant le bord, au point d'être à peine visible d'en haut; fasciole sous-anal dessinant une forte sinuosité an-dessous du périprocte.

Niveau : Suessonien moyen.

Localité : El-Gouch Abou-Saïd, à l'Onest de Farafrah.

Plesiospatangus Cotteaui (de Loriol) l'omel, 1883.

Syu. : Euspatangus Cotteani de Loriol, Monographie, etc., p. 83, pl. xI, fig. s-10, 1880. Plesiospatangus Cotteani Pomel, Classif. méthod., p. 31, 1883.

》 Cotteau, Paléontol, française, Éocène, t. I, p. 88, 1886.

L'espèce déerite par M. de Loriol sous le nom d'Euspatangus Cotteaui ayant les pétales ambulacraires pairs logés dans des sillons, MI. Pomel en a fait le type du genre Plesiospatangus. Nous 
n'avous pas cru devoir faire entrer daus ce nouveau genre l'espèce précédente Eus. libycus, qui a les pétales pairs antérieurs dans une légère dépression et les pétales postérieurs superficiels; ce type intermédiaire nous parait avoir plus d'affinité avec les Euspatangus.

Nivean : Suessonien moyen.

Localité : Envirous de Louxor.

Maretia pendula (Agassiz) Cotteau, 1885.

Syn. : Spatangus pendulus Agassiz, Catal. raisonné des Échin., p. 114, 1847.

IIemispatangus pendulus Desor, Synopsis des Échin. foss., p. 417, 1858.

\ Lortet, Géol. de la Palestine, loc. cit., p. 84, 1872.

\ de Loriol, Monographie, etc., p. 77, pl. xI, fig. 8, 1880.

Maretia pendula Cotteau, Paléontologie française, Éocène, t. I, p. 42, 1885.

Cette espèce est représentée par un exemplaire unique rapporté du Sinaï par Lefebvre, et que M. de Loriol croit appartenir au Nummulitique, bien que la gangue ne contienne pas de nummulites. Il est bien certain que le genre Maretia est jusqu’à présent inconnu dans les terrains crétacés; il y a par conséquent des chances pour que, si cet individu provient du Sinaï, il ait été récolté par Lefebrre soit dans la partie iuférieure du cours de l'Ouady Feïran entre l'Onady Gharaonel et le Gebel Nezazat, soit entre le désert du Gaa et le Golfe de Suez dans la chaine dı Gebel Araba.

Il appartiendrait alors an Lutétien I.

Maretia depressa (Dubois) Cotteall, 1889.

Syn. : Spatangus depressus

Dubois, Voyage au Cancase, pl. 1, fig. 16, sans deseription, 1831.

$\quad$ Agassiz et Desor, Catal. raisonné, p. 114, 1847.

Henispatangus depressus Desor, Synopsis, p. 417, 1858.

» Lartet, loc. cit., p. 84, 1872.

» de Loriol, Monographie, etc., p. 79, pl. xi, fig. 6, 1880.

Maretia depressa Cotteau, Paléontologie française, Éocène, t. I, 1. 41, 1865.

Espèce encore assez mal connue, se distingue du $M$. pendula 
par ses ambulacres antérieurs plus étroits, ses ambulacres postérieurs moins larges aussi et arrondis à leur extrémité.

Niveau : Suessonien moyen.

Localité : Environs de Thèbes (Delanoue). - Agassiz parle d'un individı dı Sinaï.

Nous citons à part les espèces de la famille des Spatangidées décrites tout récemment par M. Mayer-Eymar, et dont nous n'avons eu connaissance qu'après avoir terminé notre manuscrit. Les descriptions beaucoup trop courtes de l'auteur et les figures insuffisantes qu'il a domnées sont seules à notre disposition; il ne nous sera pas toujours possible de bien apprécier les types spécifiques qu'il a établis.

Micraster (Epiaster) ultinus, p. 6, pl. vi, fig. 6.

Les deux genres auxquels M. Mayer-Eymar attribue cette espèce n'ont aucun représentant jusqu'ici dans l'époque tertiaire. Il ent donc été important de bien fixer le genre. M. Mayer ne le fait pas, et il constate que le contour de son unique exemplaire est celui du Toxaster néocomien!

Niveau : Suessonien I.

Localité : Gebel Garah près d'Assouan. - Exemplaire unique.

Hemiaster Wilcocksi, p. 6, pl. v, fig. 2.

Il nous est bien difficile de nous faire une opinion sur eet oursin; est-ce bien un Hemiaster ou un Ditremaster? M. Mayel ne s'occupe ni de l'appareil apical, ni des fascioles, et la figure qu'il a dessinée en dit encore moins que le texte. C'est un exemplaire unique.

Hemiaster (Periaster) Fourtali, p. 7, pl. v, fig. 1.

Nous n'insisterons pas sur la méthode déjà signalée de mettre une espèce dans deux genres à la fois; le texte ne parle toujours 


\section{$-690-$}

pas de l'appareil apical et des fascioles, et la figure ne nous apprend rien.

Localité : Mokattan.

Niveau : Parisien I. - Quatre exemplaires.

Hemiaster (Periaster) nubicus, p. 7 , pl. vi, fig. 2.

Localité : (Suessonien I), châne de collines entre Assonan et Kourkour.

Brissopsis Pasqualit, p. 7, pl. v, fig. 3.

Les ambulacres postérieurs sont bien divergents pour un Brissopsis, et il n'y a pas de paires de pores atrophiées, si ce n'est, peut-être, dans le pétale postérieur du côté droit.

Localité : Ramaga près d'Edfou. Suessonien moyen.

Linthia Hessi, p. 8, pl. vi, fig. 5 .

Niveall : Parisien II.

Localité : Bir Moussa. Carrières au sommet du Mokattam.

Schizaster indigenus, p. 8, pl. vi, fig. 4.

Espèce cordiforme, ayant sa plus grande largeur an milieu, rétrécie et arrondie en avant avec une échancrure à peine sensible, se resserrant rapidement en arrière, de hauteur moyenne, doucement déclive vers l'avant. Appareil apical très excentrique en arrière. Sillon antérieur à fond plat avec des bords très évidés. Ambulacres pairs antérieurs dirigés en avant, droits, assez longs et larges; les postérieur's très petits et très divergents. Dessous un pell convexe.

Niveau : Parisien I.

Localité : El-Alamne près de Beni Sonef.

Schizaster Moxgei, p. 9, pl. vi, fig. 3.

Un seul exemplaire ayant tout ì fait la forme d'un Micraster cor-anguinum, sauf la hauteur qui est de 24 millimètres; échancré 
en avant par le sillon impair. Appareil apical central; sillon large avec bords assez escarpés; ambulacres pairs dans des dépressions profondes, les antérieurs très divergents, les postérieurs formant un angle aigu.

Niveau : Suessonien moyen.

Localité : Milieu de Ouadi Syout.

Macropneustes Schweinfurthi, p. 9, pl. vi, fig. 1.

Niveau : Parisien I.

Localité : Oasis Moeleh. - Exemplaire unique. Rien dans la description ne prouve que c'est bien un Macropneustes.

Macropneustes Sickenbergeri, p. 10, pl. r, fig. 4.

Contour ovale, variant un peu dans sa longueur, en forme de casque, haut vouté avec le point culminant en arrière de l'appareil; partie antérieure plus on moins déclive et escarpée, bord légèrement échancré; partie postérieure en pointe émonssée. Apex très excentrique en avant. Ambulacres $11 n$ peu profonds, à fond plat et assez ouverts à l'extrémité. Zones porifères égales à l'intervalle qui les sépare. Sillon antérieur médiocrement large, très superficiel; dessous irrégulièrement plat. Tubercules supérieurs nombreux et épars, à peu près égaux, ceux du dessous plus inégaux et plus serrés.

L'auteur compare son espèce à l'Hypsospatangus Meneghini dont elle se distingue par ses ambulacres plus longs et plus larges ì l'extrémité, ainsi que par son point cnlminant en arrière de l'appareil an lieu d'être en avant, et par ses tubercules plus miformes et plus épars. Elle se distingue du M. crassus, que M. Mayer présume être du Parisien I, tandis que son type est du Suessonien moyen (Londinien I) par sa hauteur et son sommet excentrique. Elle nous parait se rapprocher beancoup du Megapneustes grandis, dont elle diffère par sa forme relativement plus élevée, par 
sa partie postérieure plus rétrécie, par son appareil apical plus exeentrique en avant, 0.35 de la longueur au lieu de 0.43 (d'après la figure), enfin par la disposition de ses tubereules que l'auteur déclare être petits, nombreux, épars, tandis que dans le $M$. grandis ils sont bien développés et forment des séries courbes horizontales très régulières. L'insuffisanee de la deseription de M. Mayer et de la figure qu'il donne ne nous permet pas de pousser la comparaison plus loin; de même que nous ne pouvons pas préciser si c'est un Macropneustes ou un Megapneustes.

Macropaeustes shimlis, p. 10, pl. vi, fig. 7.

Espèee ovale, à peine éehanerée en avant, assez large et verticale en arrière. Apex excentrique en avant; ambulaeres déprimés, un peu rétrécis à l'extrémité; ambulacres pairs antérieurs transverses, les postérieurs formant un angle très aigu. Cette espèce proviendrait de la même localité que le $M$. Lefebvrei, et s'en distingue par sa face supérieure en forme de toit et ses aires ambulacraires plus profondes.

Niveau : Suessonien moyen (Londinien I). Deux exemplaires.

\section{Époque miocène.}

Cidaris Adansi Wright, 1864.

Syn. : Cidaris Adamsi Wright, On the fossil Echinidae of Malta, Quart. journ. Geol. Soc., p. 474, pl. xxr, fig. 5, 1864.

- Fuchs, Beiträge zur Kenntniss der Miocenfauna Aegyptens und der libyschen Wiiste, p. 32, 1882.

M. Fuchs a examiné deux plaques interambulacraires eontigues qui lui paraissent semblables à celles de Wright au point qu'il n'hésite pas à les identifier. Il a étudié également un grand nombre de radioles qu'il attribue à cette espèee et qui ressemblent 
assez à ceux du Cid. avenionensis; il n'en est point domné de figures.

Niveau : Helvétien I.

Localité : Environs de Syouah. Gebel Ndefer.

Cidaris avenionensis Des Moulins, 1837.

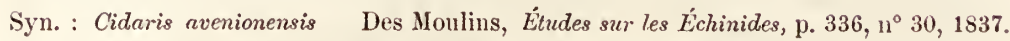
Cidaris, cf. avenionensis Fuchs, op. cit., p. 46, pl. xvr, fig. 9-12, 1882.

II. Fuchs n'ose pas affirmer absolument l'identité des radioles qu'il a recueillis au Gebel Geneffé avec ceux du Cid.avenionensis. Nous avons entre les mains un assez grand nombre de ces radioles; les uns terminés en pointe, les autres par une petite corolle; nons les avons soigneusement comparés avec une série recueillie en Provence sur les bords de l'étang de Lavalduc, nous retrouvons dans l'une et l'autre localité les mêmes variations, et nous n'y voyons aucune différence sérieuse; nous admettons done que ce sont bien les radioles du Cid. avenionensis qu'on rencontre au Gebel Geneffé. Toutefois il serait à désirer qu'on y recueillît aussi quelques fragments du test.

Niveau : Helvétien II. - Grès inférieurs avec Echinoneus Ar. tini et Schizaster sp.

Localités : Massif du Gebel Geneffé. - Tranchée du chemin de fer à Challouf.

Psammechinus Affinis Fuchs, var. depressa, 1882. Syn. : Psanmechinus affinis, var. depressa Fuchs, Beitrïge zur Kenntniss der Miocenfauna Aegyptens und der libyschen Wïste, 1882.

La mission Rholfs a trouvé dans l'oasis de Syouah un Psammechinus que M. Fuchs regarde comme une variété de celui qu'il a nommé ailleurs Ps. affinis. ${ }^{1}$ N'ayant sous les yeux que les

1. Cf. Fuchs : Ueber einige tertiüre Echiniden aus Persien, Sitzber. Wiener Akad. 1880 , Lxxxi, p. 97 .

MÉMOIRES, T. 11 . 88 
figures de l'espèce de la Perse, il nous est difficile d'aroir une opinion personnelle à ce sujet.

Le même auteur indique encore, comme rencontrés dans la région de Syoual, de nombreux fragments de Psammechinus qui paraissent appartenir à plusieurs espèces; ces matériaux sont insuffisants pour les déterminer avec certitude.

Niveau : Helvétien.

Psammechinus Monilis Desor (Desmarets).

M. Fuchs (op. cit., p. 45) donne ce titre et ne le fait suivre d'aucune explication. Il est possible qu'il ait rencontré cet Échinide au Gebel Geneffé, mais comme il n'en dit absolument rien, nous nous contenterons de remarquer d'une manière générale que c’est par erreur qu'on attribue cette espèce au genre Psammechinus : ses aires ambulacraires logées dans des sillons rectilignes avec les paires de pores presque directement superposées et non en triplets comme cliez les Echinus, ses tubercules encadrés d'une manière toute spéciale par de gros granules en font un des types les plus caractérisés du genre Arbacina Pomel.

Psammechinus dubius Agassiz, 1848.

Syn. : Psammechinus dubius Agassiz et Desor, Catalogue raisonné des Échinides, p. 65, 1848.

" Rothpletz, Stratigraphisches von der Sinaihalbinsel, Nenes Jahrbuch für Mineralogie, für 1893, p. 103.

M. Rothpletz eite cette espèce comme provenant de l'Ouady Etal (Sinaï). Je ne connais daus le Sinaï qu'mu seul Ouady de ce nom où je n'ai rencontré que du crétacé et quelques rares Crassatella, ef. Rothii Fraas, je ne vois done pas comment on aurait pu $\mathrm{y}$ trouver une espèce miocène.

Cette espèce a d'ailleurs été promenée d'un bout de la terre à l'autre et il est souvent difficile de s'en procurer les spécimens cités. 
Echinoneus AR'tini Gauthier, 1898, pl. II, fig. 7-8.

$$
\begin{aligned}
& \text { Dimensions : Longueur . . . . . . . 15 millimètres } \\
& \text { Largeur . . . . . . . . } 11 \text { millimètres } \\
& \text { Hauteur . . . . . . . . 8 } 81 / 2 \text { millimetres. }
\end{aligned}
$$

Espèce de petite taille, allongée, épaisse, rétrécie en arrière et en avant, à bords arrondis, eonvexe en-dessus et en-dessous. Apex légèrement excentrique en avant $(\tau / 15)$.

Appareil apical montrant quatre pores génitaux et cinq pores ocellaires dans les angles extérieurs; le corps madréporiforme rattaché à la plaque génitale antérieure de droite oecupe le centre.

Aires ambulacraires toutes semblables, superficielles, d'abord aigues près du sommet, s'élargissant à l'ambitus pour se rétrécir de nouveau en-dessous jusqu'au péristome. Zones porifëres déprimées dans de petits sillons, très étroites, formées de paires serrées et directement superposées de pores très fins, et se continuant sans grande modification jusqu'à la bouche; à la face inférieure cependant, les pores sont disposés plus obliquement; ils ne se multiplient pas aux approches du péristome.

L'espace interzonaire, légèrement renflé, porte de petits tubercules scrobieulés formant quatre rangées dans la partie la plus large qui atteint à peine deux millimètres. Aires interambulacraires assez larges, ornées de tubereules semblables à ceux des aires ambulaeraires, plus développés à la face inférieure.

Péristome subcentral, ovale, oblique à gauche, la pointe s'ouvrant à sept millimètres du bord antérieur. Périprocte situé à la face inférieure, en arrière du péristome, mal conservé sur nos deux exemplaires.

Nous avons déerit en 1891 un Echinoneus Thomasi de l'époque mioè̀ne, reeneilli en Algérie; notre espèce égyptienne s'en

1. Cf. Cotteau, Peron et Gauthier, Échinides fossiles de l'Algérie, fasc. x, p. 133, 1891. 


\section{- 696 -}

distingue assez faeilement : elle est plus allongée, plus cylindrique, plus épaisse; les aires ambulaeraires sont moins saillantes; les autres caraetères sont assez conformes; mais la physionomie générale est assez différente pour ne pas nous permettre de réunir les deux types. Cotteau a figuré et décrit une espèce miocène des Antilles ${ }^{1}$ à laquelle il n'a pas donné de nom spécifique à cause de la pauvreté des matériaux ì sa disposition. Notre regretté ami hésitait à affirmer l'existence du genre Echinoneus dans les terrains miocènes; il n'est plus possible d'en douter aujourd'hui. L'exemplaire des Antilles plus allongé que eelui d'Algérie est moins élevé que celui d'Égypte et porte à trois le nombre des espèces comnues jusqu'à présent pour l'époque miocène. Les espèees vivantes habitent les mers ehaudes et ne se distinguent que par des caractères peu accentués. M. Al. Agassiz n'en admet que deux, E. cyclostomus et E. semilunaris, au lieu de six ou sept admises d'abord par L. Agassiz et Desor; et même ainsi il n'est pas tonjours facile d'éviter la confusion.

Nous faisons figurer l'E. Thomasi à côté de l'E. Artini pour rendre plus facile la comparaison entre les deux types (fig. 9-10).

Nous avons dédié l'espèce égyptienne a S. E. Yacoub Artin pacha, président de l'Institnt Égyptien et sous-secrétaire d'État an Ministère de l'Instruction Publique.

Niveau : Helvétien II. - Grès brunâtres au pied du massif prineipal.

Localité : Gebel Geneffé.

Echinocyanus Thullei Gauthier, 1898, pl. Ir, fig. 11-13.

Dimensions : Longueur .......... 12 millimètres

$$
\begin{aligned}
& \text { Largeur . . . . . . . . 9 9 millimètres } \\
& \text { Hauteur . . . . . . . } 3 \frac{1}{1} / 2 \text { millimètres. }
\end{aligned}
$$

Nous désignons provisoirement sous ce nom un Echinocyamus

1. Cf. Cotteau, Échinides tertiaires des Iles St Barthélémy et Anguila, p. 14, pl. 1, fig. $28-30,1875$. 
d'assez grande taille relativement, et dont nous ne trouvons l'analogue nulle part. Il est de forme ovale, un peu plus rétréci en avant qu'en arrière; le bord est arrondi; la face supérieure paraît avoir été presque plane; la face inférieure, pulvinée sur les bords, est fortement déprimée à l'endroit du péristome. Le périprocte. très petit, de forme presque carrée, est à égale distance entre le bord postérieur et la bouche. L'exemplaire recueilli dans le miocène du Gebel Geneffé étant unique jusqu'à présent, il serait téméraire d'affirmer que nous sommes réellement en présence d'un type spécifique nouveau dans un genre si difficile et si répandu.

Localité : Gebel Geneffé, ancienne carrière Zizinia. - Helvétien II.

Amphiope truncata Fuchs, 1882.

Syn. : Amphiope truncata Fuchs, Beiträge zur Kenntniss der Miocenfauna Aegyptens und der libyschen Wiiste, p. 31, pl. x, fig. 1-4. Palacontographica, N. F. X. $2(\mathrm{xxx}), 1882$.

- Johannes Wallher, Die Korallenriffe der Sinaihalbinsel, geologische und biologische Beobachtungen, Band xiv der Abhandlungen der mathematisch-physischen Kilasse der königl. Sächsischen Gesellschaft der Wissenschaften, $\mathrm{n}^{0} \mathrm{x}, \mathrm{p}$. 454 (18) 1888.

Espèce d'assez grande taille, mince surtout en arrière, largement ovalaire en avant, plus dilatée en arrière et subtronquée; apex central; pétales ambulacraires médiocrement développés, assez larges, l'antérieur plus long que les autres; péristome central, très petit, périprocte petit, rond, éloigné du bord postérieur de huit millimètres; lunules presque ovales, pen ouvertes, plus éloignées de l'extrémité des pétales postérieurs que du bord.

Niveau : Helvétien I. - Calcaires bruns ant-dessus des Marnes feuilletées.

Localité : Environs de Syouah, Gebel Ndefer.

M. J. Walther (op. cit.) déclare avoir recueilli cette espèce aux environs de Kroum près de Tor (Sinaĩ) ce qui lui a fait classer la localité comme miocène. En 1896, 
j'ai passè près de trois mois à Tor; j'ai donc cherché le dit banc miocène et d'après la coupe figurèe par MI. Walther (op. cit., pl. vir, 9) je smis arrivé à un banc pétri de coraux qui m'ont paru avoir le même aspect que ceux du Gebel Hammam Moussa ses voisins, et par conséquent être pléistocènes. Je n'ai d'aillenrs, malgré mes rècherches, pu trouver aucun débris d'Amphiope. Il ne me reste donc qu'ả citer cette localité comme très donteuse, car je crois fermement qu'il y a eu errenr de la part du professeur d'Iéna.

Amphiope arcuata Filchs, 1882.

Syn. : Amphiope arcuata Fnchs, op. cit., p. 31, pl. xI, fig. 4-6, 1882.

Très voisine de l'A. truncata, cette espèce s'en distingue par sa forme plus circulaire avec échancrures moins prononcées, ses ambulacres plus petits et ses espaces interporifères plus larges; ses lunules sont plus ovales et les sillons de la face inférieure sont moins marqués et moins bifurqués.

Niveau : Helvétien I. - Calcaires bruns à Échinides an-dessus des Marnes feuilletées.

Localité : Environs de Syouah, Gebel Ndefer.

Scutella Amonis Fuchs, 1882. Syn. : Scutella Ammonis Fuchs, op. cit., p. 30, pl. rx, fig. 1-4, 1882.

Espèce subcirculaire, un peu plus large que longue, légèrement échancrée en face des ambulacres postérieurs. Espace interporifère à peine plus large qne l'une des zones porifères. Péristome pentagonal, les sillons se bifurquent près du péristome et sont pen ramifiés près du bord. Périprocte à moitié distance du péristome et du bord.

Niveau : Helvétien. - Calcaires à Pholas Ammonis.

Localités: Environs de Syouah, Gebel Ndefer. Collines de Pacho,

Scutella rostrata Fuchs, 1882. Syn. : Scutella rostrata Fuchs, op. cit., p. 30, pl. xir, fig. 4-6, 1882.

Se distingue du Sc. Ammonis par sa taille plus petite et plus comprimée et le bord arrière légèrement rostré entre les denx 
échancrures. Les sillons de la face postérieure se bifurquent plus près du péristome et sont moins ramifiés. Le périprocte est plus rapproché du péristome que du bord.

Niveau : Helvétien. - Calcaires à Amphiope.

Localité : Environs de Syouah, Gebel Ndefer.

ScUtelia ZitTeli Beyrich, 1882.

Syn. : Scutella Zitteli Beyrich, Veher einige geognostische Beobachtungen G. Schnceinfurth's in der Wiiste zwischen Cairo und Suez, Mém. Ac. des Sc. de Berlin, 1883.

Schweinfurth, Une visite au port de Tobrouk, Bnll. Inst. Égypt., 1884.

Scutella subrotunda Fraas non Lamark, Aus dem Orient, 1867.

Beyrich a nommé ainsi une Scutelle qui a, dit-il, la forme du Sc. subrotunda Lam. des environs de Bordeaux, mais qui se distingule non seulement de cette dernière, mais de toutes les autres Scutelles et même de tous les autres oursins par ses ambulacres en forme de feuilles, complètement irréguliers, ce qui permet de reconmaitre l'espèce à l'aide du moindre fragment. Il dome la figure d'un ambulacre.

Niveau : Helvétien II.

Localités : Gebel Damasq, Deir el-Bedah, Gebel Aouebet, plateau de la Marmarique près du port de Toubrouk.

Scutelita Innesi Gauthier, 1898.

Dimensions : Longueur . . . . . . . . . . 111 millimètres

Largeur . . . . . . . 110 millimètres

Hauteur . . . . . . . . . 10 millimètres.

Espèce de grande taille aussi large que longue, très mince relativement, un peu rétrécie en avant, subtronquée en arrière, ayant sa plus grande largeur au tiers postérieur. Pourtour légèrement onduleux avec un large sinus à l'extrémité des pétales pairs postérieurs; nous ignorons s'il y arait aussi un sinus à l'extrémité des 
pétales pairs antérieurs. Face supérieure légèrement convexe; face inférieure plate. Apex à peu près central.

Pétales ambulacraires superficiels, claviformes, à peu près égaux entre eux, longs de 37 millimètres, larges de 15. Zones

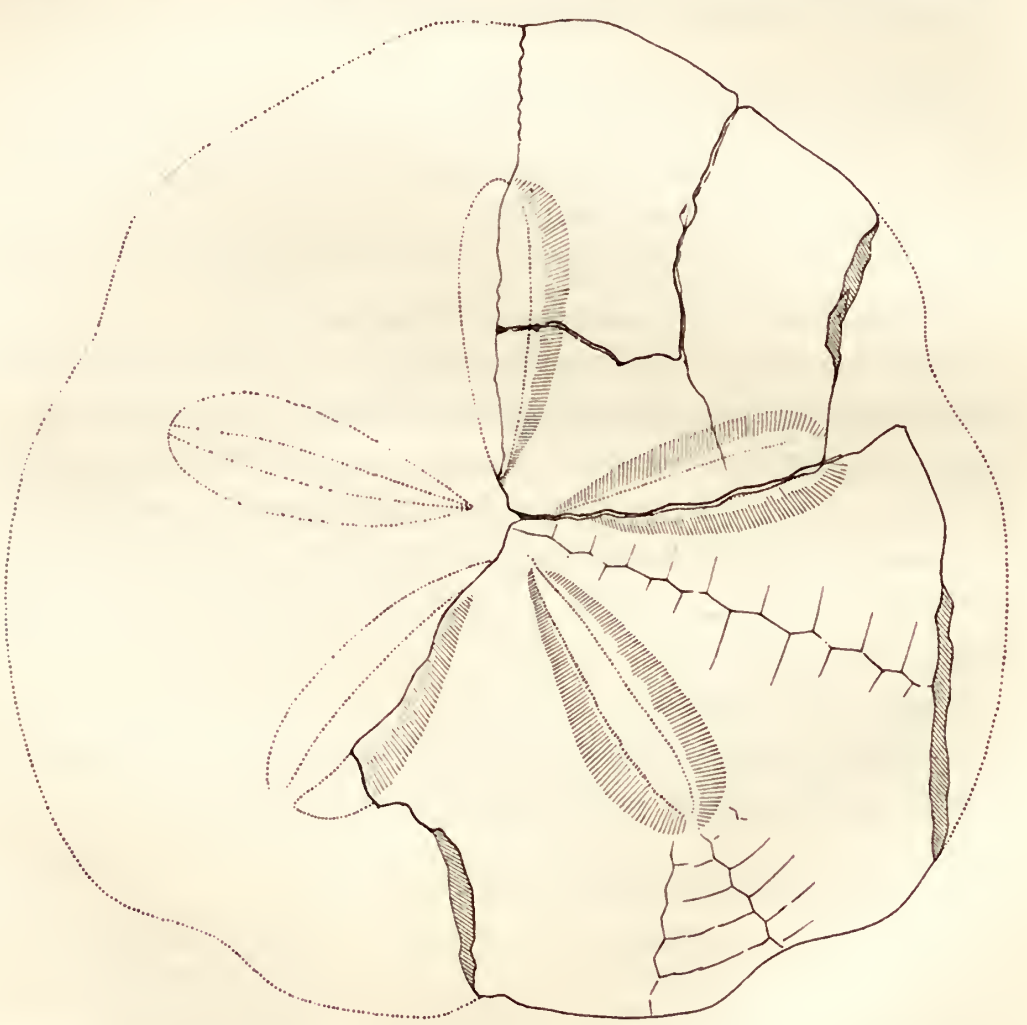

porifères présentant leur plus grand développement au tiers inférieur, assez bien fermés à l'extrémité; pores petits conjugués par de longs sillons filiformes. Les zones atteignent chacune six millimètres en largeur ne laissant entre elles qu'une zone étroite de trois millimètres. 


\section{$-701-$}

Périprocte petit, rond, placé à la face inférieure à onze millimètres du bord.

Nous ne possédons pour déerire eette espèce que la moitié du test, représentant le eôté droit dans toute sa longueur. Ce fragment nous permet de restituer assez eertainement le pourtour total, vu la symétrie de ees Échinides. L'ensemble nous paraît se distinguer de toutes les espèces eommues; la physionomie est très différeute du Sc. subrotunda Lam., qui est plus large que long; il ne ressemble pas plus au Sc. gibercula Michelin qui est de plus grande taille encore, mais plus épais et plus arrondi; les sinus du bord, à l'extrémité des ambulacres postérieurs, distinguent également notre type du Sc. paulensis Agassiz. les espèces décrites par F'uchs, Sc. Ammonis et Sc. rostrata, sont de taille plus petite et offrent une pliysionomie très différente.

Nons avons dédié cette espèce au Dr Walther Innes-Bey, conservateur du Musce de l'École de Médecine de Kast el-Aïny.

Niveau : Grès à Echinolampas amplus et Ostrea vestita. - Helvétien II.

Localité : Petites eollines à un kilomètre de distance du pied du massif du Gebel Geneffé, entre la montag'ne et la station de Geneffé.

Clypeaster Rholfas Fulis, 1882.

Syn. Clypeaster Rholfsi Fuchs, op. cit., p. 28, pl. x, fig. 5-

Forme subpentagonale ì angles trìs obtus, face supérieure terminée par un bourrelet en arrière. Apex juste au milieu de la longueur; faee inférieure plane. Péristome logé danss un infundibulum à peine aceusé : périproete ovale moins éloigné du bord que soll diamètre.

Cette espèce reeueillie par Zittel ì Syoualı et déterminée par Fuehs en 1882 avait été déjà trouvée par Rholfs ${ }^{1}$ qui ne l'avait indiquée et dessinée que sous le rocable «Asterit».

1. Cf. Rholfs, Von Tripolis nach Alexandrien, vol, II, pl. II, Bremen, 1871.

MẺMOIRES. T. III. 
Niveau : Helvétien : Brèche à Scutelles.

Loealités : Environs de Syouah et plateau de la Marmarique. Gebel Nidefer et plateau entre Syouah et Aradj.

Clypeaster stbplacunaries Fuehs, 1882. Syn. : Clypeaster subplacuncrius Fincls, op. cit., p. 29, pl. xr, fig. 1-3.

Les exemplaires de cette espèce fossile, aussi variés que ceux dı C.placunarius. virant dans la Ner Rouge, se disting'uent très difficilement de l'espèee actuelle; de toutes les différenees indiquées par Fuchs, une seule reste eonstante : e'est que, dans l'espèce fossile, l'extrémité des pétales ambulacraires est mal fermée par les zones porifères, tandis que, dans l'espèce vivante, elle l'est complitement. Un lapsus calami fait dire à l'auteur juste le contraire, p. 30, lignes 3 et 4 ; mais cette eonfusion est corrigée au bas de la page 45 .

Niveau : Helvétien avec C. Rholfsi.

Localités : Environs de Syoulah, Gebel Ndefer et collines de Paeho.

Clypeaster isthuidus Fuchs, 1882. Syn. : Clypeaster isthmicus Fuchs, op. cit., p. 45, pl. xII, fig. 1-3, 1852.

Espèee d'assez grande taille, mais peu élevée (21 mill.). presque aussi large que longue; pourtour pentagonal à angles très arrondis, surtout les postérieurs, avec des sinus peu profonds an bord des interambulacres latéraux et postérieurs. Apex à peu près central, montrant einq pores génitaux eontigus au madréporide, pétales ambulaeraires assez longs et larges, assez saillants, mal fermés à l'extrémité : tubereules assez gros à la face supérieure, plus développés à la face inférieure.

Fuehs déclare ne pas bien comaître le péristome; un de nos exemplaires nous le montre très net; il s'ouvre dans un infundibulum pentagonal, profond tout au plus de einq millimètres, évasé; 
mais l'évasement est de médiocre étendue et n'excède pas vingteing millimètres dans sa plus grande largeur. Le périprocte est près du bord.

Nous ne possédons pas d'exemplaire entier de cette espeee, bien que nous en ayons des fragments considérables et nombreux; l'ensemble est plus pentagonal que ne l'est le $C$. Rholfsi; la partie postérieure est non seulement moins arrondie, mais tronquée et entamée par un large, mais peu profond sinus.

Nivean : Helvétien II. - Calcaires à Heterostegina.

Localités : Gebel Geneffé. - Gebel Aonebet.

Clypeaster Prieni Gauthier, 1898, pl. III, fig. 1-3.

Dimensions : Longueur . . . . . . . . 105 millimetres

Largeur . . . . . . 102 millimètres

Hauteur ........ 25 millimètres.

Espèce d'assez grande taille, peu élevée, pentagonale à angles arrondis, à peu près en ligne droite sur les ê̂tés, avec sinus rentrant à la partie postérieure. Partie supérieure plate sur la marge, se relevant en pyramide au milieu; bord mince, mais non tranchant, la partie la plus épaisse, qui est l'angle antérieur, atteignant sept millimètres, et la plus mince, le milieu du sinus postérieur, quatre millimetres. Dessous plat dans la partie qui correspond it la marge supérience, puis déprimé pour l'infundibulum qui oceupe un espace équivalent à la base de la pyramide pétalifère. Apex eentral.

Appareil apieal pen développé, pentagonal, avec les einq pores génitanx contigus aux angles du madréporide. Aires ambulacraires relevées au milieu de la face supérieure en une pyramide de vingt millimètres de hauteur. Pétales saillants, ovales, arrondis à la partie supérieure, l'antérieur impair et les deux postérieurs égaux, longs de 39 millimètres, larges de 19; les deux antérieurs pairs 


\section{- $704-$}

un peu plus courts; la marge au-delà des pétales est de 15 millimètres en avant, 20 sur les côtés et 22 en arrière. Zones porifères en talus sur le flane des pétales, n'excédant pas 4 millimètres en largeur, se rapprochant à leur extrémité, tout en laissant le pétale assez ourert. Pores petits, les externes allongés, aeuminés, les internes ronds; ils sont conjugués par un long sillon; les petites côtes qui séparent les paires sont ornées de six on sept granules très fins. Espace interzonaire renflé, comme nous l'avons dit, orné de séries transverses de fins granules, chaque plaque en portant deux rangées.

Aires interambulacraires déprimées, à peine relevées vers la base des pétales, toujours plus basses que ceux-ci, mais arrivant presque à nivean au sommet où elles sont trìs aignes; elles portent des tubercules très fins, semblables à eeux des plaques interzonaires.

Péristome pentagonal, mesurant de six à sept millimètres de diamètre, placé au fond d'un infundibulum très évasé, oecupant presque la moitié de la largeur de la face inférieure, profond de 11 millimètres. Périproete petit, rond, éloigné du bord postérieur de 3 à 4 millimètres. Sillons de la face inférieure bien marqués, étroits, long's, s'étendant presque jusqu'au bord. Les tubereules de la face inférieme sont un peu plus gros que ceux de la face supérieure.

Le Cl. Priemi se distingue du Cl. isthmicus Fuehs, qu'on tronve dans la même loealité par sa forme presqu'aussi large que longue (105-102 mill.), tandis que la figure donnée par Fuchs mesure 126-114 millimetres (nons eonsidérons comme une erreur typographique les chiffres domnés par le texte, qui indiquent longueur $=130$ millimètres, largeur $=137$; l'auteur dit dans sa description presqu'aussi large que long); par sa hauteur plus considérable 25 millimètres au lieu de 21 , quoique l'exemplaire du $C l$. 
isthmicus soit sensiblement plus grand; par ses pétales bien plus renflés et arrondis; par ses aires interambulaeraires beaucoup plus déprimées dans la partie pétalée; par ses eôtés plus droits, par son bord postérieur plus sinueux; par son vaste infundibulum atteignant en largeur presque la moitié de la face inférieure et en profondeur près de la moitié de la hauteur totale du test. Nous ne connaissons pas d'autre espèce qu'on puisse comparer étroitement avec notre type; le $C l$. intermedius Des Moulins est plus allongé; ses pétales ambulaeraires sont assez semblables, mais sa pyramide supérieure présente un aspect bien différent par suite de son bord déclive, et l'infundibulum, quoique évasé, est loin de l'être aussi largement que celui du $C l$. Priemi. Les espèces basses d'Algérie à grand infundibulum, comme $\mathrm{Cl}$. peltarius Pomel, sont trop différentes pour que nous essayons d'en comparer les caractères spéeifiques; le $C l$. acclivis Pomel, qu'on trouve aussi au Gebel Geneffé, est tout à fait distinct par ses pétales bien plus saillants et son infundibulum moins évasé.

Nous avons dédié cette espèce à notre excellent confrẻre de la Société Géologique de France. M. F. P'riem.

Niveau : Helvétien II en-dessous des griès à Ostrea vestita et a Echinolampas amplus.

Loealité : Gebel Geneffé.

Clypeaster Genefinesis Gauthier 1898, pl. iII, fig. 4-6.

Dimensions : Longueur . . . . . . . . 90 millimetres

Largeur . . . . . . . . . 79 millimètres

Hauteur . . . . . . . . 23 millimetres.

Espèce d'apparenee presque rectangulaire, sauf la partie antérieure qui est rétrécie; eôtés droits ou à peine sinueux, angles très amortis, arrondis; bord partont épais, mais plus en avant qu'en arrière; face supérieure peu élevée, déelive, de l'apex au bord, couverte en partie par l'étoile assez saillante que forment 
les ambulacres; face inférieure bombée sur les bords, puis se déprimant vite pour former la dépression péristomale. Apex légèrement excentrique en avant $\left({ }^{41} / 90\right)$. Nous supposons que la longueur était 90 millimètres, notre seul exemplaire entier ne mesure que 85; mais l'extrémité antérieure est cassée et e'est en la reconstituant par la prolongation des lignes du pourtour que nous arrivons au chiffre indiqué.

Appareil apical peu développé, pentagonal, avee les pores génitaux écartés du madréporide, mais à très faible distance, un millimètre à peu près.

Pétales ambulacraires médiocrement renflés, ovales, les postérieurs et l'antérieur impair plus longs que les autres, mesurant 33 millimètres, environ les denx tiers du rayon, tandis que les antérieurs pairs n'en mesurant que 29 à 30 , leur plus grande largeur est sur toutes les aires de 17 millimètres. Zones porifères en pente sur les côtés de l'aire, larges au plus de 5 millimètres, partout en ligne courbe, se rapprochant assez à l'extrémité, mais sans fermer le pétale. Pores petits, les externes allongés et acuminés, les internes ronds, eonjugués par un sillon linéaire; les petites côtes, qui séparent les paires, portent sept granules très fins. Espace interzonaire en forme de fuseau, assez aigu aux deux extrémités, convexe au milieu et s'élevant de 3 millimètres au-dessus de laire interambulaeraire; les tubercules sont beaucoup plus gros que ceux des eostules de la zone porifère, et il y en a deux rangées transverses par plaques. Aires interambulacraires médiocrement déprimées entre les pétales, légèrement convexes à la base, étroites au sommet, portant des tubereules semblables à ceux de l'espace interzonaire.

Péristome à peu près rond, s'ouvrant au fond d'un infundibulum très évasé, un peu plus long que large, occupant la moitié du diamètre de la face inférieure et profond de 14 mil- 
limètres. Périprocte petit, rond, s'ouvrant à 5 millimètres du bord.

Les tubercules de la face inférieure sont beancoup plus gros que ceux de la face supérieure.

Le $C l$. geneffensis diffère beaucoup du Cl. Priemi, malgré la forme commune de l'infundibulum; le bord est bien plıs épais, la marge plus déclive et moins grande; les pétales ambulaeraires sont moins relevés; le bord postérieur est droit et non sinueux; la face inférieure pulvinée et non plate montre des tubercules plus accentués. Le Cl. Halaensis d'Archiac, du nummulitique de l'Inde, n'offre de ressemblance lointaine que par son bord épais; son pourtour est bien régulièrement ovale et ses pétales sont moins élevés. Ce n'est pas de ee côté qu'on peut ehercher des rapports étroits. La ressemblance du $C l$. geneffensis est plus frappante avec le $C l$. crassicostatus Agassiz (Moule Q 12). Le pourtour est le même, le bord est d'une épaisseur analogue; cependant il n'est pas possible de rémir ces deux espèces; notre type est beaucoup trop bas, ses pétales ambulacraires sont trop peu rentlés, ses aires interambnlacraires sont trop peu déprimés pour qu'on puisse l'assimiler au type d'Agassiz, même en tenant compte de la différence de taille qui d'ailleurs n'est pas considérable; l'extrémité des zones porifères enveloppe plus étroitement les pétales; la marge postérieure est plus spacieuse, bien que l'individu soit plus petit; à la face inférieure, l'infundibulum du $\mathrm{Cl}$. crassicostatus est beaucoul' moins évasé, quoique l'exemplaire soit plus grand, le périprocte est plus rapproché du bord, la surface est plate et non pulvinée. A part une sorte d'analogie dans la forme générale, tous les caractères étudiés séparément sont différents dans les deux types.

Niveau : Helvétien II, couches à Cl. isthmicus.

Localité : Gebel Geneffé. 
Clypeaster pextadactylus Peron et Gauthier 1891, pl. iv, fig. $5-9$.

Syn. : Clypeaster pentadactylus Peron et Gauthier, in Cottean, Peron et Ganthier, Échin. foss, de lalgérie, fasc. x, p. 183, pl. vi, fig. 4-5, 1891.

Nous avons déja décrit cette espèce parmi les fossiles du Mioeène algérien; la longue description que nous en avons donnée s'applique très exaetement dans tous ses détails an type égyptien que nous avons entre les mains. Ce dernier est de taille plus petite, mais le test est nettement dégagé et suffisamment conservé, quoique la partie postérieure ait été détruite à partir de l'extrémité des pétales ambulacraires. La partie antérieure qui manquait chez notre exemplaire algérien est fortement rétrécie et allongée, épaisse; le bord est très renflé sur tout le pourtour; les pétales ambulacraires très saillants, assez étroits, ont leur's zones porifères entièrement appliquées eontre leurs flanes; l'espace interzonaire eylindrique se poursuit au-delà des zones porifères par un renflement qui va jusqu'an bord. Les aires interambulacraires sont très déprimées et se réduisent à moins d'un millimètre de largeur près du sommet; les tubereules sont gros partout; sur les petites côtes qui séparent les paires de pores, il n'y en a ginère que trois bien développées, mais entre eeux-ei il y a une rangée de granules qui remplit l'espace inoceupé par les tubercules; ì la face inférieure les tubercules très gros et très serrés se touchent l'un l'autre, et domnent ainsi an test un aspect rugueux très earactéristique.

La partie inféricure, très nette sur notre nouvel exemplaire, nous permet de modifier un détail de la description que nous en avions domnée : le mauvais état de eette partie ehez notre premier type ne nous avait pas permis de mesurer l'infundibulum; nous avons dit qu'il atteignait presque le tier's de la largeur; sur notre exemplaire égyptien qui n'a en cet endroit que 70 millimètres de large au lieu de 100, l'évasement de l'infundibulum atteint 
33 millimètres, éest-ì-dire presque la moitié de la largeur du test et il devait en être de même sur notre exemplaire de l'A urès, dont la partie inférieure renflée, comme nous l'avons dit, a été refoulée par une compression qui a rétréci l'infundibulum. Le péristome est, chez notre exemplaire égyptien, à 13 millimètres au-dessus de la face inférieure, l'oursin entier mesurant 30 millimètres en hauteur.

Nous renvoyons à nos Échinides fossiles de l'Algérie pour la comparaison du Cl. pentadactylus avec les autres espèces du groupe des Crassicostati; e'est certainement le type oì les pétales ambulacraires forment la saillie la plus considérable et la plus perpendieulairement détacliée au-dessus du plan des interambulacres.

Niveau : Helvétien II, Grès à Echinolampas Amplus et Ostrea Vestita au-dessus des calcaires à Heterostegina.

Localités : Gebel Geneffé. Le type algérien provient d'EIHammam, daus la vallée de l'Oued Abdi, Aurès.

Clypeaster ACClivis Pomel, 1887, pl. Iv, fig. 1-4. syn. : Clypeaster acclivis Pomel, Paléont. de l'Algérie, Échinotermes II, p. 210, B, pl. xxi, fig. 1-9, 188 i.

- Cottean, Peron et Gauthier, Échin. joss. de l'Algérie, fasc. x, p. 18:2, 1891.

D de Loriol, Descript. des Echin. tertiaires th Portugal, p. 18, pl. v, fig. 2. 1896.

Dimensions : Longueur ......... 110 millimetres

Largeur . . . . . . . . . 100 millimetres

Hauteur . . . . . . . 37 millimètres.

Individu de taille moyenne, à pourtour pentagonal, avec angle antérieur arrondi et les quatre autres tronqués et arrondis; bord assez mince partout, un peu plus épais en avant, légèrement sinueux sur les côtés et un peu plus profondément en arrière. Face 
inférieure plate sur les bords, profondément déprimée autour du péristome. Apex légèrement excentrique en arrière $(55 / 110)$.

Appareil apical de grandeur moyeme, en forme de petit bouton, avec les pores génitaux placés aux angles du corps madréporiforme. Pétales ambulacraires trìs élevés, formant une forte saillie subhémisphérique, rétrécis à l'extrémité, mais restant assez ouverts et continués par une saillie décroissante du test qui vient expirer près du bord. Zones porifëres situées sur le flane du pétale, débordant à peine à la base du côté de l'interambulacre, atteignant six millimètres dans leur plus grande largeur; les cloisons qui séparent les paires de pores sont ornées de quatre à six petits granules. Espace interzonaire fortement convere, couvert de granules presque aussi fins que ceux des cloisons des zones porifères, formant trois rangées transverses par plaque.

Péristome pentagonal, large de 9 millimètres, placé an fond d'un infundibulum évasé, mesurant 38 millimètres pour une largeur totale de 100 à la face inférieure; des bourrelets ornent les bords à l'endroit oì il se courbe pour plonger dans le test. Sillons ambulacraires assez prononcés, s'effaçant à mesure qu'ils s'éloignent du eentre. l'ériprocte rond à 2 millimètres du bord.

Nous abrégeons la deseription de cette espèce déjà domée ailleurs par M. Pomel, M. de Loriol et nous-même. Nous nous arrêterons seulement aujourd'hui sur la comparaison du Cl. acclivis avee le $C l$. pentadactylus qu'on trouve tous deux au Gebel Geneffé. Les deux types sont trìs différents; quoique présentant l'un et l'autre les caractères les plus accusés du groupe des Crassicostati, ils ont une physionomie très distincte; ehez le Cl. pentadactylus, les angles du pourtour pentagonal sont moins accusés, surtout les antérieurs pairs; le bord est toujours bien phus épais, les pétales sont plus détachés par suite de la plus grande dépression des aires interambulacraires, et la transition entre les 


\section{$-711-$}

deux aires est plus anguleuse; dans l'appareil apical les pores génitaux sont séparés du eorps madréporiforme; la face inférieure est pulvinée et n'est plate nulle part jusqu'à la dépression de l'infundibulum qui est plus large et moins nettement pentagonal que dans l'autre espèee; les tubereules à la faee supérieure comme ì la face inférieure sont beaucoup plus gros. Il suffit d'avoir sous les yeux un exemplaire de ees deux elypéastres pour être convaincu qu'ils ne sauraient appartenir à la même espèce.

Niveau : Helvétien II, Calcaires en-dessous des conclies à Pecten Malvinae.

Loealité : Gebel Geneffé. En Algérie cette espèce se trouve dans le Cartennien (miocène inférieur) d'El-Biar.

ECHINOLAMPAS AJIPLUS Fuchs, 1882. Syn. : Echinolampas amplus Fuchs, op. cit., p. 27, pl. xx, fig. $5-8$.

- Fuchs, op. cit., p. 45.

Espèce presque eirculaire, peu élevée (26 millimètres pour 95 de longueur), eonvexe à la partie supérieure, plate en-dessous avee bord arrondi et légèrement pulviné. Appareil apical presque central, un peu en avant. Pétales longs s'étendant jusqu'au bord, assez larges, inégaux, l'impair plus eourt que les autres, les postérieurs pairs plus longs que les antérieurs. Zones porifïres assez larges, presque égales en longueur dans l'ambulaere impair, la branche antérieure plus droite et plus eourte que l'autre de cinq à six paires de pores dans tous les pétales pairs.

Péristome pentagonal, plus large que long, montrant les bourelets et le floscelle ordinaires au genre; périprocte transverse situé près du bord à la partie inférieure.

L'exemplaire dont nous venons de résumer la description provient de l'Oasis de Syouah; nous ne le eommaissons que par ee qu'en dit M. Fuehs; eet auteur rapporte au même type, à titre de variété de plus grande taille, d'antres individus qu'il a recueillis 
au Gebel Geneffé. Nous arons sous les yeux plusieurs exemplaires de cette variété qui atteint jusqu'à 120 millimètres de longueur et 37 de hauteur; nous croyons aussi que c'est le même type; nous n'y royons guère d'autre différence que celle de la taille.

Niveau : Helvétien II, Gries à Ostrea vestita.

Localités : Syouah Gebel Nilefer, très abondant au Gebel Geneffé et an Gebel Aouebet. - Nous possédons un individu appartenant à la variété de grande taille, recueilli en Algérie daus le miocène du Sud-Est de Batua.

\section{ECHINOLAMPAS nov. sp.}

M. Fuchs décrit sous cette désignation un exemplaire en très maurais état, provenant de Syouah; il est arrondi, fortement convexe et se distingue de toutes les espèces commues; il est très voisin de l'E. hemisphaericus Lam., que M. Mayer-Eymar dit avoir rencontré daus le miocène du Gebel Chelloul à 3 kil. au Sud des Pyramides de Ghizeh," plus encore de l'E. pyramidalis Abich, dont il ne diffère que par la présence d'un floscelle bien développé. tandis qu'Abieh dit que l' E. pyramidalis n'en a pas.

Pliolampas Pioti Gauthier, 1898. pl. ini, fig. 7-10.

Dimensions : Longneur . . . . . . . 37-42 millimetres

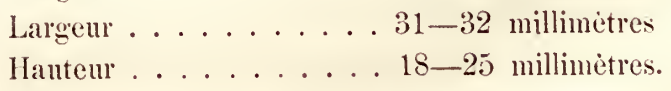

Espèce assez grande pour le genre, épaisse, allongée, ovale, un peu rétrécie en avant, ayant sa plus grande largeur au tiers postérieur. un peu acuminée en arrière. Face supérieure renflée, ayant sa plus grande élévation à l'appareil apical, déclive aux extrémités, convexe sur les côtés; bord arrondi; face inférieure pul-

1. Cf. Mayer-Eymar, Revision der Formenreihe des Clypeaster altus. 
vince arec une médiocre dépression daus la région du péristome. Apex exeentrique en avant $\left({ }^{15} / 3_{3}\right)$.

Appareil apieal peu développé, montrant sur un de nos exemplaires quatre pores génitaux, les deux antérieurs plus rapprochés que les postérieurs; sur un autre exemplaire il parait n'y aroir que trois pores génitaux : e'est l'antérieur gauehe qui manque; cette particularité n'est pas rare dans le genre Pliolampas. Le corps madréporiforme occupe le centre de l'appareil et déborde un peu en arrière; au milieu il écarte légèrement les génitales pour aller jusqu'aux ocellaires qu'il ne courre pas.

Aires ambulacraires toutes semblables; pétales superficiels, assez larges, mal fermés à l'extrémité, l'antérieur impair et les postérieurs égaux, les deux antérieur's pairs plus courts que les autres et plus divergents. Zones porifères droites, égales dans chaque pétale, formées de pores inégaux, les externes allongés en fente, les internes moins développés et à peu près ronds; il y a environ 23 paires de pores par zone dans les pétales pairs antérieur's et 4 ou 5 de plus dans les autres; les paires de pores sont séparées par une petite côte portant 3 ou 4 granules; l'espace interzonaire peu développé, égale en largeur une des zones; il est couvert de petits granules semblables à ceux des aires interambulaeraires.

Péristome un peu excentrique en avant, pentagonal, plus long que large, avee des phyllodes assez développés et des bourrelets marqués, mais peu saillants; une petite bande d'apparence lisse s'étend en arrière jusqu'au bord. Périprocte à la partie acuminée de la face postérieure, au milieu d’un rostre peu accentué, également visible en-dessus et en-dessous, mais plus porté vers la face inférieure. 'Tubercules ordinaires aux Cassidulidées, un peu plus gros en-dessous qu'en-dessus.

Nous n'arous pas à revenir iei sur le genre Pliolampas qui, 
comme nous l'avons démontré ailleurs, est une transformation des Echinantus à l'époque miocène. Le Pl. Pioti est assez abondant; malheureusement il n'est pas toujours bien conservé; sa taille est plus grande que celle des espèces algériemnes $P l$. medfensis Peron et Gauthier et $P l$. Weschi Pomel; il est aussi plus étroit en arrière que ce dernier et il a les pétales ambulacraires beaucoup plus développés. Le Pl.Vassali Wright (sub Pygorhynchus) de Malte est de taille bien inférieure; il reproduit assez bien la forme générale de notre type; ses pétales ambulacraires sont moins développés, son apex est plus central; l'auteur paraît d'ailleurs ne l'avoir figuré qu'à l'aide d'un exemplaire de conservation médiocre. Le $P l$. elegantulus Millet (sub Echinolampas) a la taille à peu près égale à celle de nos exemplaires; il a les pétales ambulacraires également développés, mais sa forme est plus élargie et relativement plus courte.

Nous avons dédié eette espèce à II. J.-B. Piot-Bey, vétérinaire en elıef des Domaines de l'État au Caire et Membre de l'Institut Égyptien.

Niveau : Helvétien II, Couehes au-dessous du Nivean des Heterostegina.

Localités : Gebel Geneffé. Gebel Aouebet.

Brissopsis FraAsi Fuchs, 1882. Syn. : Brissopsis Fraasi Fuehs, op. cit., p. 43, pl. xvin, fig. 4-5.

Nous avons entre les mains un exemplaire de plus petite taille que celui qu'a décrit M. Fuchs, ear il ne mesure que 30 millimitres de longueur au lieu de 41; malheureusement il est peutêtre eneore moins bien conservé. La forme est la même : le test est déclive d'arrière en avant, ayant son point eulminant sur la carène dorsale postérieure; le pourtour est ovale et légèrement polygonal; la face inférieure est renflée daus la région du plastron; l'appareil apical est excentrique en avant, le sillon impair assez 
large; les pétales pairs sont logés dans des dépressions profondes, tous assez eourts, les antérieurs plus longs que les postérieurs, bien plus divergents, mais non infléehis; les zones porifères sont plus larges ehaeune que l'espace interzonaire, et les séries antérieures montrent 5 ou 6 paires de pores atrophiés près du sommet. Le péristome est détruit sur notre exemplaire, et M. Fuehs ne l'a pas vu davantage sur le sien; le périprocte est an sommet de la face postérieure, qui est rétréeie à cet endroit. Les tubereules ont été en grande partie détruits; on en voit eependant encore quelquesuns assez aceentués sur les eôtés près du bord; la surface, polie par les agents atmosphériques, n’a conservé aucune trace des faseioles.

Niveau : Helvétien II, Calcaires gréseux à Cidaris avenionensis.

Localité : Gebel Geneffé, versant oriental.

Agassizia Zitteli Fuehs, 1882. Syn. : Agassizia Zitteli Fuchs, op. cit., p. 44, pl. 1, fig. 5-8.

Espèce de petite taille, ovale, renflée à la partie postérieure jusqu’a l'apex, qui est situé aux deux tiers de la longueur, et de là lentement déelive en avant et plus brièvement en arrière. Face inférieure légèrement bombée.

Ambulacre impair invisible, situé dans une très faible dépression. Pétales ambulacraires pairs antérieurs longs, étroits arqués à l'extrémité, ne présentant que la zone postérieure, l'autérieure étant atrophiée; pétales postérieurs complets, égalant à peine en longueur la moitié des antérieurs. Péristome semi-lunaire, au quart autérieur; périproete rond au sommet de la faee postérieure. Fascioles effacés.

Niveau : Helvétien II.

Localité : Gebel Geneffé. 
Pericosures Lronsi Gauthier, 1898, pl. IV, fig. 10-11.

Dimensions : Longueur . . . . . . . . 56 millimètres

Largenr . . . . . . . . . 50 millimètres

Hauteur . . . . . . . . 32 millimetres.

Exemplaire de taille moyenne pour le genre, eordiforme, subeonique à la partie supérieure; pourtour arrondi, fortement échaneré par le sillon antérieur; face inférieure eonvexe surtout dans la région du plastron; face postérieure triangulaire, peu élevée; apex un peu excentrique en avant.

Appareil apical dans une petite dépression, montrant trois pores génitaux, l'antérieur de droite faisant défaut. Les einq plaques ocellaires sont placées dans les angles extérieurs des génitales; le eorps madréporiforme couvre en partie la plaque interambulaeraire antérieure de droite. oceupe le milien de l'appareil et se prolonge en arrière entre les neellaires qu'ils séparent.

Ambularre impair logé dans un sillon assez profond, étroit près de l'apex, s'élargissant régulièrement jusqu'au borl où il eause une échanerure de 12 millimètres de large. Zones porifires formées de paires obliques de très petits pores, rapproehées près du sommet, mais se distançant vite, ear les plaques sont hautes de 2 nillimètres des le tiers supérieur et augmentent ensuite rapidement. L'espace interzonaire est oeeupé par des granules inégaux et quelques petits tubercules vers le bas.

Pétales ambulacraires pairs logés dans des sillons assez profonds et bien limités, longs de 20 millimètres pour les antérieurs et de 18 pour les postérienrs; larges de 4 millimètres. Zones porifères formées de paires de pores ovalaires, les externes un pen plus longs que les internes, eomptant 28 paires dans les pétales antérieurs et 23 dans les postérieurs; l'espace interzonaire est plus étroit qu'une des zones.

Le péristome de notre unique exemplaire a été détruit. Péri- 
procte placé en haut de la face postérieure, transverse, largement ouvert.

Fasciole péripétale en ligne brisée, remontant assez haut dans les interambulaeres; faseiole marginal visible seulement au-dessous du périprocte, les bords de l'oursin étant presque partout cassés.

La forme subeonique de sa partie supérieure donne au P. Lyonsi un aspeet tout partieulier; on ne saurait le eonfondre avee le $P$. Peroni Cotteau, du Miocène de la Corse, dont la partie antérieure est bien plus abrupte; il se rapprocherait plutôt du P. latus Agassiz, avee lequel il n'est pas sans affinité. Notre type est relativement plus allongé, la hauteur est moins considérable; les interambulaeres antérieurs sont plus aplatis et forment ainsi dans cette région une pente plus déelive, tandis que e'est tout le eontraire dans la région postérieure dont la pente est plus faible; le sillon antérieur est moins ereusé et plus large; la partie postérieure est plus rétrécie. La disposition des pétales ambulacraires est à peu près la même, sauf que les postérieurs sont plus ereusés et moins évasés dans l'espèee de la Corse. Les caractères divergents nous paraissent assez aceentués, pour que nous ne puissions pas réunir les deux types.

Nous avons dédié cette espèce au Cant. H. G. Lyons. R. E. Directeur du Service Géologique d'igypte.

Niveau : Helvétien II. - Conehes à Pecten Malvinae.

Localités : Gebel Geneffẻ, Gebel Aonebet, Gebel Damasq.

\section{SCHIZASTER sp.?}

J'ai recueilli au Gebel Geneffé six ou sept exemplaires appartenant au genre Schizaster, mais tellement détériorés et déformés qu'il n'est pas possible de les assimiler sûrement à aueune des espèces eonnues, ni d'en faire des types spécifiques nouveaux. Tous sont de taille moyenne ou petite. Un seul fait exeeption et mesure 71 millimètres en longueur, 64 en largeur, la hauteur était 
proportionnée, mais notre sujet étant déformé et écrasé, le chiffre exact que domerait la mesure de l'exemplaire, tel que nous l'avons sous les yeux, ne pourrait qu'induire en erreur. L'apex presque central, à peine rejeté en arrière; les pétales postérieurs longss pour le genre, les pétales antérieurs bien développés et s'étendant jusqua 12 ou 13 millimètres du bord; le sillon impair médiocrement élargi et fortement creusé sans entamer excessivement l'ambitus lui domnent beaucoup de ressemblance avec le Sch. Parkinsoni Defrance; mais nous ne pouvons pas établir nettement cette assimilation; le test, outre qu'il est déformé, est tellement usé et corrodé que nous ne sommes pas mêmes certains du genre, et que nous pourrions tout aussi bien être en présence de quelque grand Opissaster, comme on en a rencontré en Algérie et au Portugal. Un autre exemplaire plus petit, avec son appareil très excentrique en arrière, ses sillons ambulacraires très creusés et limités par des carènes aigues, rappelle de très près le $S c h$. Scillae; mais la conservation est insuffisante. Nous ne pouvons rien dire des autres exemplaires qui sont trop endommagés.

Brissus Aegrptiacus Gauthier, 1898, pl. III, fig. 11-12.

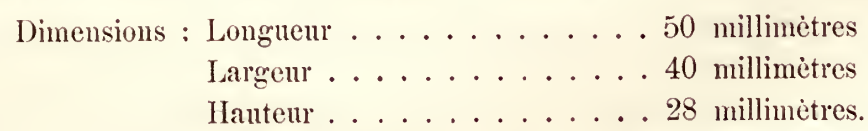

Exemplaire de taille moyemne relativement assez large et élevé, arrondi en avant, à côtés médiocrement infléchis et presque droits. Face supérieure très déclive en avant et sur les flanes, avec carène dorsale presque horizontale entre l'apex et la face postérieure; bord arrondi, face inférieure renflée. Apex excentrique en avant $\left({ }^{17} / 50\right)$.

Appareil apical ordinaire au gemre, montrant quatre pores génitaux dont les deux postérieurs sont plus écartés et plus ouverts; 
le corps madréporiforme sépare ces deux derniers et se prolonge au-delà de l'appareil.

Ambulacre impair superfieiel, peu visible sur notre exemplaire; nous n'en voyons que les sept premières paires de pores, qui sont très exigues et assez rapprochées; le reste est empâté; il n'y a aneune apparence de sillon antérieur.

Pétales ambulacraires pairs antérieurs placés dans des sillons bien marqués, mais de profondeur médiocre perpendiculaire ì l'axe longitudinal du test; droits et très légèrement infléchis en avant à leur extrémité; ils mesurent 14 nillimètres en longueur et presque 4 en largeur. Zones porifères bien développées, légèrement inégales, la postérieure étant la plus large; elles comptent dans chaque série environ 25 paires de pores ovales et petits; l'espace qui sépare les deux zones est très étroit et réduit ì me simple rangée de gramnles ou de petits renflements qui séparent elaque paire de celle qui est en face; les deux extrémités ont une tendance à se rapproeher. Pétales postérieurs peu divergents, suivant de près la earène dorsale, légèrement infléchis en-dehors a l'extrémité, beaucoup plus long's que les antérieurs (19 millimìtres); on y compte environ 30 paires de pores dans chaque zone.

Péristome placé an quart antérieur, transverse, large, labié en aurière. Fasciole péripétale très sinneux, remontant dans l'interambulacre entre les sillons ambulacraires; fasciole sous-anal bien visible, mais incomplet daus notre exemplaire dont la partie postérieure est détériorée. Tubercules assez gros et serrés à la partie antérieure, plus petits et plus uniformes en arrière des ambulacres pairs antérieurs, sauf quelques-uns près du sommet dans les aires interambulacraires latérales; à la face inférieure, les tubereules les plus gros sont aussi en avant du péristome; les autres, moins saillants, mais bien marqués, sont serrés et entourés d'un 
cercle de petits granules dont ils n'occupent pas exaetement le centre.

C'est la première fois que le genre Brissus est signalé daus le Miocène de l'Égypte. Bien que le type générique soit très constant et ne présente que des différences spéeifiques peu aceentuées, notre exemplaire nous paraît ne pouvoir être rapporté à aucune des espèees fossiles recueillies ailleurs. Les deux types déerits en Algérie, B. Gouini Pomel et B. Nicaisei Peron et Gauthier, sont moins élevés, moins larges relativement et ont les pétales postérieurs moins allongés; le $B$. Cordieri, qui n'est guère comnu que par un moule en plâtre d'Agassiz, est plus allongé et a l'apex plus exeentrique en avant; les autres espèees méditerranéemes éteintes, B. cylindricus Ag. et B. latus W right, offrent des formes plus étroites ou plus larges; le B. unicolor Klein, qui vit dans la Méditerranée, est plus allongé; ses pétales postérieurs, quoique longs, ne s'étendent pas aussi près du bord; ses sillons ambulacraires, à taille égale, sont plus étroits, et la bande longitudinale, qui sépare les zones porifères, est lisse, an lieu d'être ornée par les renflements dout nous arons parlé.

Niveau : Helvétien II, Grès inférieurs avec Echinoneus Artini et les Schizaster.

Loealité : Gebel Geneffé.

\section{Lovenia? sp.}

J'ai recueilli au Gebel Geneffé un fragment malheureusement très insuffisant d'un grand Spatangö̈de, eonsistant en une partie d'interambulacre près du bord; ce fragment montre à eôté d'un reste de pétale ambulacraire de gros tubercules logés dans des serobicules très profonds et qui paraissent déprimés au-delà de l'épaisseur du test; ils forment deux séries verticales de quatre tubereules chacune. La face inférieure de ee fragment est aussi 
conservée et les tubercules du dessous, nombreux et serrés en lignes assez régulières, augmentent de volume à mesure qu'ils s'éloignent du bord. Néanmoins, il n'y a pas là de quoi déterminer ce fragment: ce n'est pas un Euspatangus; le bord serait plus épais et les gros tubercules, limités par un fasciole, ne descendraient point si bas; ce peut être un reste de Lovenia ou de Sarsella ou même de Maretia comme M. ocellata Defrance; cependant les scrobicules nous paraissent trop profonds pour ce dernier genre.

Notre fragment ressemble beaucoup à la moitié d'un autre fragment appelé par Fraas Euspatangus tuberosus et figuré par M. de Loriol (Monographie, pl. xI, fig. 5). Fraas aurait recueilli ce deruier daus les détritus de l'Éocène de l'Onady el-Tih. Le nôtre est miocène, et nous n'insistons pas, parce que de tels matériaux ne peuvent pas nous autoriser à insister. M. Fuchs cite aussi au Gebel Geneffé un Hemispatangus sp.? (p. 43) et se contente d'ajouter : «Fragment indéterminable;» c'est peut-être un reste du même échinide que le nôtre.

\section{Époque pliocène.}

Clypeaster Aegrptiacus Wright (in collect.).

Syn.: Clypeaster aegyptiacus Michelin, Monographie des Clypéastres fossiles, 1. 121, pl. xxiv, fig. a-g, 1861.

Fraas, Aus dem Orient, tome I, 1869.

Fuchs, Beitrïge zur Kenntniss der Miocenfauna Aegyptens und der libyschen Wiiste, 1882.

Beyrich, Ueber eine geologische Beobachtung G. Schweinfurth's in der Wiiste zwischen Cairo und Suez, Mém. Ac. des Sc. de Berlin, 1883.

Mayer-Eymar, Die Formenreihe des Clypeaster altus, Vierteljahresschrift der natuf. Gesellschaft in Zürich, 1897.

Fourtall, Les sables à Clypéastres des environs des Pyramides de Ghizeh, Bull. Inst. Égypt., 1898. 
Clypenster pliocenicus Seguenza, Le formazioni tertiarie nella provincia di Reggio, p. 215, pl. xv, fig. $2 \pi, 1880$.

Espèce de grande taille, de forme générale presque régulièrement pentagonale, allant en s'amineissant ì partir du sommet des ambulacres : face supérieure bombée sous les ambulaeres, un peu exeavée sous le eorps madréporiforme. Corps madréporiforme pentagonal, un peu plus bas que les parties élevées des ambulacres.

Aires ambulacraires larges, arrondies, entr'ouvertes vers la base, et oceupant les deux tiers de la longueur de hant en bas, bombées, pétaliformes et présentant quelquefois des irrégularités dans les sillons porifères et leurs eloisons.

Zones porifères, larges avee sillons ereux terminés par des pores ronds à l'intérieur et allongés à l'extérieur, chaque paire de pores est séparée par une large cloison ornée de 7 à 8 tubereules.

Péristome subpentagonal au fond d'un infundibulum assez profond : périprocte submarginal, un peu eordiforme; la pointe tournée vers le péristome.

Hors de l'Égypte, le Cl. aegyptiacus a été recueilli par Mr. le Mesle sur la eôte Est de la Tunisie, aux îles Kuriat, en face de Monastir, dans des eouches plioeènes renfermant l'Anapesus maurus Pomel, l'Echinolampas Orbignyi Cotteau et deux autres espèces d'Echinolampas inédites. Nous croyons, comme Beyrich, que le $C l$. pliocenicus Seguenza doit être identifié avee l'espèce qui nons occupe; la figure domnée par l'auteur italien reproduit bien la physionomie de eertains exemplaires égyptiens, car le type est très variable en hauteur. Malheureusement Segunenza n'a donné que des figures réduites de moitié, ce qui rend l'interprétation difficile et parfois incertaine, et, de plus, il ne domne point de description. Ce Clypéastre est un des fossiles caractéristiques de son étage Zanéléen ou partie inférieure du Pliocène; il y est abondant comme en Tunisie et comme en Égypte. 


\section{$-723-$}

Niveau : ${ }^{1}$ Sables gris agglutinés arec Strombus, ef. coronatus Defr. Plaisancien.

Localités : Gebel Chelloul (Garet Loriol! de M. Mayer-Eymar) à 3 kilomètres au Sud de la grande Pyramide de Ghizeh. Ravins du pied Onest de l'Attaka (Schweinfurth). Il semble étomnant que le Pliocène d'Ég'ypte n'ait fourni jusqu'à ce jour qu'un seul échinide. Des recherches ultérieures nous ont fait déeouvrir dans le même gisement deux autres espèees, un Echinolampas malhenreusement en trop mauvais état pour permettre une détermination eertaine et un Echinocardium sp. n. que nous déerirons dans le premier supplément.

1. Pour l'établissement du niveau et la discussion des indications des autres auteurs se rapporter à mes notes sur Les sables ì Clypéastres des environs des Pyramides, Bull. Soc. Géol. de France, 1898. 


\title{
RÉSUMÉ MÉTHODIQUE.
}

Dans ce catalogue nous avons décrit on cité 153 espèces d'Égypte se répartissant en 64 gemres. La plus grande partie appartient sans contredit an tertiaire, qui comprend 40 genres et 121 espèces, tandis que le crétacé ne donne que 31 espèces comprises en 22 genres. Nous en donnons ici un résumé méthodique. Dans ce résumé, les caractères italiques indiquent les espèces et les genres nouveaux; la lettre A. signifie que l'espèce se trouve anssi en Algérie; T., en 'Tunisie; E., en Europe; S., en Syrie.

\section{SPATANGOÏDES.}

(21 genres et 63 espéces.)

\author{
Crétacés. \\ (Echinocorys ovatus, Zittel. E. \\ Micraster sp. Zittel. \\ Linthia oblonga, d'Orbigny. E. \\ Periaster elatus, d'Orbigny. E. \\ Epiaster distinctus, d'Orbigny. E. \\ Hemiaster Fourneli, Deshayes. A., 'T., E. \\ - gracilis, Cottean. E. \\ - procclivis, Peron et Gauthier. A. \\ - Heberti, Peron et Gauthier. A., T., E., S. \\ - Batnensis, Coquand. A., T. \\ - cubicus, Desor. E.
}




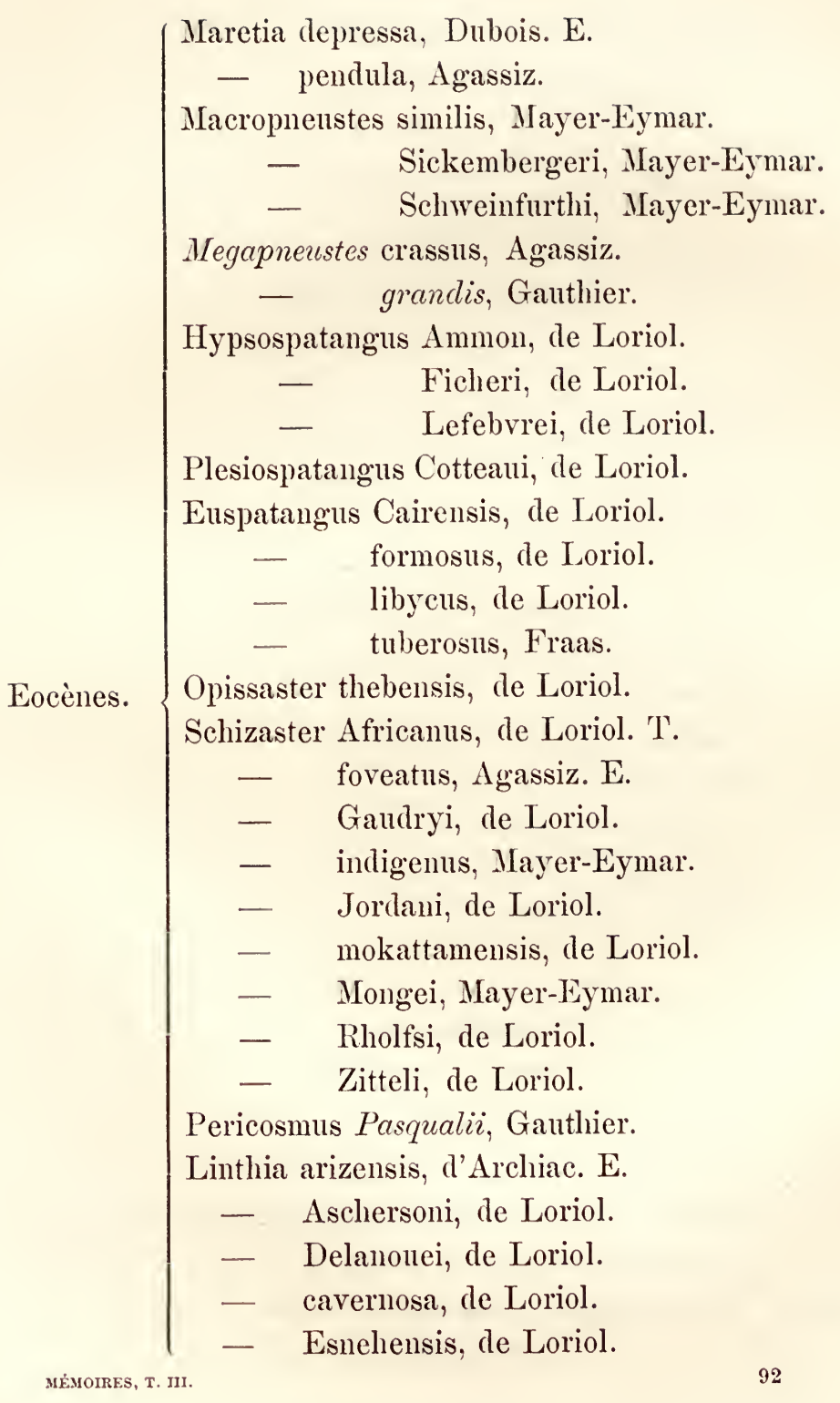




\section{Linthia Hessi, Mayer-Eymar. \\ - latisulcata, de Loriol. \\ - Navillei, de Loriol. \\ Hemiaster Archiaci, de Loriol. \\ - Pellati, Cotteau. E. \\ - Fourtaui, Mayer-Eymar. \\ - nubicus, Mayer-Eymar. \\ Éocènes. \\ Miocènes. $\left\{\begin{array}{l}\text { Lovenia sp. } \\ \text { Brissus aegyptiacus, Gauthier. } \\ \text { Schizaster sp. }\end{array}\right.$ \\ - Schweinfurthi, de Loriol. \\ - Wilcocksi, Mayer-Eymar. \\ Micraster ultimus, Mayer-Eymar. \\ Anisaster gibberulus, Cotteau. \\ Brissopsis angusta, de Loriol. \\ - Lorioli, Bittner. E. \\ - Pasqualii, Mayer-Eymar. \\ Palaeostoma Zitteli, de Loriol. \\ Pericosmus Lyonsi, Gauthier. \\ Agassizia Zitteli, Fuchs. \\ Brissopsis Fraasi, Fuchs.}

\section{Cassidulidés.}

(12 genres et 30 espèces.)

Crétacé. $\left\{\begin{array}{l}\text { Claviaster cornutus, d’Orbigny. } \\ \text { Nucleolites Luynesi, Cotteau. S. } \\ \text { Echinobrissus pseudominimus, Peron et Gauthier. A. }\end{array}\right.$

Éocènes. $\left\{\begin{array}{l}\text { Cassidulus amygdala, Desor. E. } \\ \text { Echinolampas africanus, de Loriol. T. }\end{array}\right.$ amygdala, Desor. E. 


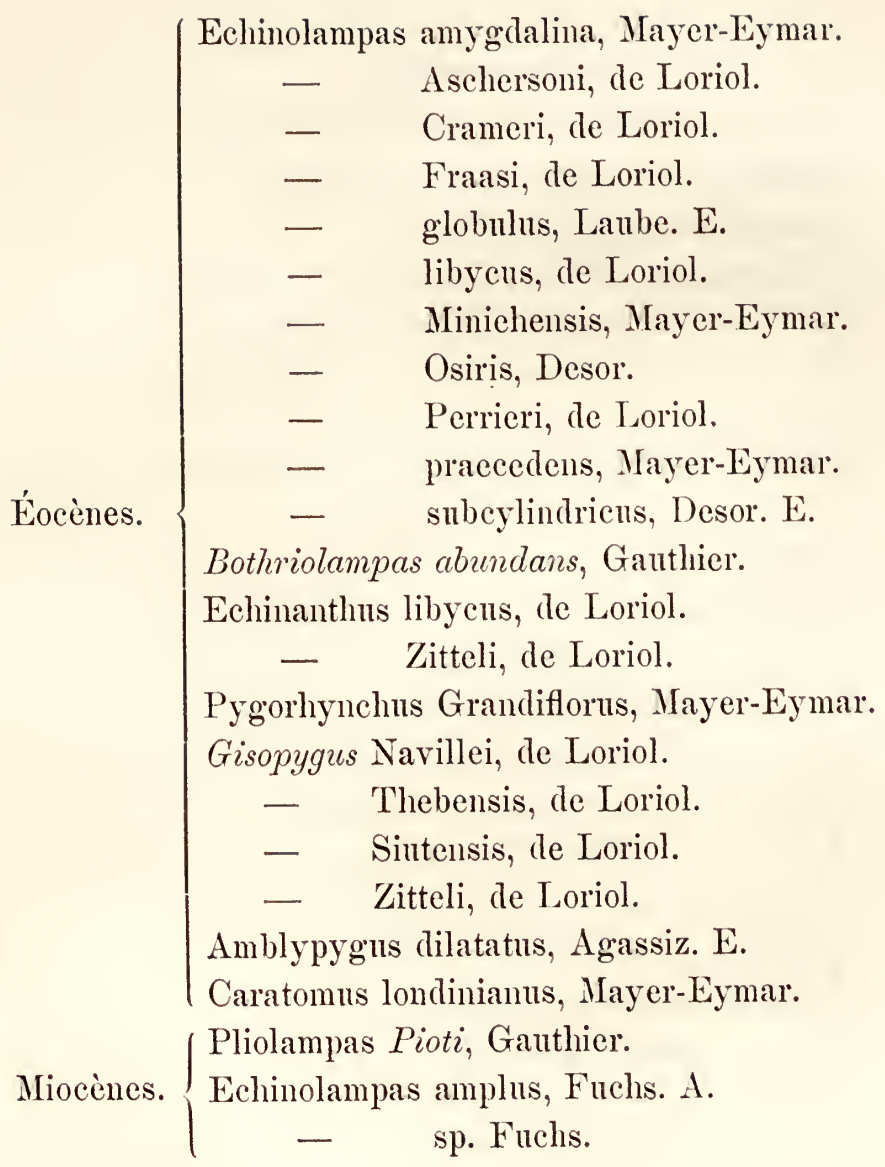

EChinoneidés.

(1 genre et 1 espéce.)

Miocène. \{ Echinoneus Artini, Gauthier. 
ECHinoconidés.

(3 genres et 5 especces.)

Crétacés. $\left\{\begin{array}{l}\text { Echinoconus aegyptiacus, d'Orbigny. } \\ \text { Discoidea pulvinata, Desor. } \\ \text { Holectypus excisus, Desor. A., T., E., S. } \\ -\quad \begin{array}{l}\text { crassus, Cotteau. T., E., S. } \\ --\end{array} \text { cenomanensis, Gueranger. A., T., E., S. }\end{array}\right.$

Fibularidés, Scutellidés et Clypeastridés.

( 7 genres et 23 espèces.)

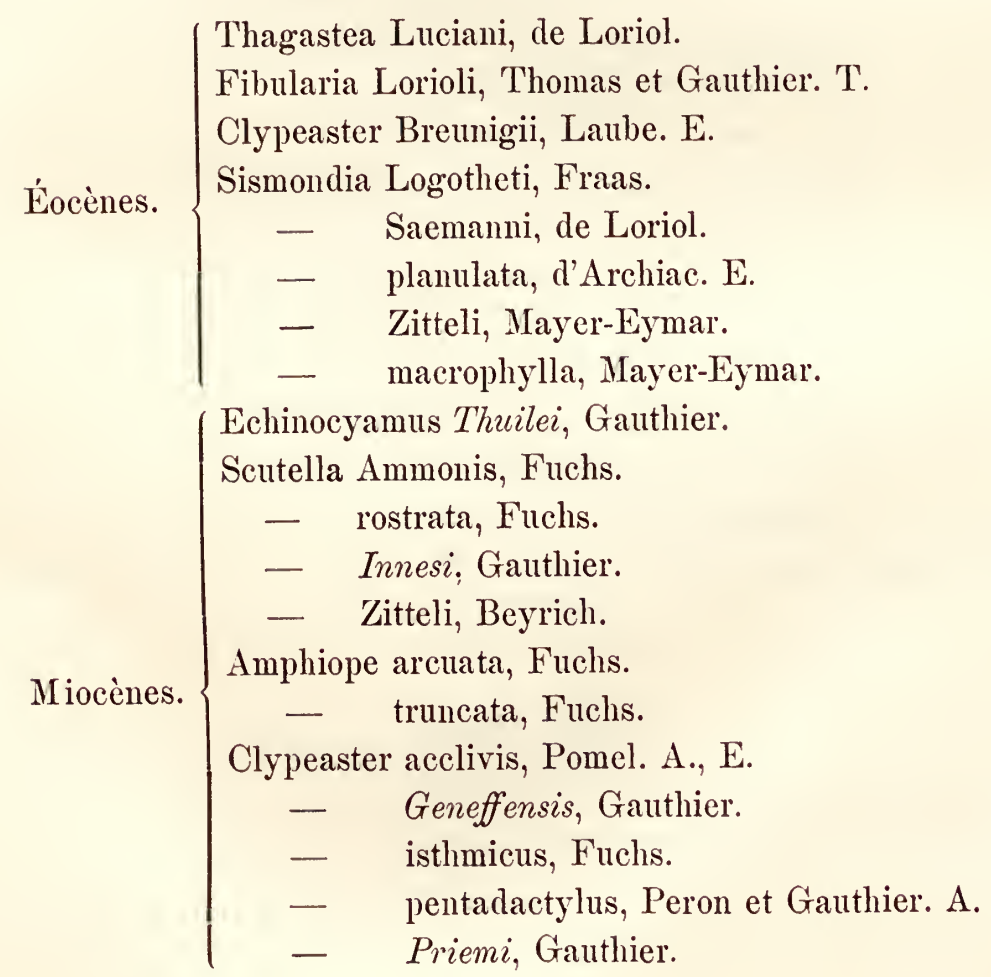




\section{$-729-$}

Miocènes. $\left\{\begin{array}{cc}\text { Clypeaster subplacunarius, Fuchs. } \\ - & \text { Rholfsi, Fuchs }\end{array}\right.$

Pliocène. $\{$ Clypeaster aegyptiacus, Wright. T., E.

CONOCLYPÉIDÉS.

(1 genre et 2 espéces.)

Éocènes. $\left\{\begin{array}{cc}\text { Conoclypeus conoideus, Goldfuss. E. } & \text { Delanouei, de Loriol. }\end{array}\right.$

Cidaridés.

(5 genres et 12 espèees.)

Carboniférien. \{ Archaeocidaris sp. Beyrich.

Crétacés. $\left\{\begin{array}{l}\text { Cidaris glandaria, Lang. S. } \\ \text { Pseudocidaris Pasqualii, Gauthier. } \\ \text { Rhabdocidaris Crameri, de Loriol. }\end{array}\right.$

Éocènes. $\left\{\begin{array}{cc}\text { Porocidaris Schmideli, Munster. } \\ \text { Rhabdocidaris itala, Laube. E. } \\ -\quad & \text { miniehensis, Mayer-Eymar. } \\ - & \text { Zitteli, de Loriol. } \\ - & \text { Lorioli, Mayer-Eymar. } \\ - & \text { solitaria, Mayer-Eymar. }\end{array}\right.$

Miocènes. $\left\{\begin{array}{cc}\text { Cidaris Adamsi, Wright. E. } \\ -\quad \text { avenionensis, Des Moulins. E. }\end{array}\right.$

SALÉNIÉES.

(1 genre et 1 espèce.)

Crétacé. \{ Salenia batnensis, Coquand. A.

Diadematidés et Crphosomatidés.

(13 genres et 16 espéces.)

Crétacés. $\{$ Heterodiadema libycum, Cotteau, A., T., E., S. I Pseudodiadema sp. Zittel. 
Crétacés.

Pseudodiadema Meunieri, Gauthier.

Diplopodia variolaris, Desor. T., E.

Pedina Sinaica, Desor.

Orthopsis Ruppelii, de Loriol.

Codiopsis sp. Zittel.

Cyphosoma Abbatei, Gauthier.

Éocènes. $\left\{\begin{array}{cc}\text { Micropsis Fraasi, de Loriol. } & \text { mokattamensis, Cotteau. }\end{array}\right.$

Echinopsis libycus, de Loriol.

Mistechinus Mayeri, de Loriol.

Miocènes. $\left\{\begin{array}{c}\text { Psammechinus dubius, Agassiz. E. } \\ -\quad \text { affinis, Fuchs. Perse. } \\ \text { Arbacina monilis, Desor. E. }\end{array}\right.$

En somme, sur les 152 espèces et 64 genres cités, nous avons 3 genres nouveaux et 14 espèces nouvelles.

Les 138 antres espèces se répartissent ainsi :

4 espèces se trouvent aussi en Algérie, en Tunisie, en Europe et en Syrie.

1 espèce se trouve en Algérie, en Tunisie et en Europe.

1 espèce se trouve en Tunisie, en Europe et en Syrie.

1 espèce se retrouve en Algérie et en Tunisie.

1 espèce se retrouve en Algérie et en Europe.

2 espèces se retrouvent en Tunisie et en Europe.

5 espèces ont été indiquées en Algérie seulement.

3 espèces ont été indiquées en Tunisie seulement.

2 espèces ont été récoltées en Syrie seulement.

1 espèce a été récoltée aussi en Perse.

1 espèce a aussi été recueillie dans l'Inde.

Enfin 23 espèces existent aussi en Europe.

Total $\overline{45}$ espèces communes à l'Egypte et à d'autres pays. 


\section{$-731-$}

Le restant, soit 93 espèces avaient déjà été reeueillies et indiquées en Égypte seulement.

Tels sont les résultats que nous avons obtenus. Cependant ils ne sont pas définitifs : il reste encore de vastes territoires inexplorés dans les channes libyques et arabiques, et nous nous proposons de publier ehaque amnée un supplément à ce eatalogue, contenant les espèces nouvelles et les faits intéressants qui nous seront parvenus. Nous serons done recomnaissant à tous eeux qui voudront bien nous confier les matériaux qu'ils ont reeneillis ou qu'ils recueilleront dans leurs courses en Égypte. 


\section{A D DENDA.}

Depuis la remise de notre mémoire au bureau de l'Institut Égyptien jusqu'au jour de sa publication il s'est passé un laps de temps assez long, pendant lequel de nouvelles observations nous ont permis de rectifier certains points de notre mémoire; nous croyons devoir consigner ici lẹs principales, afin de prendre date certaine pour nos publications ultérieures dans lesquelles elles seront développées.

Dictyopleurus Hainei Duncan et Sladen.

Dans une excursion an Gebel Kibli el-Ahram faite il y a quelque temps, j'ai eu la bonne fortune de recueillir deux spécimens de cette espèce indienne. La dernière phrase consacrée à cette espèce dans notre mémoire n'a donc plus sa raison d'être et il n'y a plus ancun doute sur sa présence en Égypte.

Le niveau est le Lutétien II, couches à Anisaster gibberulus et Echinolampas Crameri (R. F.).

Echinolanipas Perrieri de Loriol.

C'est par erreur que j'ai rapporté à cette espèce les exemplaires de Tunisie; un examen attentif du type égyptien m'a convaincu que les individus recueillis par M. Thomas diffèrent spécifiquement; ils devront dès lors prendre le nom d'Echinolampas cherichirensis Gauthier (V. G.).

Mistechinus Mayeri de Loriol.

J'ai recueilli dernièrement dans le Lutétien I des environs de 
Minieh un individu beaucoup plus développé que le type décrit par M. de Loriol, et qui prouve que les exemplaires que notre excellent confrère a eu entre les mains sont des jeunes. Nous décrirons ultérieurement cet intéressant spécimen. (R. F.)

\section{ERRATA.}

P. 607. La répartition du Turonien et du Sénonien doit être modifiée comme suit :

Calcaires à Hippurites cormu-vaccinum Bronn et Echinoconus aegyptiacus d'Orb. du Gebel Attaka et du Gebel Abou Daragué.

Calcaires it Rudistes, Cyphosoma Abbatei Gauthier, Acteonella Salomonis Fraas et Nerinea sp. du massif d'Abou Roach.

Calcaires i Ostrea acanthonota Coq., Plicatula Ferryi Coq., et Rhabdocidaris Crameri de Loriol, du massif d'Abou Roacl.

Turonien inférieur

Turonien supérieur

Au lieu de : Danien, lire : Aturien.

P. 608. Le Suessonien doit être divisé comme suit :

Calcaires à Cardita soudenica Mayer-Eymar et Bothriolampas abundans Gauthier des environs d'Assonan.

Calcaires à Graphularia desertorum Zittel, Operculina libyca Schwager, Lucina globosa Lamk., Conoclypeus Delanouei de Loriol, Linthia caremosa de Loriol, des environs de Louxor et Ghirgheh de loasis de Farafrah.

Calcaires à Callianassa nilotica Fraas, Nummulites Biarritzensis d'Arehiac, Sismondia Loghoteti Fraas, des environs d'Assiout et de Minieh.

Senonien infẻrieur (Santonien) 
P. 621, ligne 6, au lieu de: des petits ares ..., lire : de petits ares; ligne 13, au lieu de : L'espace ..., lire : Espace.

P. 624, ligne 5, au lien de : dont parle . . ., lire : que parle.

La synonymie d'Holectipus excisus Desor (sub Discoidea excisa) doit être hue ainsi :

Discoidea excisa Desor, etc.

Holectypus excisus Duncan, ete.

» Cotteau, Peron et Gauthier, Échin. foss. de l'Algérie, fasc. v. p. $169,1876$.

ఎ 'Thomas et Gauthier, Descript, des Échin. rec. en Tunisie, p. $58,1889$.

ॠ. A. Zittel, etc.

P. 625. A la synonymie de Holectypus cenomanensis, ajouter :

I. cenomanensis Cotteau, Peron et Gauthier, op. cit., fasc. v, p. 171, 1876.

P. 626 , ligne 25, lire : fasc. vII.

P. 628, ligne 30, an lieu de : n'ayant pas encore atteint, lire : n'ayant pas atteint.

P. 632, ligne 27, au lieu de : d'Algérie, lire : de la 'Tunisie.

P. 636, ligne 7, an lieu de : Cloisons aiguées et d'apparences lisses, lire : et d'apparence lisse.

P. 637, ligne 1, au lieu de : le bouton assez saillant et surmonté, lire : est surmonté.

P. 639, ligne 9, au lieu de: The fossil Echinoidae, lire : Echinoidea.

P. 641, ligne 1, au lieu de : place à, lire : placé à.

P. 643 et 644, au lieu de : Soemanni, lire : Saemanni.

P. 644, ligne 33, au lieu de: qui est seul à employer, lire : qu'il est seul à employer.

P. 650, ligne 6, au lieu de : P. Navillei, lire : G. Navillei. 


\section{TABLE ALPHABÉTIQUE.}

(Les caractères en italique indiquent les synonymes.)

\begin{tabular}{|c|c|c|}
\hline Agassizia & gibberula. Voir Axisaster ... 668 & Planche \\
\hline BLYPYGUS & Zittel $\cdots \cdots \cdots \cdots \cdots \cdots$ & $1, \operatorname{tin}, 13-1$ \\
\hline MPHIOPE & 698 & $1,11 \mathrm{~g} \cdot 10-10$ \\
\hline - & 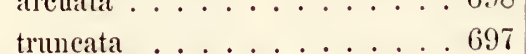 & \\
\hline Ananchytes & ovata. Voir Echrxocorys . . . 632 & \\
\hline ANISASTER & confusus ........6668 & \\
\hline - & gibberulus . . . . . . . . 668 & \\
\hline $\begin{array}{l}\text { Archieocida } \\
\text { Archiacia }\end{array}$ & 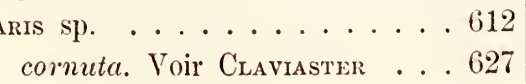 & \\
\hline Botmriolami & Pas (Genre) . . . . . . . . 652 & \\
\hline - & abundans . . . . . . 655 & I, tig. 9-12. \\
\hline Brissopsis & angusta . . . . . . . . 6666 & \\
\hline - & Fraasi ........... 714 & \\
\hline - & Lorioli . . . . . . . . . 666 & II, fig. $3-4$. \\
\hline - & Pasqualii . . . . . . . . 690 & \\
\hline Brissus & aegyptiacus ........718 & III, fig. $11-12$. \\
\hline Caratomus & londinianus ......... 663 & \\
\hline Cassidulus & amygdala . . . . . . . . 663 & \\
\hline Crdaris & Adamsi . . . . . . . . . 692 & \\
\hline - & avenionensis . . . . . . 693 & \\
\hline - & glandaria . . . . . . . . . 612 & \\
\hline Cidarites & glandarius. Yoir Cidaris. . . . 612 & \\
\hline - & Schmideli. Voir Porocidaris . . 638 & \\
\hline Claviaster & cornutus ........ 627 & \\
\hline Clypeus & Pretiosus. Voir Anblypygus . . 646 & \\
\hline Clypeaster & acclivis . . . . . . . . 709 & IV, fig. $1-4$. \\
\hline - & Aegrptiacus ........ . 721 & \\
\hline - & Breunigii . . . . . . . 645 & \\
\hline - & Genefiensis . . . . . . . . 705 & $\begin{array}{c}\text { III, fig. } 4-6 . \\
93^{*}\end{array}$ \\
\hline
\end{tabular}


Clupeaster istlumicus . . Page

- pentadactylus ....... . 708

- pliocenicus ........ 721

- Priemi .......... . 703

- Rholfsi ........... . 701

- subplacunarius ....... . . 702

Coniopsis sp. 11. . . . . . . . 620

Conoclypeus conoidens . . . . . . . . . 645

- Delanonei ........... 646

- Osiris. Voir Echinolampas . . 658

Crphosoma Abbatei ........... 620

Diadema Ruppellii. Voir Orthopsis . . .619

Sinaicum. Voir Drplopodia . . 619

Dictyopleurus Haimei . . . . . . 639 et 732

Diplopodia Sillaica . . . . . . . . . . . 619

Variolaris . . . . . . . . . 619

Discoidea excisa. Voil Holectyres . . . . 624

pulvinata . . . . . . . 626

Ditremaster Schueinfurthi. Voir Hemiaster 665

Echinanthus libyens . . . . . . . . . 652

Zitteli . . . . . . . . 651

Echinomerssus pisendominimus . . . . . . . 626

Echocyanus Luciani. Voir Thagastea . . . 642

Thuilei . . . . . . . 696

Echnocosus aegyptiacus . . . . . . 626

ovatus . . . . . . . 632

Echinolampas africamus . . . . . . . . 657

- amplus ............ 711

- amygdala ........660

- amygdalina ......... 662

- Aschersoni ........ 661

- Crameri ..........661

- Fraasi ..........658

- globulus .........660

- libyens .........662
IV, fig. 5-?.

III, tig. 1-33.

I, fig. 2-6.
II. ti… $11-13$. 


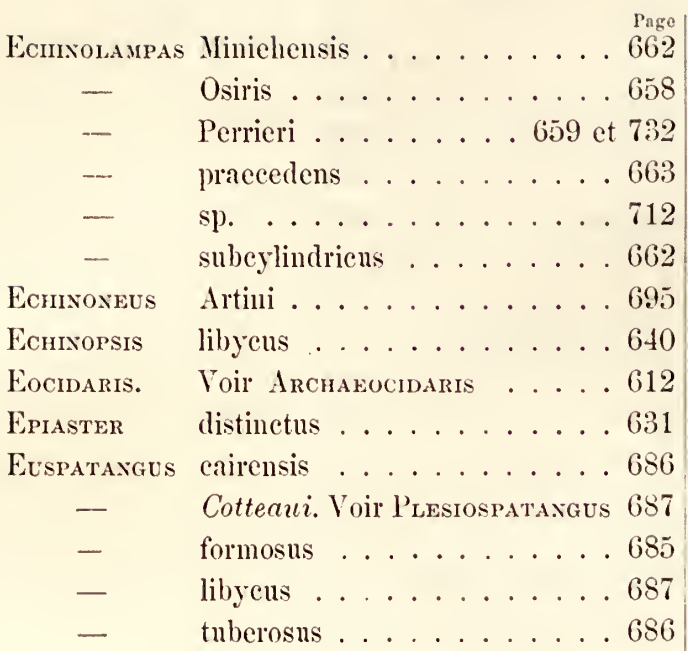

Fibularia Lorioli ............ . . 641

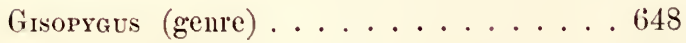

— Navillei . . . . . . . . 649

- siutensis ......... . . 650

- Thebensis ......... . . 650

- Zitteli .......... 65ั0

Hemaster Archiaci . . . . . . . . . 664

- arizensis. Voir Linthia . . . . . 671

- batnensis ......... 629

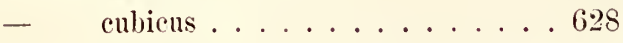

- Fonmeli ...........631

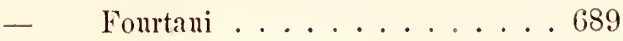

— gracilis ........... . . 630

- gibberulus. Voir Axisaster . . 668

- Heberti ............ . 629

- latisulcatus. Voir Linthia . . . 670

- nubicus.......... 690

- Pellati ............664

- procclivis .........6630
II, fig. $7-8$. 
Hemiaster Schweinfurthi . . . . . . 665

Wilcoksi . . . . . . . . 689

Hemicidaris libyca. Voir Heterodiadesa 618

Heterodiadema libycum . . . . . . 618

Holectypus cenomanensis . . . . . 625

- crassus ........ 625

- excisus .........6.624

Hemispatangus depressus. Voir Maretia ..688

pendulus. Id. . . . . . 688

Hypsospataxgus Ammon . . . . . . . . . 679

- Ficheri ........ 681

- Lefebvrei.......... . 680

Leiopneustes Ficheri. Voir Hypsospatangus . 681

Listнi arizensis . . . . . . . . . . 671

- Aschersoni. . . . . . . . . . 671

- Cavernosa ............6670

- Delanonei ... . . . . . . . . 669

- Esnehensis. . . . . . . . . . . 671

- Hessi . . . . . . . . . . . . 690

- latisulcata .......... . 670

- Navillei ... . . . . . . . . 670

- oblonga ............ . . 631

Liopatagus Ficheri. Voir Hrpsospatangus . 681

Loventa sp. . . . . . . . . . . . 720

Macropareustes (Groupe des) . . . . . . 677

- ammon. Voir Hypsospatangus 679

- crassus. Voir Megapneustes 684

- Ficheri. Voir Hypsospataxgus 681

- Lefebvrei. Id. . . . . . . 680

- Schweinfurthi ......691

- Sickembergeri ...... 691

- similis . . . . . . . . 692

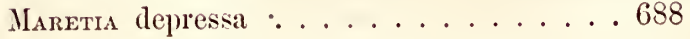

pendula . . . . . . . . . . 688

Megapaeustes crassus . . . . . . . . . 684 


\begin{tabular}{|c|c|c|}
\hline \multicolumn{2}{|c|}{ Megarpaustes grandis . . . . . . . 681} & \multirow[t]{2}{*}{$\begin{array}{l}\text { Plancle } \\
\text { II, fig. } 5-6 .\end{array}$} \\
\hline Micropsis & Frasi . . . . . . . 639 & \\
\hline - & Mokattamensis . . . . . . 640 & \\
\hline Micraster & sp. . . . . . . . . . 6 632 & \\
\hline- & ultimus . . . . . . . . . 689 & \\
\hline Mistechinus & Mayeri . . . . . . b4t1 et 732 & - \\
\hline Nucleolites & Luynesi . . . . . . . . . . 627 & \\
\hline Opissaster & thebensis . . . . . . . . 676 & \\
\hline ORthopsis & Ruppelii . . . . . . . . . . 619 & \\
\hline Palaeostoma & Zitteli . . . . . . . . . . 665 & \\
\hline Pedixa & sinaica . . . . . . . . . . 619 & \\
\hline Periaster & arizensis, Voir Listhia . . . 671 & \\
\hline- & elatus. . . . . . . . . 6 631 & \\
\hline- & latisulcatus. Voir Listhia . . 670 & \\
\hline - & oblongus. Id. . . . . . . . 631 & \\
\hline- & subglobosus. Voir Axisaster . 668 & \\
\hline Pericosius & Lyonsi . . . . . . . . . . 716 & W, tig. $10-11$ \\
\hline - & Pasqualii . . . . . . . . 672 & II, tig. $1-2$ \\
\hline \multicolumn{2}{|c|}{ Plesiospatangus Cotteani . . . . . . . 6 687 } & \\
\hline Pliolampas 1 & Pioti . . . . . . . . . 712 & III, fig. $7-10$. \\
\hline Porocidaris $\mathrm{S}$ & Schmideli . . . . . . . . . 638 & \\
\hline Psammechinus a & affinis . . . . . . . . . . 6 693 & \\
\hline - & dubins . . . . . . . . . 694 & \\
\hline- & monilis . . . . . . . . . . . 694 & \\
\hline Pseudocidaris & Pasqualii $\ldots \ldots \ldots 613$ & I, tig. 1. \\
\hline Pseudodiadema & A Meunieri . . . . . . . 617 & I, fig. $23-27$. \\
\hline- & Ruppelii. Voir Orthorsis. . 619 & \\
\hline- & sp. . . . . . . . . . 616 & \\
\hline - & Variolare. Voir Diptopodia. 619 & \\
\hline Pygorinyachius & abundans. V. Bothiniolampas 655 & \\
\hline- & grandiflorus . . . . . . 651 & \\
\hline Prgunus & nummuliticus . & \\
\hline RHABDOCIDARIS & Crameri . . . . . . . . 6 615 & \\
\hline
\end{tabular}




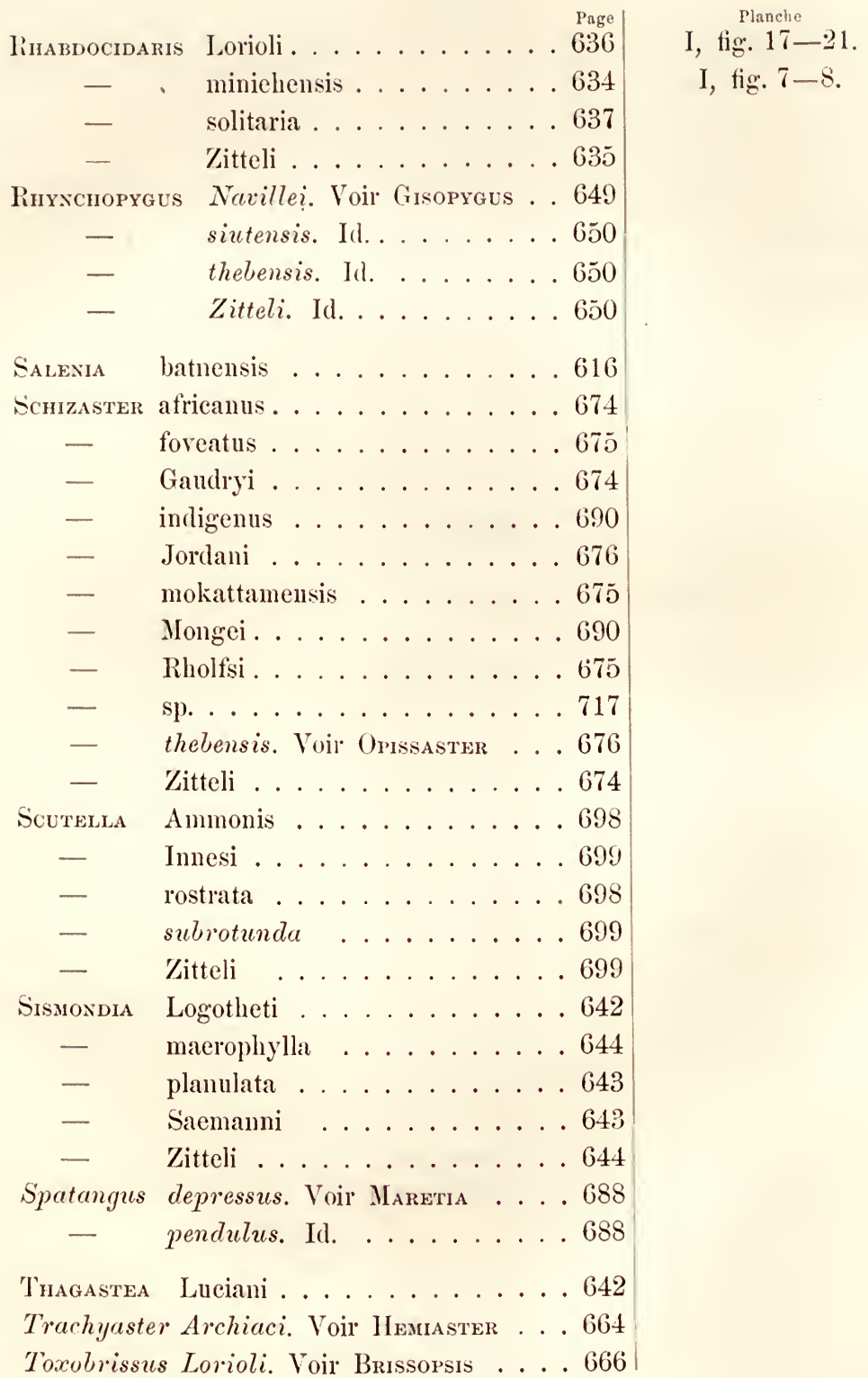




\section{Planche I.}

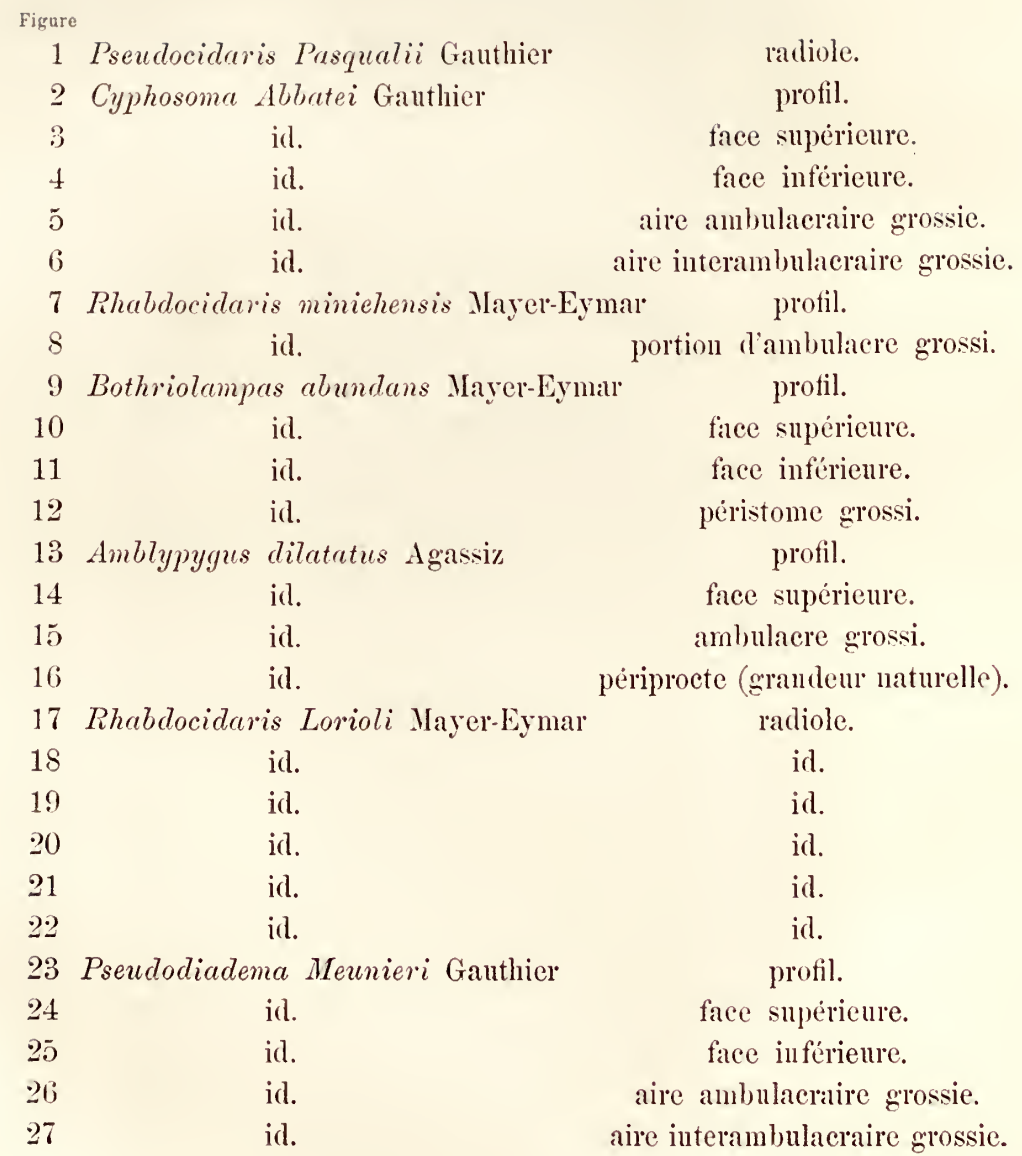



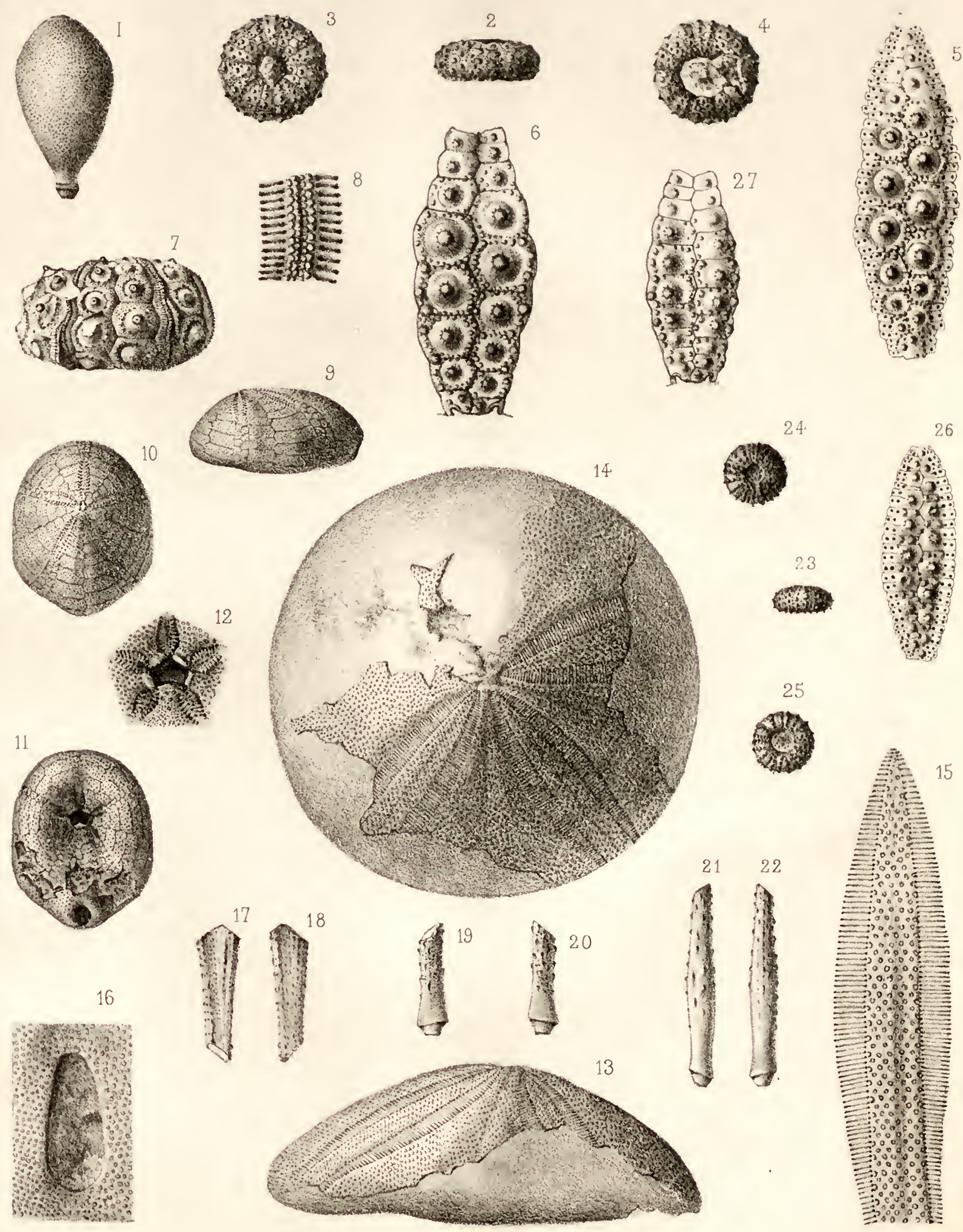

F. Gauthier del. et lith.

Imp. Edouard Bry. Faris.

Revision des Echinides fossiles de l'Egypte. 


\section{Planche IK}

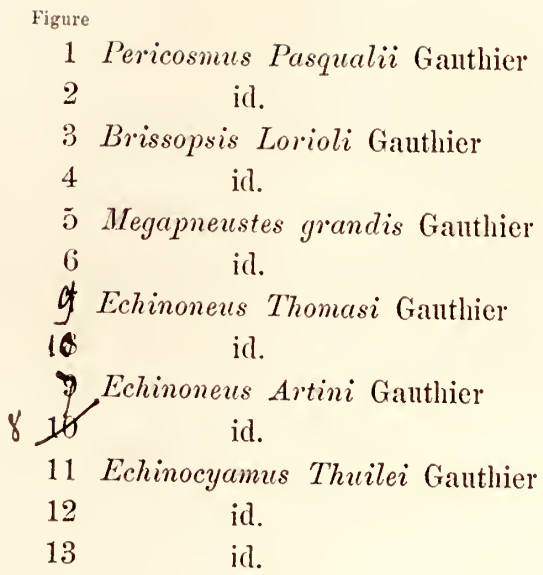

profil.

face supérienre.

profil.

face supérieure.

profil.

face supérieure.

profil.

face supérieure.

profil.

face supérieure.

profil.

face superieure.

face inféricure. 
9ট̈de de 916. Foudaur.
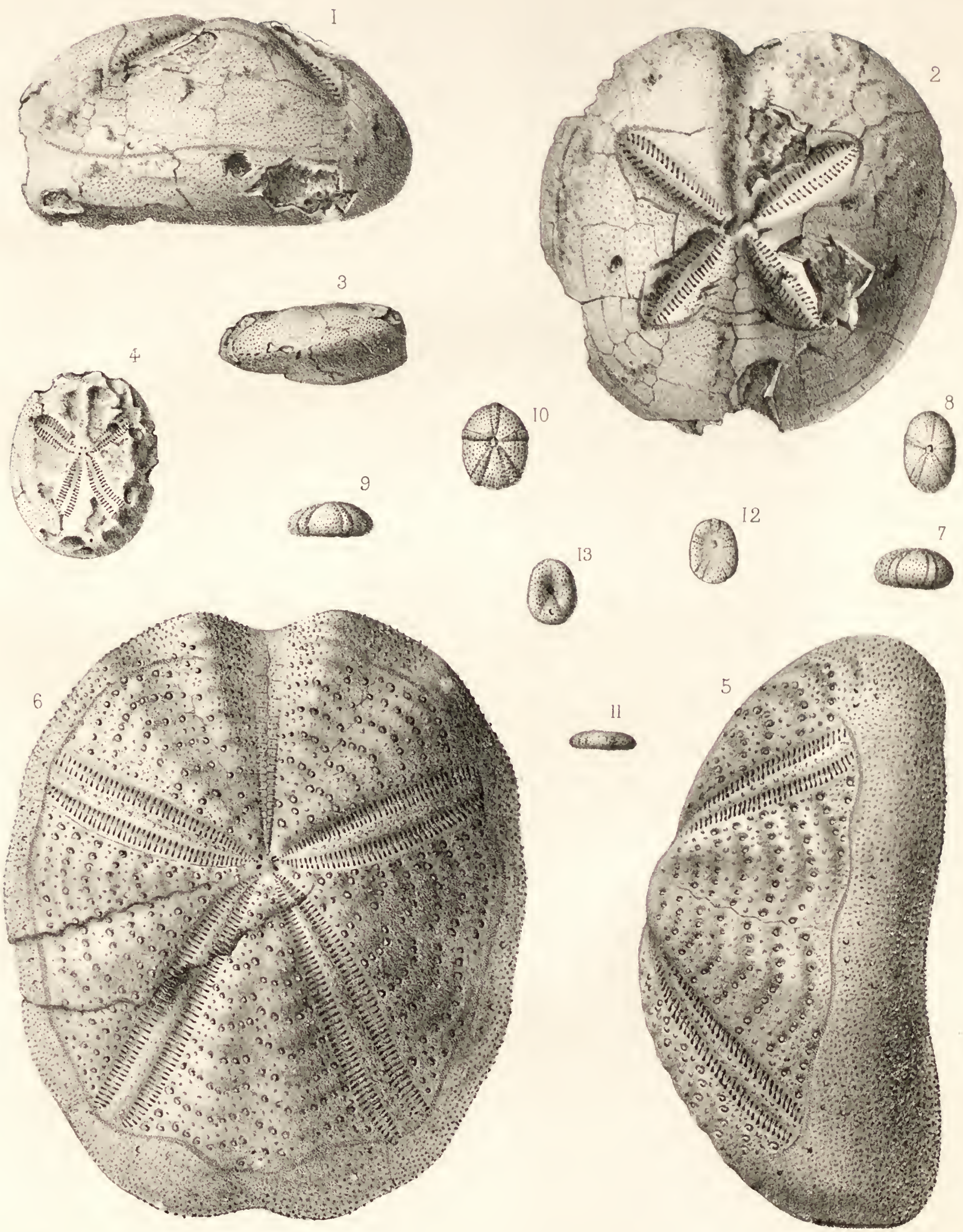

F'Gauther del et lith.

Imp. Edouard Bry, Paris.

Revision des Echinides fossiles de l'Egyple. 


\section{Phanche II!}

\begin{tabular}{|c|c|c|}
\hline \multicolumn{3}{|c|}{ Figure } \\
\hline 1 & Clypeaster Priemi Gauthier & profil. \\
\hline 2 & id. & face supérieure. \\
\hline 3 & id. & portion d'ambulacre grossi. \\
\hline 4 & Clypeaster Geneffensis Gauthier & profil. \\
\hline$\check{5}$ & id. & face supérieure. \\
\hline 6 & id. & portion d'ambulaere grossi. \\
\hline 7 & Pliolampas Pioti Gauthier & profil. \\
\hline 8 & id. & face supérieure. \\
\hline 9 & id. & face inférieure. \\
\hline 10 & id. & antre individu plus renflé vu de profil. \\
\hline 11 & Brissus Agyptiacus Gauthier & profil. \\
\hline 12 & id. & face supérieure. \\
\hline
\end{tabular}




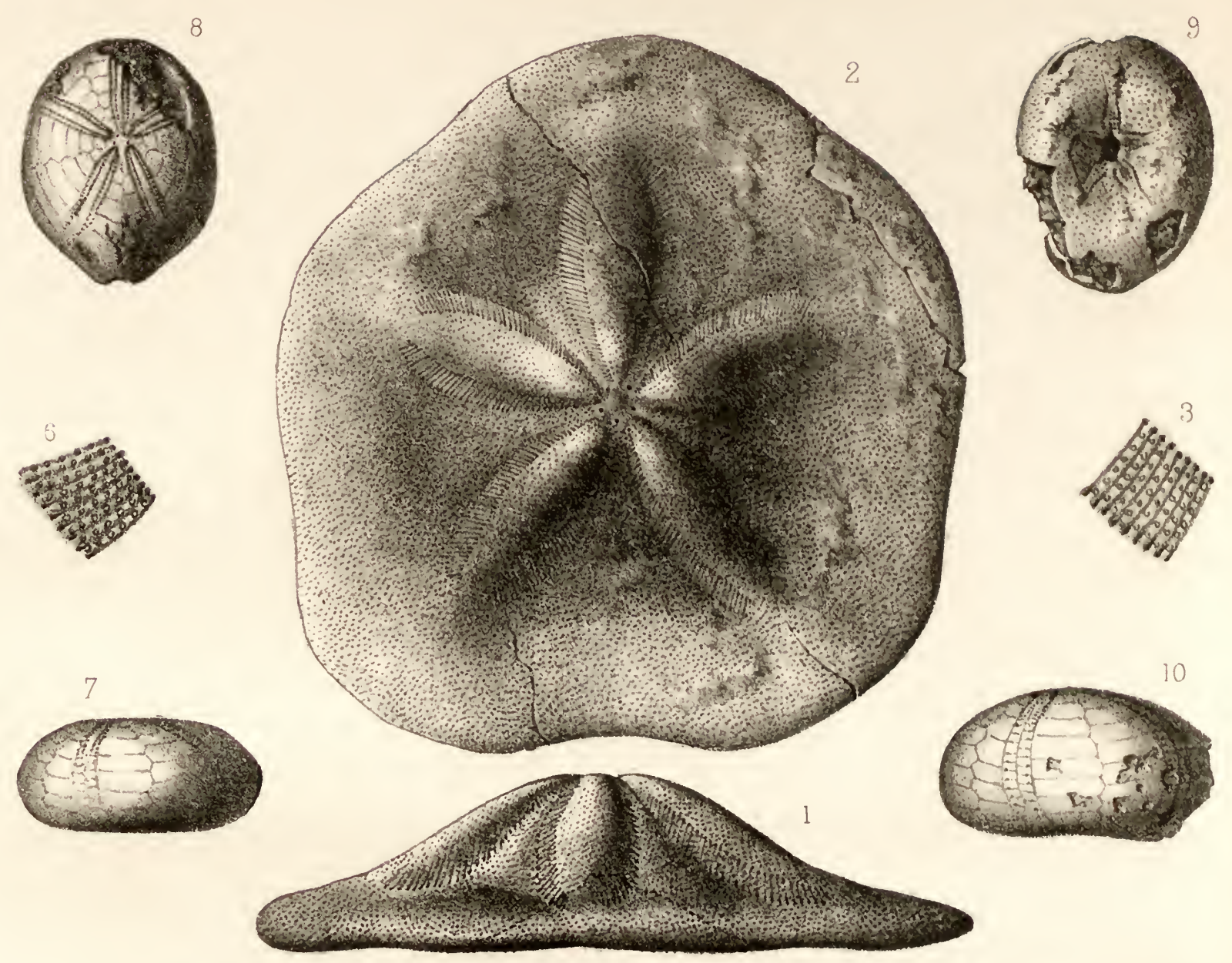

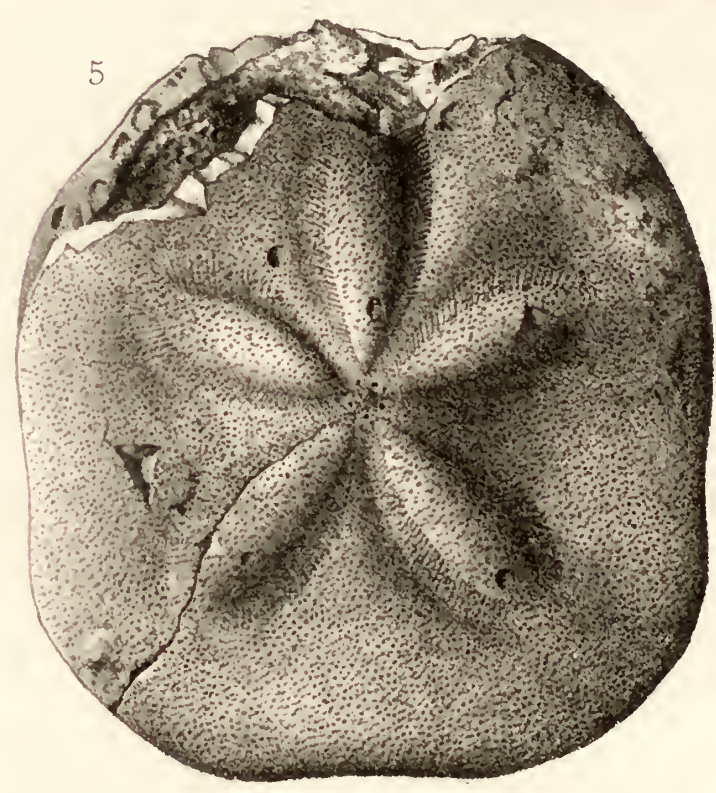

F. Gauthier, del.et suth.

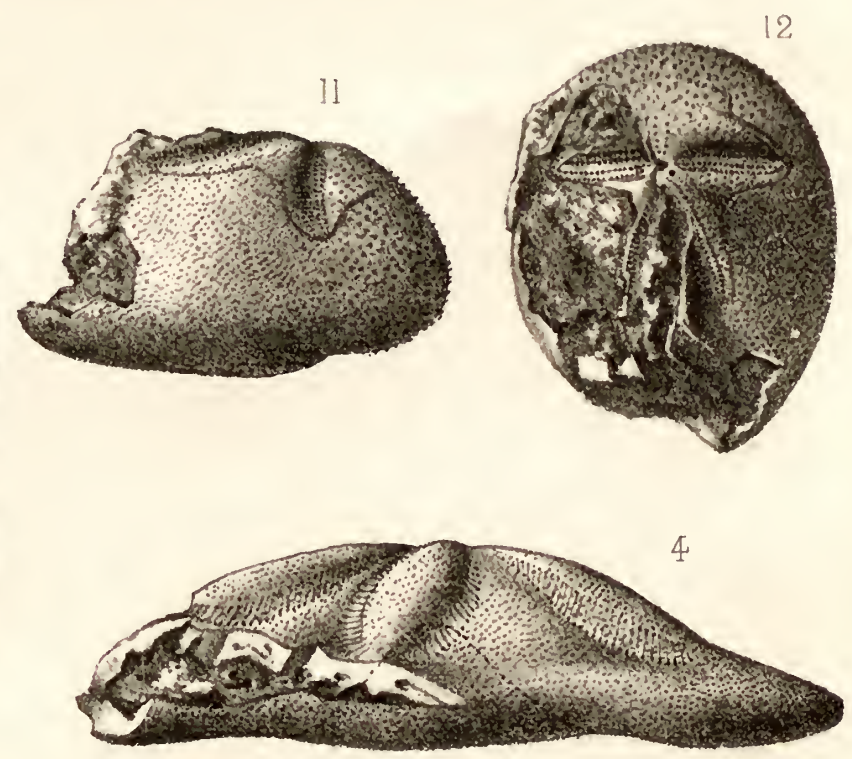

Imp. Edouard Bry, Paris.

Revision des Echinides fossiles de l'Egypte. 


\section{PlaNCHe IV.}

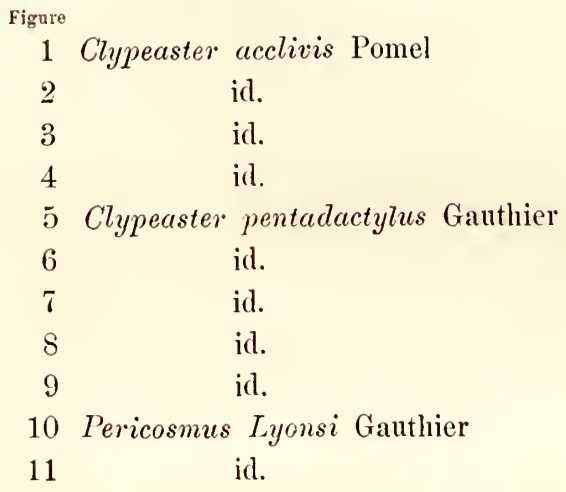

profil.

face supérieure.

portion d'ambulacre grossi.

péristome.

profil.

face superieure.

face infërieure.

appareil apical grossi.

portion d'ambulacre grossi.

profil.

face supérieure. 

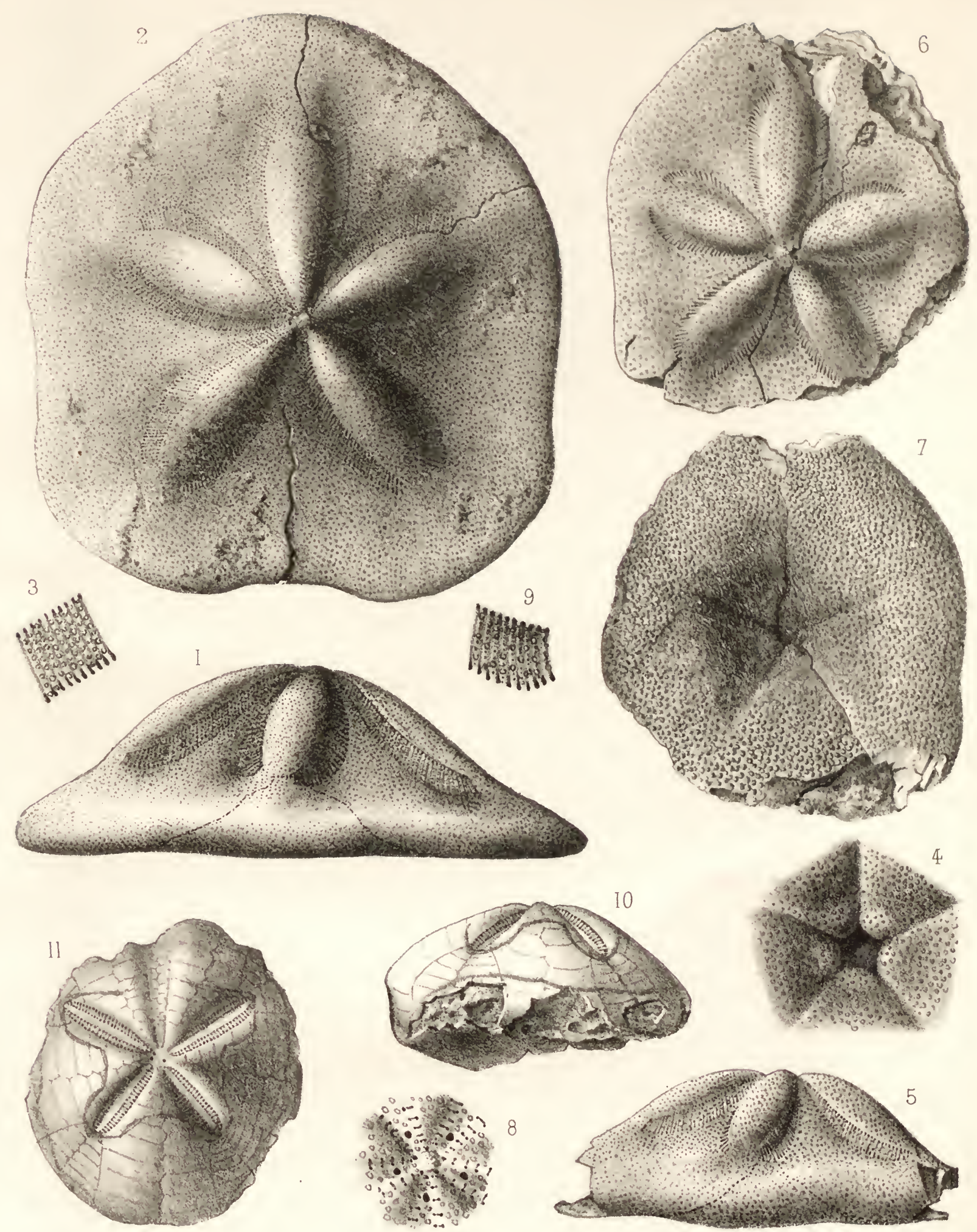

FGauthier, del et lith.
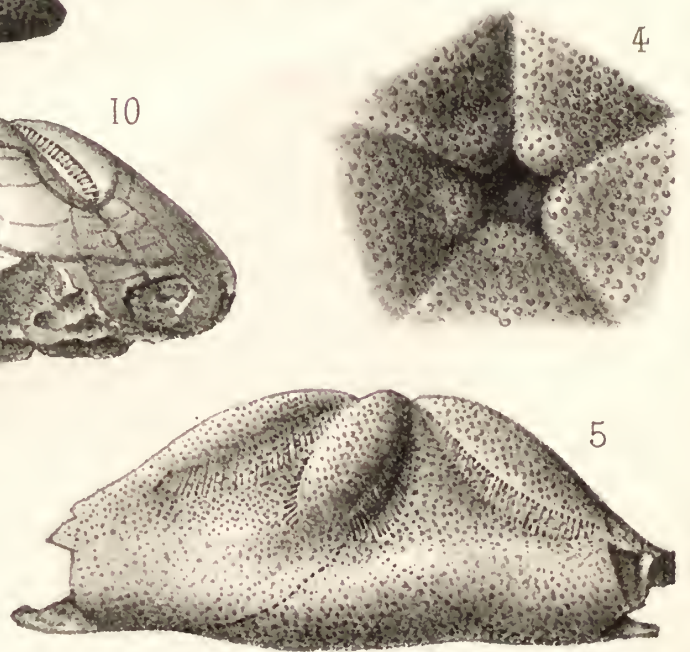

Imp. Fdouard Bry, Paris.

Revision des Echinides fossiles de l'Égypte. 